Amanda Pagliotto da Silva

Efetividade de um programa de reabilitação fonoaudiológica para pacientes adultos com trauma de face e restrição em mobilidade mandibular

Tese apresentada à Faculdade de Medicina da Universidade de São Paulo para obtenção do título de Doutor em Ciências

Programa: Ciências da Reabilitação

Orientadora: Dra. Fernanda Chiarion Sassi

São Paulo

2019 


\section{Dados Internacionais de Catalogação na Publicaçăo (CIP)}

\section{Preparada pela Biblioteca da}

Faculdade de Medicina da Universidade de Săo Paulo

Creprodução autorizada pelo autor

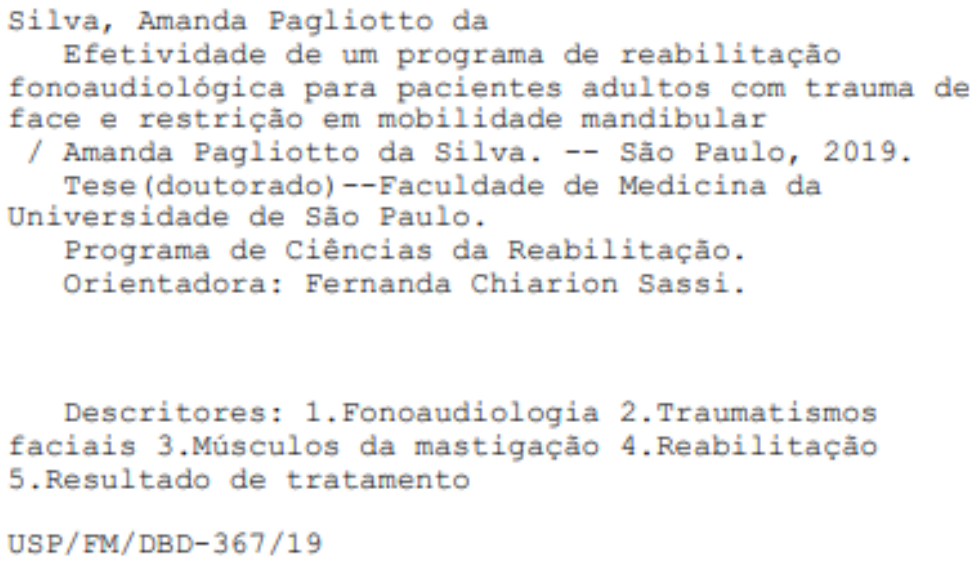

Responsável: Erinalva da Conceição Batista, CRB-8 6755 


\section{DEDICATÓRIA}

Dedico esse trabalho à minha família, em especial, aos meus pais Orestes e Neusa. Tudo o que consegui foi possível graças ao amor, apoio e dedicação que vocês sempre tiveram por mim. 
Agradeço a Deus por guiar minhas escolhas e possibilitar minhas experiências e aprendizados.

À minha orientadora, Dra. Fernanda Chiarion Sassi, agradeço pelas oportunidades de crescimento que me foram proporcionadas no decorrer do processo. Seus conselhos e sugestões foram essenciais para a elevação do nível e da importância deste estudo. Muito obrigada por acreditar no meu potencial e no meu trabalho e por me guiar de forma brilhante ao longo dessa jornada.

À Profa. Dra. Claudia Regina Furquim de Andrade, pela orientação de seus alunos e equipes, por ter proporcionado a criação e o desenvolvimento contínuo da Divisão de Fonoaudiologia do HCFMUSP. A senhora é base para este trabalho e uma fonte de inspiração para minha carreira.

Agradeço ao Dr. Nivaldo Alonso, Dra. Fabiola Juste, Dra. Karina Bernardiz Buhler, Profa. Dra. Débora Maria Befi-Lopes e Dra. Paula Nunes Toledo, pelas sugestões e contribuições realizadas na banca de qualificação.

À equipe da Cirurgia Craniomaxilofacial da Divisão de Cirurgia Plástica Reparadora e Queimaduras do ICHC-FMUSP pela parceria e aprendizado, em especial ao Dr. Nivaldo Alonso e Ms. Endrigo Bastos, agradeço pelos ensinamentos e pela parceria estabelecida.

À Dra. Ana Paula Ritto, pela realização da análise estatística dos dados obtidos nesta Tese. 
À fonoaudióloga Dra. Fabiola Juste, por auxiliar na revisão de Língua Portuguesa e formatação final desta Tese.

Aos alunos e ex-alunos que passaram pela Divisão de Fonoaudiologia do HCFMUSP, agradeço imensamente a oportunidade de difundir o conhecimento desenvolvido na área da Fonoaudiologia Hospitalar e pelo incentivo na busca constante do aperfeiçoamento das práticas e técnicas terapêuticas. Agradeço também pelos agradáveis períodos que passei com vocês e pelo incentivo durante todo o desenvolvimento desta Tese.

Aos fonoaudiólogos que atualmente compõe a equipe e aos que já passaram pela Divisão de Fonoaudiologia do HCFMUSP, agradeço por compartilharem seus conhecimentos, angústias e realizações pessoais e profissionais. Agradeço em especial às fonoaudiólogas Dra. Gisele Chagas de Medeiros, Dra. Dicarla Motta Magnani, Ms. Maira Santilli, Ms. Karoline Kussik e todas os demais fonoaudiólogos que contribuem diariamente com a Divisão de Fonoaudiologia do HCFMUSP.

Agradeço à Fga. Ms. Juliana Lopes Ferrucci, pela amizade construída nesses anos e pelo apoio em todos os meus momentos no Hospital. A Fga Ms. Tharsila Moreira Gomes da Costa, por todos os conselhos e também pela amizade.

Agradeço aos secretários da Divisão de Fonoaudiologia do HCFMUSP, em especial: Juliana dos Anjos, Gisele Lúcia, Celia Gomes, Francisco Goes.

Aos meus pais, Orestes e Neusa, agradeço pelo apoio incondicional, pela compreensão das minhas ausências, pelo acolhimento nos momentos mais difíceis e pelas celebrações das vitórias profissionais e pessoais. 
Aos meus irmãos, Angélica e Anderson, pelos conselhos, broncas e parcerias em todos esses anos. Vocês são fundamentais no meu dia-a-dia, minha fortaleza. Anderson, obrigada pela estação de trabalho montada, que contribuiu para a finalização deste trabalho.

Aos meus sobrinhos Giovanna, Giovanni, Bruna e Heloisa, por sempre me lembrarem da importância de estarmos juntos. Vocês me fazem muito bem!

Aos meus familiares, avós, tios e primos, por todos os momentos maravilhosos que passamos juntos. É muito gratificante saber que vocês me apoiam e torcem por mim.

À KWAS, principalmente Simone e Katia, agradeço o compartilhamento de experiências e os momentos de descontração.

Às "girls", Daniela, Débora, Eleonora, leda, Mariana e Natalia, vocês foram verdadeiros presentes que a FMUSP me deu.

Às amigas do "apê 51", Ligia e Thaynã, pela convivência diária, opiniões, discussões fonoaudiológicas, literárias e tantas outras. Agradeço por me acompanharem diariamente, pelo apoio nos momentos mais difíceis e por todas as nossas celebrações.

Agradeço aos participantes do grupo controle desta Tese, selecionar o grupo e coletar os dados foram desafios para o desenvolvimento desse trabalho. Valorizo a todos, por terem deixado suas atividades para comparecer, em dois momentos distintos, à Divisão de Fonoaudiologia do HCFMUSP para realizar as avaliações necessárias. Não tenho palavras para expressar a minha gratidão. Agradeço também a todos que me ajudaram na captação destes participantes e na realização da coleta dos dados, em especial à Fga. Ms Juliana Ferrucci e ao Anderson Pagliotto. 
Aos pacientes que participaram desse estudo, agradeço imensamente a oportunidade e a confiança que depositaram em mim. Vocês são a motivação para a busca de procedimentos terapêticos cada vez mais eficientes, para que possamos alcançar níveis cada vez mais eficazes de reabilitação. Vocês são uma fonte inesgotável de aprendizado. 


\section{EPÍGRAFE}

"Conheça todas as teorias, domine todas as técnicas, mas ao tocar uma alma humana, seja apenas outra alma humana".

Carl Jung 


\section{NORMATIZAÇÃO ADOTADA}

Esta tese está em conformidade com as seguintes normas, em vigor no momento desta publicação:

Resolução CoPGr n 6884, de 25 de agosto de 2014. Baixa o Regulamento do Programa de Pós-Graduação em Ciências da Reabilitação da Faculdade de Medicina. Diário Oficial do Estado de São Paulo, 28 ago 2014; Seção I do Executivo: 59-60.

Universidade de São Paulo. Faculdade de Medicina. Serviço de Biblioteca e Documentação. Guia de apresentação de dissertações, teses e monografias. Elaborado por Annelise Carneiro da Cunha, Maria Júlia de A. L. Freddi, Maria F. Crestana, Marinalva de Souza Aragão, Suely Campos Cardoso, Valéria Vilhena. 3a ed. São Paulo: Serviço de Biblioteca e Documentação; 2011.

Referências adaptadas dos Uniform Requirements for Manuscripts Submitted to Biomedical Journals, elaborados pelo International Committe of Medical Journals Editors (Vancouver).

Abreviaturas dos títulos dos periódicos de acordo com List of Journals Indexed in Index Medicus. 
Lista de Siglas e Abreviaturas

Lista de Figuras

Lista de Tabelas

Resumo

Abstract

1. APRESENTAÇÃO

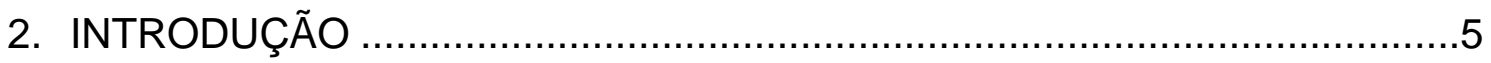

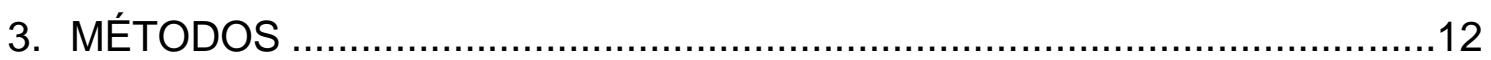

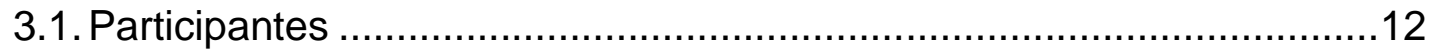

3.2. Avaliação Fonoaudiológica..................................................................14

3.2.1. Avaliação Miofuncional Orofacial...............................................14

3.2.2. Avaliação da mobilidade mandibular .........................................15

3.2.3. Auto Percepção dos Sinais e Sintomas de DTM..........................17

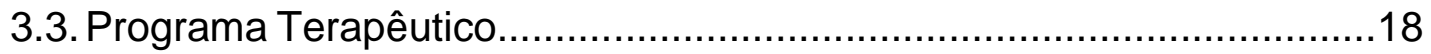

3.4. Avaliação Complementar - Musculatura Mastigatória.............................20

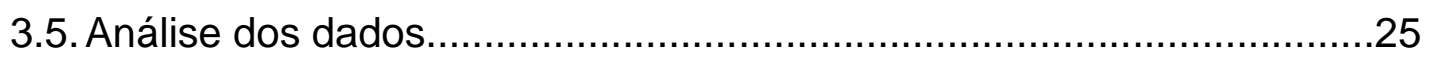

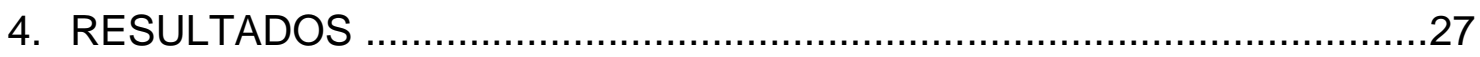

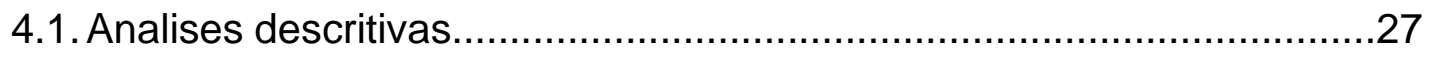

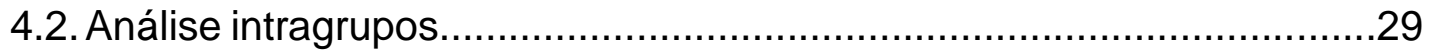

4.2.1. Avaliação Miofuncional Orofacial..............................................29

4.2.2. Avaliação da Mobilidade Mandibular.........................................30

4.2.3. Autopercepção dos Sinais e Sintomas de DTM...........................32 


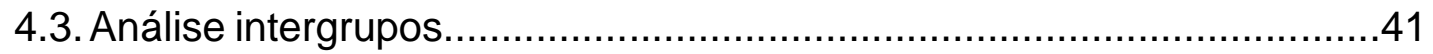

4.4. Avaliação complementar - Musculatura Mastigatória............................45

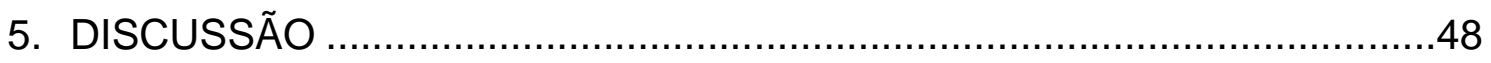

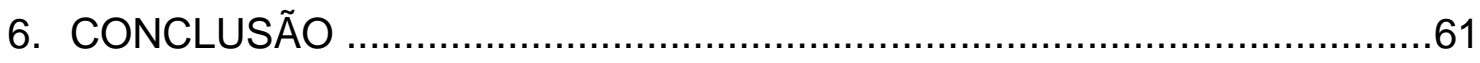

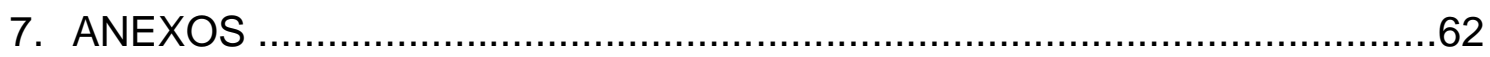

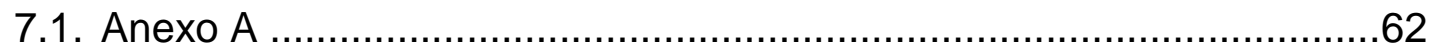

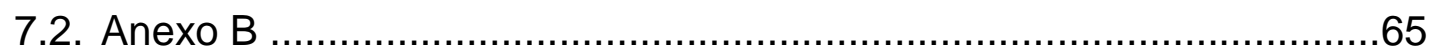

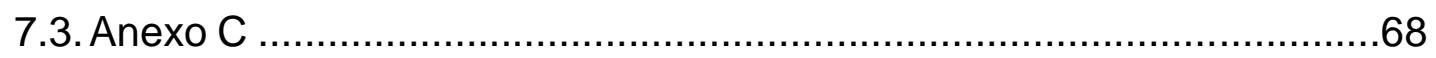

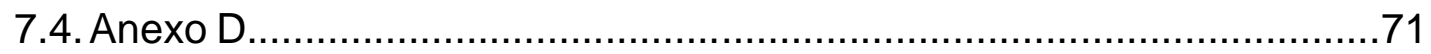

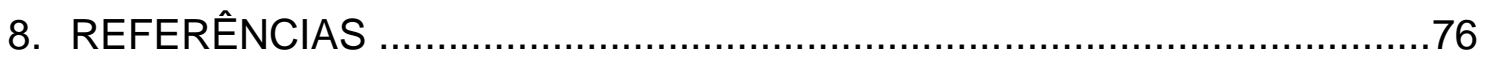




\section{LISTA DE ABREVIATURAS E SIGLAS}

ATM - Articulação temporomandibular

AMIOFE-E - Avaliação Miofuncional Orofacial com Escores Expandido

ALG - Apertamento dentário máximo com rolete de algodão entre os dentes

B - Bilateral

CAPPesq - Comissão de Ética para Análise de Projetos de Pesquisa

D - Direita

DP - Desvio padrão

DTM - Disfunção da articulação temporomandibular

E - Esquerda

EMGs - Eletromiografia de superfície

$\mathrm{F}$ - Feminino

FMUSP - Faculdade de Medicina da Universidade de São Paulo

GC - Grupo controle

GP1- Grupo pesquisa 1

GP2 - Grupo pesquisa 2

GP3 - Grupo pesquisa 3

HCFMUSP - Hospital das Clínicas da Faculdade de Medicina da Universidade de São Paulo

$\mathrm{Hz}-\mathrm{Hertz}$

IC - Instituto Central

MIC - Máxima intercuspidação dentária 
M - Masculino

M - Média

MAST - Mastigação habitual

MM - Músculo masseter

MMD - Músculo masseter direito

MME - Músculo masseter esquerdo

mm- milímetros

MTD - Músculo temporal direito

MTE - Músculo temporal esquerdo

$\mathrm{N}$ - Número de participantes

NT - Número total de participantes

PTFs - Planos Terapêuticos Fonoaudiológicos

RMS - Root mean square

TCLE - Termo de consentimento livre e esclarecido

TMO - Terapia miofuncional orofacial

$\mu \mathrm{V}-$ micro volts

$\%$ - Porcentagem 


\section{LISTA DE FIGURAS}

Figura 1 - Fluxograma referente aos participantes do estudo.........................14

Figura 2 - Medição da abertura oral máxima................................................16

Figura 3 - Medição da lateralidade mandibular..............................................16

Figura 4 - Medição da protrusão mandibular...............................................17

Figura 5 - Delineamento do processo terapêutico........................................20

Figura 6 - Tempo para avaliação e reavaliação dos Grupos Pesquisa e

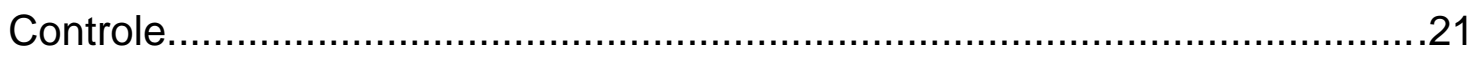

Figura 7 - Traçado eletromiográfico (apertamento dentário em RMS).............24 


\section{LISTA DE TABELAS}

Tabela 1 - Comparação intergrupos das variáveis demográficas e dados do prontuário médico.

Tabela 2 - Comparações de pares de acordo com as variáveis demográficas e dados do prontuário médico. .28

Tabela 3 - Comparação intergrupos das variáveis demográficas e dados do prontuário médico. 29

Tabela 4 - Comparações intragrupos de acordo com os resultados do protocolo AMIOFE. 30

Tabela 5 - Comparações intragrupos de acordo com os resultados da avaliação da mobilidade mandibular 30

Tabela 6 - Comparações intragrupos de acordo com os resultados da avaliação da mobilidade mandibular. 31

Tabela 7 - Comparação intragrupo GP1 - resultados da avaliação de autopercepção dos sinais e sintomas de DTM (sintomas gerais)

Tabela 8 - Comparação intragrupo GP1 - resultados da avaliação de autopercepção dos sinais e sintomas de DTM (sintomas observados durante a movimentação mandibular) .33

Tabela 9 - Comparação intragrupo GP1 - resultados da avaliação de autopercepção dos sinais e sintomas de DTM (sintomas observados durante as funções) 
Tabela 10 - Comparação intragrupo GP2 - resultados da avaliação de autopercepção dos sinais e sintomas de DTM (sintomas gerais)

Tabela 11 - Comparação intragrupo GP2 - resultados da avaliação de autopercepção dos sinais e sintomas de DTM (sintomas observados durante a movimentação mandibular) .36

Tabela 12 - Comparação intragrupo GP2 - resultados da avaliação de autopercepção dos sinais e sintomas de DTM (sintomas observados durante as funções) .37

Tabela 13 - Comparação intragrupo GP3 - resultados da avaliação de autopercepção dos sinais e sintomas de DTM (sintomas gerais)

Tabela 14 - Comparação intragrupo GP3 - resultados da avaliação de autopercepção dos sinais e sintomas de DTM (sintomas observados durante a movimentação mandibular) .39

Tabela 15 - Comparação intragrupo GP3 - resultados da avaliação de autopercepção dos sinais e sintomas de DTM (sintomas observados durante as funções) .40

Tabela 16 - Comparação intergrupos - resultados do protocolo AMIOFE$\mathrm{E}$

Tabela 17 - Comparação intergrupos - índice de melhora do protocolo AMIOFEE

Tabela 18 - Comparação intergrupos - resultados da avaliação da mobilidade mandibular .42 
Tabela 19 - Comparação intergrupos - resultados da avaliação da mobilidade mandibular após o tratamento fonoaudiológico

Tabela 20 - Comparação intergrupos - resultados da avaliação de autopercepção dos sinais e sintomas de DTM (sintomas gerais)

Tabela 21 - Comparação intergrupos - resultados da avaliação de autopercepção dos sinais e sintomas de DTM (sintomas observados durante a movimentação mandibular)

Tabela 22 - Comparação intergrupos - resultados da avaliação de autopercepção dos sinais e sintomas de DTM (sintomas observados durante as funções) .45

Tabela 23 - Comparação intergrupos - resultados da análise eletromiográfica pré-tratamento. 45

Tabela 24 - Comparação intergrupos - resultados da análise eletromiográfica pós-tratamento. 46

Tabela 25 - Comparação intergrupos (GP e GC) - resultados da análise eletromiográfica. 


\section{RESUMO}

Silva AP. Efetividade de um programa de reabilitação fonoaudiológica para pacientes adultos com trauma de face e restrição em mobilidade mandibular [tese]. São Paulo: Faculdade de Medicina, Universidade de São Paulo; 2019.

Objetivo: Verificar a efetividade de um programa de reabilitação fonoaudiológica para pacientes adultos com trauma de face e restrição na mobilidade mandibular por meio de avaliação clínica da motricidade orofacial e mobilidade mandibular, autopercepção do paciente e avaliação eletromiográfica dos músculos mastigatórios. Métodos: Os 65 participantes deste estudo foram divididos em três grupos: GP1- composto por 24 participantes submetidos à avaliação fonoaudiológica em até um mês após a correção da fratura; GP2- composto por 29 participantes submetidos à avaliação fonoaudiológica de um a três meses após a correção da fratura; GP3 - composto por 12 participantes submetidos à avaliação fonoaudiológica de três meses ou mais após a correção da fratura. Todos os participantes foram submetidos à avaliação constituída pela aplicação de um protocolo clínico para a avaliação da motricidade orofacial, da mobilidade mandibular e de autopercepção dos sinais e sintomas de DTM. Os participantes foram submetidos ao Programa Terapêutico Fonoaudiológico para Traumas de Face com Restrição em Amplitude Mandibular, com duração de 6 semanas e após a finalização do programa, os pacientes foram reavaliados. Como avaliação complementar, foi realizada a avaliação da musculatura mastigatória pela eletromiografia de superfície em $38 \%$ dos participantes dos grupos de pesquisa e em 25 participantes do grupo controle. Resultados: Os resultados indicaram que independentemente do tempo transcorrido entre a correção das fraturas e a intervenção fonoaudiológica, todos os grupos de pesquisa apresentaram melhora significativa em: postura, mobilidade e funções miofuncionais orofaciais, mobilidade mandibular e nos sinais e sintomas de DTM. Em relação à análise eletromiográfica, verificou-se melhora da fisiologia e do desempenho muscular de indivíduos com traumas de face após reabilitação fonoaudiológica. Conclusão: O programa de reabilitação adotado neste estudo mostrou-se eficaz em sua proposta. As diferenças observadas entre os grupos nas avaliações prétratamento foram minimizadas após aplicação do programa terapêutico fonoaudiológico.

Descritores: Fonoaudiologia; Traumatismos faciais; Músculos da mastigação; Reabilitação; Resultado de tratamento. 
Silva AP. Effectiveness of a rehabilitation program for adults with facial trauma and mandibular mobility restriction [tese]. São Paulo: "Faculdade de Medicina, Universidade de São Paulo"; 2019.

Purpose: to verify the effectiveness of a speech-language rehabilitation program for adult patients with facial trauma and mandibular mobility restriction. For this purpose we inclued a clinical assessment of orofacial motricity and mandibular mobility, a patient self-perception protocol and an eletromyographic evaluation of the masticatory muscles. Methods: Patients included in the study presented midface and/or lower face fractures and were divided in groups according to the time between fracture reduction and the oral motor clinical and self-perception assessments: 0-1 months (Group $1-24$ participants), 1-3 months (Group $2-29$ participants) and $>3$ months (Group $3-12$ participants). All participants underwent an evaluation that consisted of a clinical protocol for the evaluation of orofacial motricity, mandibular range of movements, and a self-perception protocol of temporomandibular disorders signs. The adopted oral motor therapy program for facial trauma and restricted mandibular range of movements consisted of six weekly 40 minutes sessions. After the treatment program ended, patients were reassessed using the same protocols. As a complementary evaluation, the masticatory muscles were evaluated using surface electromyography (sEMG). Results: The results indicated that regardless of the time elapsed between the facial fracture reduction and the oral motor treatment program, all groups presented a significant improvement in the posture and mobility of the orofacial organs, in the orofacial myofunctional functions, in the mandibular range of movements and a reduction of the signs related to temporomandibular disorders. In addition, we observed an improvement in the physiology and muscle performance of patients. Conclusion: The adopted treatment program demonstrated to be effective in its purpose. The differences observed between the groups prior to treatment were minimized after the program was concluded.

Descriptors: Speech-Language and Hearing Science; Facial injuries; Mastigatory muscles; Rehabilitation; Treatment outcome. 


\section{APRESENTAÇÃO}

A escolha da temática abordada nesta Tese, pacientes acometidos por trauma de face, justifica-se por dois fatores principais: pela escassez de pesquisas publicadas em periódicos científicos de alto impacto e pelo número reduzido de participantes apresentados nos poucos estudos na área da motricidade orofacial.

A minha dissertação de Mestrado, defendida em dezembro de 2015, teve como principal objetivo realizar a descrição detalhada dos elementos alterados no sistema miofuncional orofacial desses indivíduos.

Como já apontado anteriormente, diante da escassez de artigos disponíveis na literatura que abordassem a reabilitação da musculatura orofacial em pacientes acometidos por trauma de face, meu projeto de Doutorado foi delineado abordando esta temática.

Nos últimos anos, existe uma demanda crescente de pacientes que buscam a reabilitação fonoaudiológica na cidade de São Paulo por apresentarem sequelas decorrentes de traumas de face. Este aumento pode ser explicado pela elevação no número de acidentes automobilísticos, pelas novas atividades profissionais da cidade e pelo aumento nos índices de violência urbana. $O$ Hospital das Clínicas da Faculdade de Medicina da Universidade de São Paulo (HCFMUSP), mais especificamente a Disciplina de Cirurgia Plástica e Queimaduras, é responsável por aproximadamente 770 atendimentos/ano relacionados às fraturas de face, sendo que destes, 146 necessitam de algum tipo de procedimento cirúrgico. A necessidade de reabilitação do sistema 
miofuncional orofacial é fundamental para estes pacientes, principalmente no que diz respeito ao reestabelecimento do equilíbrio da função mastigatória e da mobilidade mandibular.

Durante minha Graduação em Fonoaudiologia, iniciada em 2005 na Faculdade de Medicina da Universidade de São Paulo (FMUSP), tive a oportunidade de iniciar meu contato com a pesquisa, realizando um projeto de Iniciação Científica nos anos de 2007 e 2008, orientada pela Profa. Dra. Haydée Fizsbein Wertzner. Este projeto teve como temática o estudo da velocidade de fala em pacientes com transtorno fonológico. Ainda no ano de 2007, em conjunto com outra colega de graduação, com a Dra. Fernanda Chiarion Sassi e com a Profa. Dra. Claudia Regina Furquim de Andrade, auxiliei na elaboração e abertura da Liga de Fonoaudiologia em Disfagia, que em 2008, foi ampliada com a criação da Liga de Fonoaudiologia em Funções da Face.

Após a conclusão da minha graduação em 2009, ingressei no Aprimoramento Hospitalar em Funções Orofaciais do HCFMUSP. Durante o Aprimoramento, tive a oportunidade de aprimorar minha prática na assistência fonoaudiológica ao paciente internado, realizando avaliações e atendimentos relacionados à disfagia em beira de leito. Tive também a oportunidade de me aperfeiçoar minha prática em nível ambulatorial, no Ambulatório Fonoaudiológico de Cirurgia de Cabeça e Pescoço e no Ambulatório Fonoaudiológico de Paralisia Facial e Queimaduras da Divisão de Fonoaudiologia do HCFMUSP. Ao término do Aprimoramento, apresentei minha Monografia de Conclusão de Curso, que teve como objetivo a realização de uma revisão sistemática da literatura sobre a influência da consistência e viscosidade dos alimentos na deglutição orofaríngea. 
Em julho de 2010, fui aprovada no concurso para seleção de fonoaudiólogos da Divisão de Fonoaudiologia do HCFMUSP. Iniciei minha atuação na equipe de Fonoaudiologia junto aos pacientes disfágicos internados e nos Ambulatórios de Apneia Obstrutiva do Sono e Traumas de Face.

Durante a estruturação dos Ambulatórios, percebi que o trabalho com pacientes acometidos por trauma de face era um grande desafio, considerando o reduzido número de publicações sobre o assunto e a dificuldade em compreender suas necessidades terapêuticas, principalmente pela heterogeneidade das fraturas e pelo acometimento da articulação temporomandibular (ATM).

Em julho de 2013, ingressei no Mestrado junto ao Programa de PósGraduação em Ciências da Reabilitação da FMUSP com o título: “Caracterização Miofuncional Clínica e Eletromiográfica de Paciente Adultos com Trauma de Face", orientada pela Dra. Fernanda Chiarion Sassi. Ao término do Mestrado, em dezembro de 2015, fui convidada pela Profa. Dra. Claudia Regina Furquim de Andrade a assumir o cargo de Diretora Técnica da Divisão de Fonoaudiologia do HCFMUSP, para realizar as funções de coordenação educacional e atividades administrativas relacionadas a gestão financeira e de recursos humanos. A dissertação de Mestrado resultou na publicação do artigo: Silva AP, Sassi FC, Andrade CRF. Caracterização miofuncional orofacial e eletromiográfica de pacientes submetidos à correção da fratura condilar por redução aberta e fechada. CoDAS. 2016;28(5):558-566¹.

Durante a finalização do Mestrado, juntamente com a minha orientadora, iniciamos a elaboração de um programa de terapêutico voltado aos pacientes com traumas de face. Com o objetivo de atender melhor essa população, 
participei da elaboração de um capítulo de livro, com a proposição de um programa terapêutico para pacientes com trauma de face e restrição de amplitude mandibular: Silva AP, Sassi FC, Mangilli LD, Andrade CRF. Trauma de Face com Restrição de Amplitude Mandibular. In: Pró-Fono (org). Planos Terapêuticos Fonoaudiológicos (PTFs). Barueri: Pró-Fono; 2015. v.2, p.539$456^{2}$.

Seguindo essa linha de pesquisa, em janeiro de 2016, ingressei no Doutorado com o projeto de pesquisa: "Efetividade de um programa de reabilitação fonoaudiológica para pacientes adultos com trauma de face e restrição de movimento mandibular", também orientado pela Dra Fernanda Chiarion Sassi. Este trabalho iniciado em 2016 solidifica a linha de pesquisa em alterações fonoaudiológicas em pacientes acometidos por traumas de face. Neste período de execução do Doutorado, foram publicados dois artigos: Silva AP, Sassi FC, Bastos E, Alonso N, de Andrade CRF. Oral motor and electromyographic characterization of adults with facial fractures: a comparison between different fracture severities. Clinics. 2017;72(5):276-283³ e Sassi FC, Silva AP, Santos RKS, Andrade CRF. Tratamento para disfunções temporomandibulares: uma revisão sistemática. Audiol Commun Res. 2018;23(0):e18714. O artigo - Silva AP, Sassi FC, Andrade CRF. The effects of time on orofacial functions and self-perception of temporomandibular disorders signs in a population with heterogeneous facial fractures - foi submetido em outubro de 2019 para o Journal of Oral and Maxillofacial Surgery (periódico internacional indexado na base ISI) e encontra-se em avaliação. 


\section{INTRODUÇÃO}

Mundialmente, os traumas são responsáveis por mais de 16.000 mortes por dia ${ }^{5}$. Considerando que a face é o local mais exposto e menos protegido do corpo humano, as fraturas faciais são descritas como o tipo mais prevalente de trauma (isoladas ou associadas à outras alterações) ${ }^{6}$. Segundo a Organização Mundial da Saúde ${ }^{7}$, países com renda per capita média apresentam maiores taxas de fatalidade quando comparados aos países de renda baixa ou alta.

De maneira geral, observa-se na literatura uma escassez de informações referentes aos custos do gerenciamento de pacientes com traumas. Contudo, sabe-se que fraturas causadas por quedas custam aproximadamente 12.5 bilhões de dólares por ano para a sociedade americana e que o valor médio destinado aos pacientes com fraturas faciais isoladas foi de 3.556 dólares para dois dias de permanência hospitalar. Por esse motivo, traumas de face são considerados um problema importante para o sistema de saúde.

A ocorrência de fraturas faciais vem aumentando nas últimas quatro décadas ${ }^{9}$. Acredita-se que o aumento do número de veículos motorizados e da violência urbana contribuíram para o aumento do número de fraturas faciais ${ }^{2}$. Países como Áustria ${ }^{10}$, Brasil ${ }^{11}$, Alemanha ${ }^{12}$, Irã ${ }^{13}$, Itália ${ }^{14}$, Japão ${ }^{15}$, Nova Zelândia $^{16}$ e Nigéria $^{17}$ apresentam alguns dados referentes a incidência e etiologia dos traumas maxilofaciais. Em geral, esses estudos indicaram que fatores demográficos (ex.: maior ocorrência de traumas em indivíduos do gênero masculino, entre segunda e terceira décadas de vida - seguimento mais ativo economicamente), culturais e socioeconômicos (ex.: países menos 
desenvolvidos com maior risco de acidentes de trânsito, uso de drogas e álcool, países mais desenvolvidos com maior número de políticas públicas relacionadas à segurança e redução de fatores causadores de traumas), culturais e ambientais (ex.: aumento do número de mulheres no mercado de trabalho em atividades que envolvem veículos motorizados, aumento do consumo de álcool e drogas e uso de aparelhos eletrônicos durante a direção) influenciam fortemente a etiologia dos casos de traumas.

O Brasil apresenta grande variabilidade etiológica do trauma de face, sendo que estes dados têm relação direta com a região geográfica estudada. No Recife, foi observada maior ocorrência de traumas de face relacionadas aos acidentes de trânsito $(37,2 \%)$, seguido por quedas $(30,6 \%)$ e agressões físicas $(23 \%)^{18}$. Este resultado é semelhante aos estudos de países como Irã, Emirados Árabes, Nigéria, Paquistão e Egito ${ }^{13,17}$. Já na região Sudeste, verificou-se que a principal causa do trauma de face foi a violência interpessoal $(48,1 \%)$, dado semelhante aos encontrados no Canadá, Finlândia e Estados Unidos da América ${ }^{19,20}$.

As fraturas faciais, assim como as demais fraturas ósseas do corpo, precisam ser tratadas para que o funcionamento adequado das estruturas adjacentes possa ser reestabelecido. Estudos referentes a localização das fraturas faciais indicam que fraturas mandibulares são duas vezes mais comuns do que fraturas em ossos do terço médio da face e compreendem a maioria dos traumas tratados por cirurgiões maxilofaciais ${ }^{21}$. Essas fraturas são frequentemente associadas às fraturas condilares, com frequência de $26 \%$ a $57 \%{ }^{9,22}$. As lesões na região da cabeça ou colo do côndilo acarretam na redução da força máxima de mordida e desconforto durante a mastigação ${ }^{1}$. Além disso, 
fraturas bilaterais de côndilo, associadas à outras fraturas faciais, representam um desafio no trauma maxilofacial, principalmente quanto ao gerenciamento da fratura. Para esses pacientes, é difícil determinar se as complicações miofuncionais orofaciais existentes são secundárias ao tratamento da fratura condilar por si só, ou se são decorrentes das fraturas associadas ${ }^{23}$.

A incidência de disfunção da articulação temporomandibular (DTM) após traumas de face é alta, sendo que a taxa de incidência tende a aumentar gradualmente com o aumento do tempo de seguimento ${ }^{24}$. Traumas na articulação temporomandibular (ATM) podem acarretar em fraturas intracapsulares ou contusões na $\mathrm{ATM}^{25}$. Mudanças na estrutura da ATM (ex.: deslocamento agudo do disco articular devido às fraturas subcondilares ou fraturas mandibulares contralaterais, lesões neuromusculares regionais e alterações crônicas devido às mudanças oclusais) são descritas mesmo na ocorrência de traumas indiretos nessa estrutura 25 .

Os procedimentos emergenciais e o prognóstico em pacientes com traumas de face estão diretamente relacionados ao estado geral do paciente, a localização e número de fraturas e ao envolvimento dos tecidos moles adjacentes. Apesar da região maxilomandibular conter importantes estruturas ósseas e de tecidos moles para a execução de funções vitais como deglutição, mastigação e fala, poucos estudos focam na investigação dos resultados funcionais em pacientes com fraturas de face. Esses estudos descreveram que pacientes com fraturas faciais apresentaram frequentemente déficits graves em mobilidade mandibular, desempenho ruim na execução de movimentos orofaciais e alterações no desempenho da mastigação e da deglutição ${ }^{1,3,24}$. As fraturas faciais podem acarretar em complicações como edema; ruptura de 
artérias, nervos ou mucosas; abalos dentários; imobilidades mandibulares; trismo; alterações oclusais; desvios mandibulares no repouso e durante a mobilidade; desvios nas funções orofaciais; alterações na oclusão dentária e na movimentação da ATM e assimetrias faciais ${ }^{1,3,26}$. A anquilose temporomandibular por exemplo, é considerada uma condição extremamente restritiva, causando dificuldades para as funções de mastigação, deglutição, fala e para a realização da higiene oral ${ }^{27}$. Algumas causas de anquilose da ATM tem relação com a imobilização maxilomandibular em longo prazo, prejuízo do disco articular, fraturas de côndilo e terço médio da face, principalmente as que envolvem o zigomático e o processo coronóide ${ }^{28}$.

A qualidade de vida também é um fator importante no gerenciamento do trauma de face. O tratamento cirúrgico promove a qualidade de vida nos casos de fraturas mandibulares e múltiplas ${ }^{29}$. Contudo, a presença de dor, edema e estresse cirúrgico pode alterar a qualidade de vida desses pacientes ${ }^{29,30}$. No tratamento das alterações mandibulares, a restauração da oclusão original, a melhora da deglutição com a adequação óssea da mandíbula, combinadas com analgesia adequada, auxiliam na promoção da qualidade de vida ${ }^{29-31}$. Em média, os pacientes apresentam pior qualidade de vida quando é analisado o período pós-cirúrgico. Os preditores para pior qualidade de vida incluíram hábito de fumar, fixação mandibular e fraturas do tipo Le Fort ${ }^{32}$. Assim sendo, o diagnóstico precoce, em conjunto com a educação e orientação ao paciente, são as questões centrais para o gerenciamento eficaz de pacientes acometidos por traumas de face.

Levando-se em consideração o local, o tipo, a extensão da lesão e a situação geral ou comprometimento do sistema miofuncional orofacial, justifica- 
se a participação do fonoaudiólogo como um dos profissionais envolvidos na equipe multidisciplinar, visando a reabilitação dos pacientes tratados por meio de terapêutica cirúrgica ou conservadora ${ }^{1}$. A intervenção fonoaudiológica nos casos de fraturas mandibulares envolve o trabalho miofuncional oral e visa restabelecer a mobilidade mandibular, evitando possíveis assimetrias ou limitações funcionais ${ }^{33}$. O aumento da amplitude da abertura da boca, a adequação dos movimentos mandibulares evitando adaptações nocivas e promovendo a simetria do movimento e da face e a estabilidade funcional são também objetivos do tratamento fonoaudiológico ${ }^{33}$.

De maneira geral, sabe-se que as compensações podem ocorrer durante a recuperação muscular (ex.: hiperfunção de masseteres, temporais e esternocleidomastoideo) ${ }^{20}$ decorrentes de alterações nas estruturas ósseas, musculares e no funcionamento articular. Essas compensações são, em um primeiro momento, necessárias para a viabilização funcional, uma vez que o comprometimento estrutural impede a fisiologia normal e torna necessária a utilização de musculatura correlata ${ }^{34}$. Nessa fase é importante minimizar a atrofia muscular, as alterações em fibras musculares, as alterações condilares e demais alterações observadas ${ }^{35}$.

Conforme a Classificação Brasileira de Procedimentos em Fonoaudiologia ${ }^{36}$, a terapia fonoaudiológica miofuncional orofacial tem como definição a "habilitação e reabilitação morfológica e funcional das estruturas quanto à simetria, tonicidade, mobilidade, sensibilidade, diadococinesia; dinâmica das estruturas e funções de fala, sucção, mastigação, deglutição; dinâmica respiratória e articulação da fala”. 
A terapia fonoaudiológica resulta em reabilitação funcional da mandíbula e da face, dirigindo e organizando os movimentos, assim como estimulando a adequação das funções orofaciais, evitando possíveis sequelas ${ }^{37}$. Estudos realizados com pacientes submetidos à cirurgia ortognática podem explicar alguns dos achados obtidos em pacientes após a correção das fraturas de face, uma vez para estes pacientes, também são observadas mudanças ósseas e de estruturas moles após o procedimento cirúrgico. Para os pacientes submetidos à cirurgia ortognática, a terapia funcional deve incluir manutenção da oclusão e a garantia da mobilidade mandibular. Segundo a literatura, as técnicas terapêuticas de reabilitação favorecem a posição condilar durante o processo de regeneração óssea ${ }^{38}$, auxiliando na recuperação precoce do funcionamento dos músculos masseteres e temporais seis meses após o procedimento cirurgico ${ }^{39,40}$

$\mathrm{Na}$ terapia miofuncional orofacial, são incluídos exercícios motores orais com a finalidade de equilibrar a musculatura orofacial, favorecendo a execução das funções orais. O objetivo da terapia é a redução significativa da dor em todos os músculos da face, a melhora da mobilidade mandibular e a melhora das condições gerais miofaciais ${ }^{41}$. Embora os exercícios miofuncionais orofaciais façam parte de diversos tipos de abordagem terapêutica, são escassos os trabalhos que comparam e discutam a eficácia dos mesmos ${ }^{42}$.

Considerando as lacunas de informação sobre os efeitos da reabilitação motora oral em pacientes com traumas de face, assim como o impacto do tempo de fratura na eficácia da reabilitação, o objetivo do presente estudo foi verificar a efetividade de um programa de reabilitação fonoaudiológica para pacientes adultos com trauma de face e restrição da mobilidade mandibular, por meio da avaliação clínica da motricidade orofacial e mobilidade mandibular, avaliação da 
autopercepção do paciente e da avaliação eletromiográfica dos músculos mastigatórios. A hipótese do estudo foi que pacientes com menor tempo entre a correção da fratura e a intervenção fonoaudiológica apresentariam melhores resultados após o tratamento. 


\section{MÉTODOS}

O desenho metodológico deste estudo foi prospectivo clínico longitudinal. Esta pesquisa foi aprovada pela Comissão de Ética para Análise de Projetos e Pesquisas da Instituição (CAPPesq HCFMUSP 1.856.950 - Anexo A). Os procedimentos para coleta de dados somente tiveram início após assinatura do Termo de Consentimento Livre e Esclarecido (TCLE) pelos participantes da pesquisa (Anexos B e C).

\subsection{Participantes}

A amostra foi composta por indivíduos adultos acometidos por trauma de face. A coleta de dados foi realizada entre dezembro de 2015 a dezembro de 2018. Sendo assim, foram incluídos neste estudo 65 participantes, de ambos os gêneros, com idade superior a 18 anos, com diagnóstico médico de fratura facial, encaminhados para a Divisão de Fonoaudiologia do HCFMUSP para avaliação e tratamento fonoaudiológico. A presença de fratura de face foi confirmada pela equipe médica da Disciplina/Serviço de Cirurgia Plástica Reparadora e Queimaduras do mesmo Hospital.

No HCFMUSP, o encaminhamento do paciente com trauma de face para a Divisão de Fonoaudiologia ocorre somente quando o mesmo apresenta alguma queixa de DTM e/ou restrição de abertura de boca. Quanto ao tratamento médico para redução das fraturas de face, a Divisão Cirurgia Plástica Reparadora e Queimaduras adota os seguintes critérios: a) redução aberta da 
fratura - é realizada quando o paciente apresenta alteração oclusal, deslocamento da fratura maior que $30^{\circ}$, translocação superior a $4 \mathrm{~mm}$ ou superposição lateral; b) redução fechada com bloqueio maxilomandibular - é realizada quando o deslocamento da fratura condilar é classificado como moderado, ou quando não é observado deslocamento ou risco de deslocamento da fratura.

Foram incluídos na pesquisa todos os indivíduos adultos, com fratura de face (pelo menos uma fratura em mandíbula ou maxila), sem distinção de gênero ou condição sócio-econômico-cultural. Foram excluídos da pesquisa os indivíduos com comorbidades cognitivas e neurológicas, histórico de procedimento cirúrgico anterior à fratura em região de cabeça e pescoço e indivíduos que não concluíram o programa terapêutico.

Os participantes deste estudo foram divididos em três grupos, de acordo com o tempo decorrido entre a correção da fratura da face e a avaliação fonoaudiológica (Figura 1).

- Grupo de pesquisa 1 (GP1) - Composto por 24 participantes (36,9\% da amostra) que foram submetidos à avaliação fonoaudiológica em até um mês após a correção da fratura;

- Grupo de pesquisa 2 (GP2) - Composto por 29 participantes (44,6\% da amostra) que foram submetidos à avaliação fonoaudiológica de um a três meses após a correção da fratura;

- Grupo de pesquisa 3 (GP3) - Composto por 12 participantes (18,5\% da amostra) que foram submetidos à avaliação fonoaudiológica em três meses ou mais após a correção da fratura. 


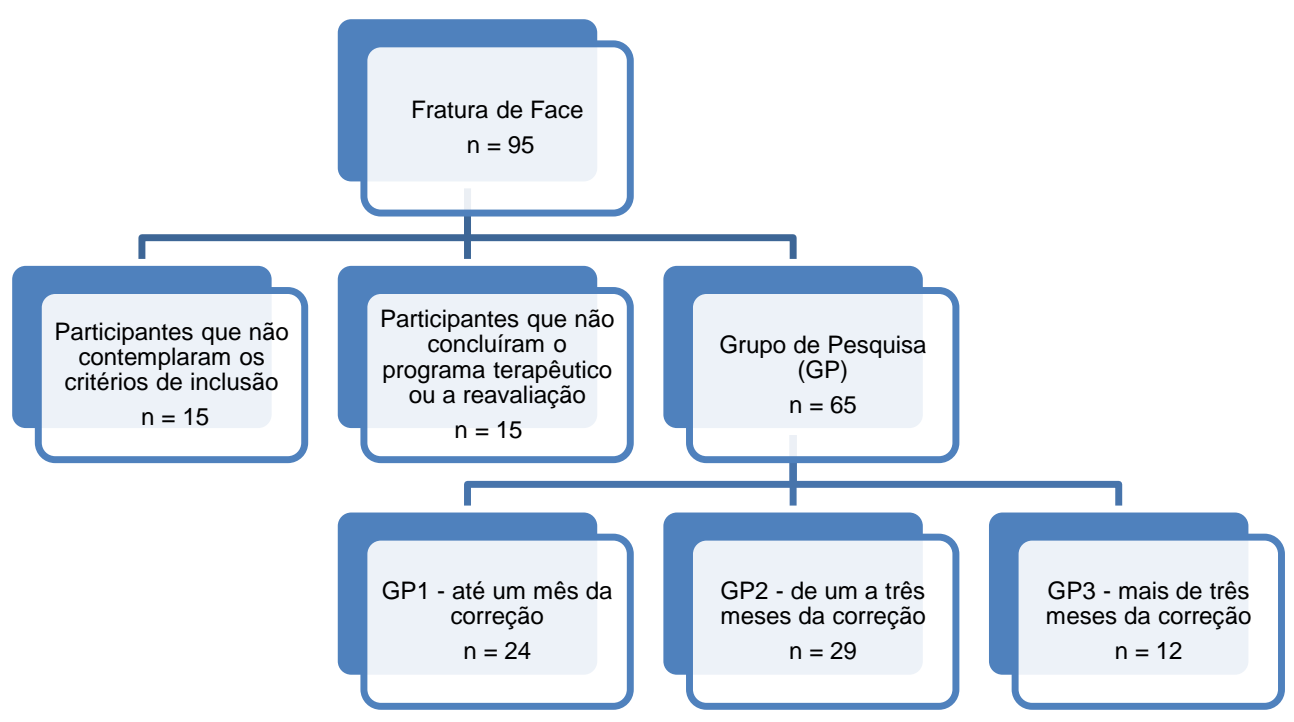

Figura 1 - Fluxograma referente aos participantes do estudo

\subsection{Avaliação Fonoaudiológica}

Todos os participantes foram submetidos ao mesmo procedimento de avaliação em dois momentos distintos: pré e pós-aplicação do programa de tratamento. Cada um dos momentos de avaliação foi realizado em uma única sessão de 60 minutos de duração. Os procedimentos de avaliação encontramse descritos abaixo.

\subsubsection{Avaliação Miofuncional Orofacial}

O protocolo de Avaliação Miofuncional Orofacial com Escore Expandido ${ }^{43}(A M I O F E-E)$, é um instrumento para a avaliação clínica das estruturas orofaciais. Este protocolo foi elaborado com base em modelos anteriores de avaliação, com a adição de escalas numéricas que refletem as características físicas e comportamentos orofaciais dos indivíduos ${ }^{44}$. 
O objetivo foi avaliar os componentes do Sistema Miofuncional Orofacial em termos de aspecto/postura, mobilidade e desempenho durante as funções de deglutição e de mastigação, contendo 32 tarefas e escore total de 230 pontos. A coleta de dados foi realizada por meio de inspeção visual durante a avaliação, e pela análise dos registros das fotos e filmagens, em câmera digital (Sony DSCW120). Para o registro das fotos e filmagens, o paciente utilizou touca descartável, estava sem maquiagem e sem acessórios. Os registros foram realizados com o paciente em pé e restritos às regiões da face e cervical.

Com o objetivo de garantir a fidedignidade dos resultados da avaliação clínica, todos os participantes foram avaliados por dois fonoaudiólogos, examinadores independentes com experiência na área. O Coeficiente de Kappa foi utilizado para verificar a concordância entre os examinadores, sendo que o resultado indicou alto nível de concordância $(0,83)$.

\subsubsection{Avaliação da Mobilidade Mandibular}

Para a avaliação da mobilidade mandibular, foi utilizada metodologia baseada na literatura já existente em pacientes com trauma de face ${ }^{1,3}$. As medições foram realizadas utilizando um paquímetro digital (Digimess Pró-Fono, Pró-Fono Produtos Especializados para Fonoaudiologia Ltda, Brasil), sendo obtidas as seguintes medições (em mm):

- Abertura oral máxima - distância entre as faces incisais dos dentes incisivos superiores e dos inferiores, acrescida da medida do trespasse vertical (Figura 2); também foi considerada nessa análise a presença de desvio durante abertura oral, sendo marcado se foi negativo ou positivo (neste caso, para qual lado foi o desvio). 


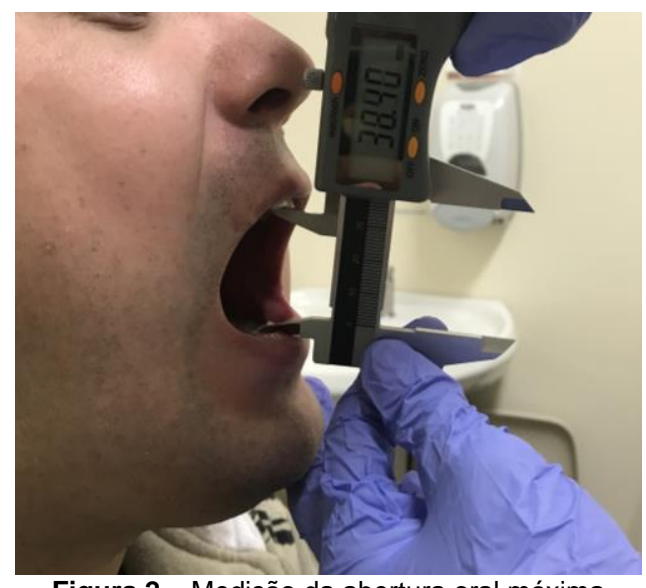

Figura 2 - Medição da abertura oral máxima

FONTE: Acervo da Divisão de Fonoaudiologia do HCFMUSP - Uso da imagem autorizada. Anexo B.

- Lateralidade mandibular - distância horizontal da linha entre os incisivos centrais inferiores à linha entre incisivos centrais superiores, após o deslize lateral da mandíbula para o lado direito e em seguida para o lado esquerdo. Em caso de presença de desvio de linha média, foi realizado o ajuste pertinente (Figura 3).

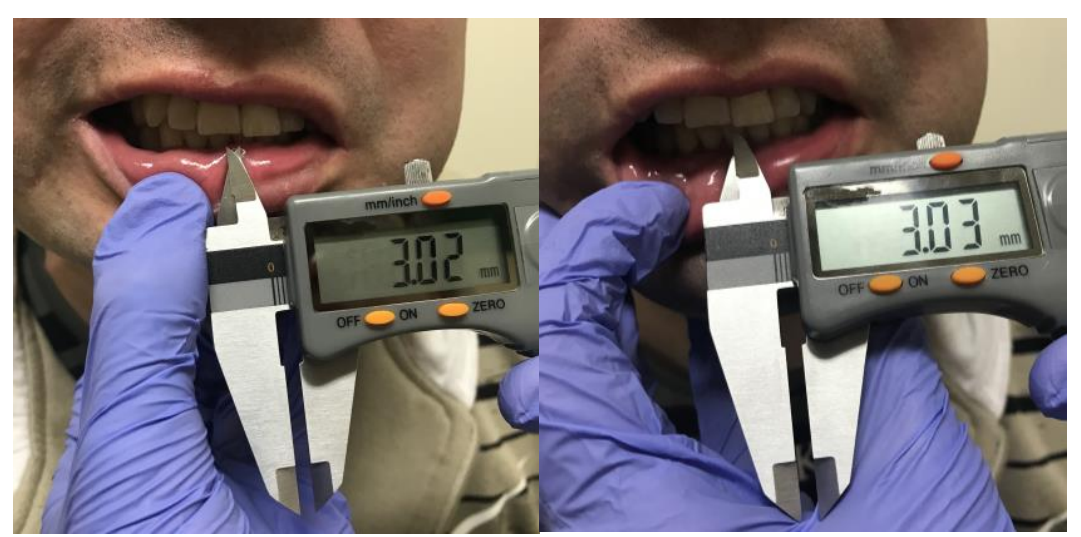

Figura 3 - Medição da lateralidade mandibular

FONTE: Acervo da Divisão de Fonoaudiologia do HCFMUSP - Uso da imagem autorizada. Anexo B.

- Protrusão mandibular - somatória da medida do trespasse horizontal com a medida do deslizamento horizontal máximo da mandíbula (Figura 4). 


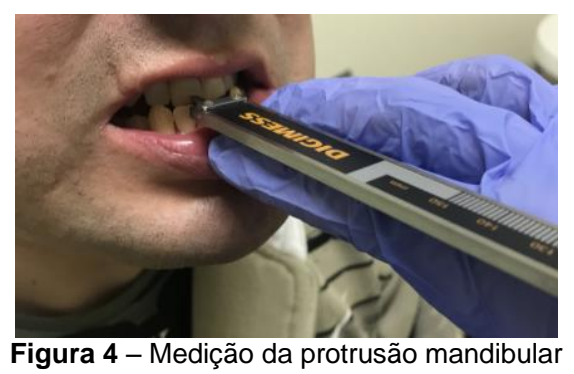

FONTE: Acervo da Divisão de Fonoaudiologia do HCFMUSP - Uso da imagem autorizada. Anexo B.

O posicionamento dos participantes para obtenção das medidas foi: sentado, pés apoiados no chão, cabeça em posição padronizada, orientada segundo o plano horizontal de Frankfurt. O examinador manteve-se à frente dos participantes para obtenção das medidas.

\subsubsection{Autopercepção dos Sinais e Sintomas de DTM}

Para esta avaliação, foi aplicado protocolo de investigação de sinais e sintomas de DTM ${ }^{42}$. O protocolo é dividido em sintomas gerais, relacionados a mobilidade mandibular e sintomas que podem surgir durante as diferentes atividades diárias (ao acordar, mastigar, falar e durante o repouso). A primeira parte contém questões que admitem apenas respostas afirmativas ou negativas; no caso de respostas afirmativas, o participante deve indicar o lado do sintoma (esquerdo, direito ou bilateral). A segunda parte é composta por perguntas referentes à mobilidade mandibular, também com respostas afirmativas ou negativas. Na terceira parte, os participantes foram solicitados a indicar o quanto cada sinal ou sintoma era grave ao acordar, ao mastigar, ao falar e em repouso, utilizando uma escala numérica impressa de 11 pontos, graduada da seguinte maneira: zero foi considerado ausência completa do sintoma ou sinal e 10, a maior gravidade possível. 
A gravidade de cada sinal ou sintoma foi determinada pela somatória dos escores atribuídos nas quatro situações questionadas e, posteriormente, classificados quanto à gravidade da seguinte maneira: grau 0 (sinal/sintoma ausente); grau 1 (somatória variando de 1 a 10); grau 2 (de 11 a 20); grau 3 (de 21 a 30 ) e grau 4 (de 31 a 40$)^{42}$.

\subsection{Programa Terapêutico}

Os participantes de GP1, GP2 e GP3 foram submetidos ao Programa Terapêutico Fonoaudiológico para Trauma de Face com Restrição em Amplitude

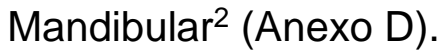

O programa terapêutico aplicado foi elaborado para pacientes que tenham como achados edemas faciais agudos, limitação e/ou desvio dos movimentos mandibulares, dor na musculatura mastigatória ou ATMs durante realização de movimentos e/ou funções mandibulares, posicionamento inadequado de mandíbula e língua, alteração no padrão mastigatório, dificuldades durante alimentação e alterações na qualidade de vida após trauma de face como restrição alimentar e outras, tendo como objetivo o equilíbrio das funções miofuncionais orofaciais. Como objetivos gerais o programa propõe redução de edemas, redução e prevenção de dor orofacial, relaxamento da musculatura mastigatória, melhora da lubrificação e funcionamento das ATMs, aumento de amplitude e simetria dos movimentos mandibulares, otimização do funcionamento da musculatura mastigatória, melhoria do padrão e eficiência das funções do sistema miofuncional orofacial e estabilidade dos resultados obtidos. 
Durante o programa terapêutico, foram realizados exercícios focando orientação e percepção do sistema miofuncional orofacial, drenagem manual de edemas, manipulação e alongamento cervical, exercícios de mobilidade de língua e mandíbula, manipulação e alongamento dos músculos temporais, masseteres e pterigoideos e exercícios para a funcionalidade do sistema miofuncional orofacial.

O programa proposto é composto por seis sessões de terapia fonoaudiológica, com 30 minutos de duração cada, realizadas uma vez por semana. A cada sessão o participante foi instruído a realizar os exercícios em casa, diariamente, três vezes por dia. Todos os participantes se comprometeram a cumprir as orientações e anotavam diariamente quando realizavam os exercícios. As anotações eram levadas semanalmente para conferência do terapeuta. Os participantes que faltaram às sessões foram excluídos da pesquisa. $O$ delineamento do processo terapêutico encontra-se ilustrado na Figura 5.

Após as seis sessões do programa, os participantes foram submetidos à reavaliação, constando das mesmas provas realizadas inicialmente. 


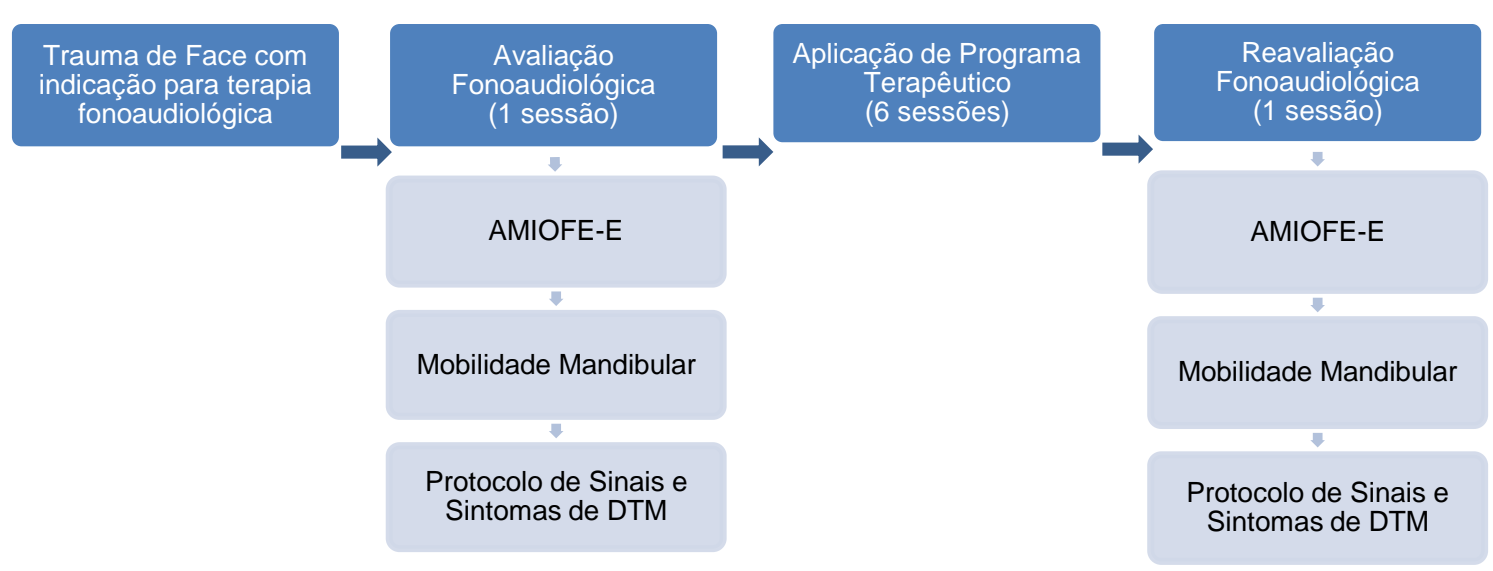

Figura 5 - Delineamento do processo terapêutico

\subsection{Avaliação Complementar}

\subsubsection{Avaliação da Musculatura Mastigatória - Eletromiografia de}

\section{Superfície (EMGs)}

Para verificar de maneira objetiva possíveis mudanças no funcionamento das fibras musculares decorrentes do tratamento proposto, foi realizada a avaliação dos músculos mastigatórios por meio da EMGs. Para tanto, foram selecionados randomicamente 25 participantes incluídos no estudo ( $38 \%$ do total de participantes) para a realização dos procedimentos de análise eletromiográfica. Nessa etapa da pesquisa, não houve diferenciação dos participantes quanto ao tempo de fratura.

Além dos 25 participantes do Grupo Pesquisa selecionados randomicamente, foram incluídos nesta etapa 25 indivíduos saudáveis (Grupo Controle $-\mathrm{GC}$ ), que foram submetidos ao mesmo procedimento de testagem eletromiográfica em dois momentos distintos, com seis semanas de intervalo 
entre eles, respeitando a temporalidade do tratamento adotado para os grupos de participantes com trauma de face. O objetivo desta inclusão foi garantir que as possíveis mudanças observadas nessa avaliação foram decorrentes do programa terapêutico adotado e não de interferências do dia de testagem.

O GC foi composto por indivíduos adultos, sem alterações no sistema miofuncional orofacial e em região de cintura escapular, com dentição permanente completa (podendo ser aceita a ausência/extração dos $3^{\circ}$ molares), com relação de molar Classe I de Angle ${ }^{45}$ e ausência de mal oclusão grave ${ }^{45}$, sem uso de aparatologia ortodôntica no momento da avaliação ou tratamento fonoaudiológico prévio. O GC foi pareado ao Grupo Pesquisa (GP) por idade e gênero.

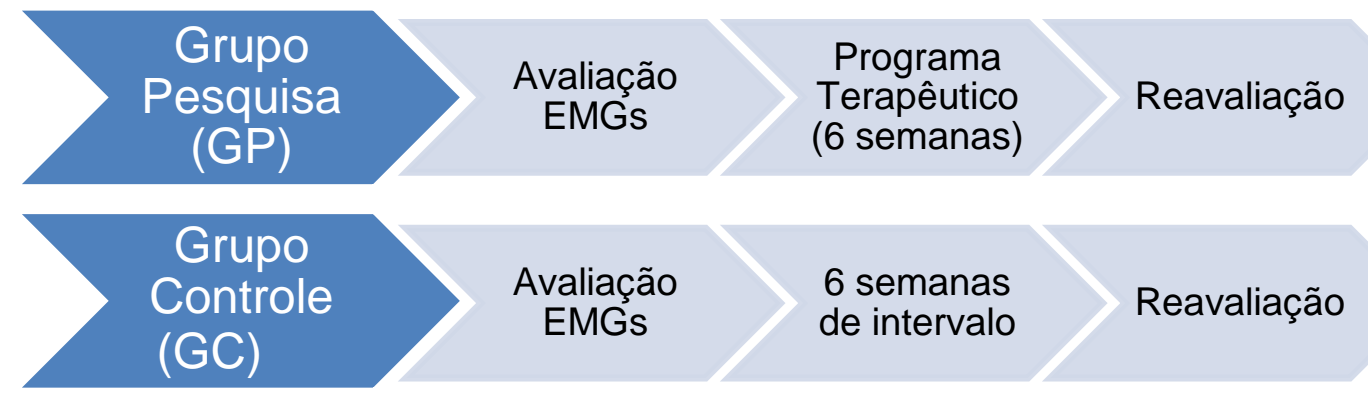

Figura 6 - Tempos para avaliação e reavaliação dos Grupos Pesquisa e Controle

A avaliação eletromiográfica dos músculos mastigatórios foi realizada com base na metodologia apresentada em estudos anteriores proposta por Nakata et. al e Sforza et. al ${ }^{46,47}$. Para realização da EMGs, foi utilizado o Eletromiógrafo - Miotool 400, com 4 canais, calibrados em 500 microvolts $(\mu \mathrm{V})$ com filtro do tipo passa banda $(20-500 \mathrm{~Hz})$ e do tipo notch $(60 \mathrm{~Hz})$ e ganho de

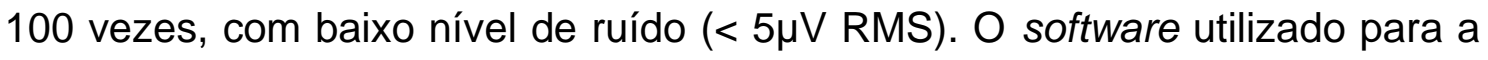


captação e processamento do exame de EMGs foi o MiotecSuite ${ }^{T M} 1.0$, do fabricante Miotec® Equipamentos Biomédicos, que faz aquisição, armazenamento e processamento on-line de sinais e é executado sob o sistema operacional Windows $X P$. Os sinais da atividade elétrica dos movimentos musculares foram captados por eletrodos duplos bipolares de superfície $\mathrm{Ag} / \mathrm{AgCl}$, descartáveis, modelo SDS500.

Todos os exames de EMGs foram realizados por um fonoaudiólogo com experiência na área, nas mesmas condições ambientais. Previamente à coleta dos dados, o equipamento foi calibrado conforme normas estabelecidas pela International Society of Electrophysiological Kinesiology - ISEK. O posicionamento dos eletrodos obedeceu a técnica de colocação do ponto médio do ventre muscular, na direção longitudinal do feixe muscular, na posição mesodistal do músculo, conforme sugerido por Soderberg e Cook $^{48}$, onde observa-se maior amplitude de sinal para este tipo de eletrodo. Para garantir o correto posicionamento dos eletrodos, foi realizada a identificação dos músculos masseteres e temporais por meio da palpação durante o repouso e na contração máxima - foi solicitada a máxima intercuspidação dentária (MIC). Após esta etapa, a função muscular foi testada para a verificação de possíveis erros de posicionamento e realizada nova colocação dos eletrodos, quando necessário.

A atividade elétrica simultânea dos músculos temporais (direito - MTD e esquerdo - MTE) e masseteres (direito - MMD e esquerdo - MME) em ambas as hemifaces foi avaliada durante as seguintes tarefas:

- Repouso - durante 30 segundos, foram realizadas três coletas para obtenção da média da atividade elétrica. 
- Apertamento dentário máximo com máxima intercuspidação dentária (MIC) - máxima intercuspidação dentária (apertamento dentário máximo). Foi solicitado aos participantes realizar a mordida com a máxima força possível por cinco segundos, três vezes seguidas, com intervalos de cinco segundos.

- Apertamento dentário máximo com rolete de algodão entre os dentes (ALG) - foi colocado um rolete de algodão de $10 \mathrm{~mm}$ entre os primeiros e segundos molares bilateralmente e solicitado aos participantes a mordida com a máxima força possível o algodão por cinco segundos, três vezes seguidas, com intervalo de cinco segundos.

- Mastigação Habitual (MAST) - Foi solicitado aos participantes a mastigação de um pedaço de pão francês de forma habitual. Os registros foram gravados por 20 segundos.

Entre cada prova foi realizado repouso de três minutos, sem gravação, para evitar fadiga muscular.

Para a coleta dos dados, todos participantes foram confortavelmente sentados em uma cadeira, com as costas apoiadas, pés apoiados no chão, mãos apoiadas nos membros inferiores, cabeça posicionada adequadamente (Plano de Frankfurt paralelo ao chão), olhos abertos e buscando um ponto fixo prédeterminado. A pele da face foi preparada utilizando gaze embebida em álcool $70^{\circ}$ e realizada tricotomia local, para garantir a impedância adequada durante a realização do exame. Os sinais captados foram analisados em root mean square 
(RMS) e expressos em microvolts $(\mu \mathrm{V})$. O cabo de referência foi conectado ao eletrodo e fixado sobre o pulso direito.

Para a análise dos resultados da EMGs, foi utilizada a análise do domínio temporal. Neste caso, a informação obtida descreve em que momento o evento ocorreu e qual a amplitude (indicador da magnitude da atividade muscular) de sua ocorrência. Na situação de repouso, os valores obtidos representaram a média (RMS) da atividade eletromiográfica observada em 30 segundos. A amplitude da atividade muscular durante as tarefas de apertamento dentário (ALG e MIC) foi obtida pela seleção do trecho representativo da ativação muscular (situação on e off). A situação on foi determinada pelo início da contração muscular acima dos valores basais. O off foi determinado pelo retorno do músculo à sua atividade basal. Esse trecho foi selecionado com o cursor do próprio programa de eletromiografia e convertido em $\mu \mathrm{V}$ (Figura 7).

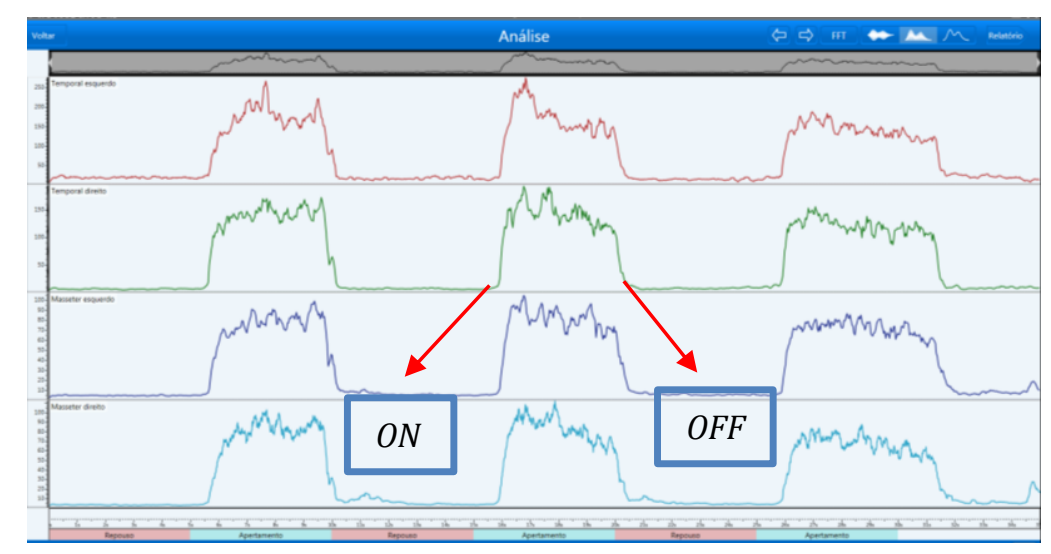

Figura 7 - Traçado eletromiográfico (apertamento dentário em RMS)

Para a comparação dos resultados, os valores de amplitude da EMGs nas tarefas AL e MIC foram normalizados em relação à atividade de repouso, possibilitando assim a comparação entre os participantes e entre os grupos. 
Além disso, para fins de comparação da atividade muscular entre os grupos, foi calculado o índice de assimetria, os lados entre as atividades foram comparados para os músculos temporais e masseteres. O índice tem valor máximo de um, sendo que quanto mais próximo de um, mais simétrico é o indivíduo.

Sabe-se que existe subjetividade na leitura de medidas de EMGs e por essa razão, foi realizada uma análise de confiabilidade, a fim de determinar o índice de concordância entre os examinadores garantindo maior fidedignidade das medidas. Para a análise, foram selecionadas randomicamente 60 amostras eletromiográficas de um total de 600 amostras. Essas amostras foram analisadas independentemente por dois fonoaudiólogos com experiência na área, cegos ao estudo. O Coeficiente de Kappa foi utilizado para verificar a concordância entre os examinadores, sendo que o resultado indicou alto nível de concordância $(0,92)$.

\subsection{Análise dos dados}

Os dados coletados foram submetidos à análise estatística no software SPSS versão 25. Os dados quantitativos receberam análise descritiva (média e desvio padrão), e inferencial comparando os grupos (teste de Kruskal-Wallis para as comparações múltiplas, com análise post hoc de pares pelo teste de Dunn com correção de Bonferroni, se significativo). Para estes dados, também foram realizadas análises intragrupo, comparando os resultados obtidos antes do tratamento aos resultados obtidos após o tratamento (teste de Wilcoxon para amostras pareadas). Os dados qualitativos receberam análise descritiva (contagem total e porcentagem) e inferencial comparando os grupos (teste Qui- 
Quadrado de Pearson, com análise post hoc de pares pelo teste de Dunn com correção de Bonferroni, se significativo). Para estes dados, também foram realizadas análises intragrupo, comparando os resultados obtidos antes do tratamento aos resultados obtidos após o tratamento (teste Qui-Quadrado de Pearson). O nível de significância adotado em todas as análises foi de 5\%.

Os dados eletromiográficos coletados foram submetidos à análise estatística no software SPSS versão 25. Os dados receberam análise descritiva (média e desvio padrão), e inferencial, comparando os grupos (teste de MannWhitney), e também intragrupo, comparando os resultados obtidos antes do tratamento aos resultados obtidos após o tratamento (teste de Wilcoxon para amostras pareadas). O nível de significância adotado em todas as análises foi de $5 \%$. 


\section{RESULTADOS}

\subsection{Analises descritivas}

As Tabelas abaixo apresentam os resultados obtidos para os três grupos de participantes com fraturas de face incluídos no estudo. A Tabela 1 exibe as análises descritivas de caracterização dos grupos quanto a idade, gênero, participantes com fratura de côndilo, participantes que realizaram tratamento cirúrgico, tempo entre a correção da fratura e início da terapia fonoaudiológica e o terço da face acometido pela fratura. Foram encontradas diferenças entre os grupos para o número de participantes que tiveram fraturas envolvendo o côndilo e para o tempo entre a correção da fratura e o início do tratamento fonoaudiológico.

Tabela 1 - Comparação intergrupos das variáveis demográficas e dados do prontuário médico

\begin{tabular}{|c|c|c|c|c|}
\hline & $\begin{array}{c}\text { GP1 } \\
(n=24)\end{array}$ & $\begin{array}{c}\text { GP2 } \\
(n=29)\end{array}$ & $\begin{array}{c}\text { GP3 } \\
(n=12)\end{array}$ & $p$-value \\
\hline $\begin{array}{l}\text { Idade (em anos) } \\
\qquad( \pm D P)\end{array}$ & $31,3( \pm 12,6)$ & $29,9( \pm 10,0)$ & $37,7( \pm 13,0)$ & 0,204 \\
\hline $\begin{array}{l}\text { Gênero } \\
\text { NT (\%) }\end{array}$ & $\begin{aligned} M & =20(83,3 \%) \\
F & =4(16,7 \%)\end{aligned}$ & $\begin{aligned} M & =21(72,4 \%) \\
F & =8(27,6 \%)\end{aligned}$ & $\begin{aligned} M & =9(75,0 \%) \\
F & =3(25,0 \%)\end{aligned}$ & 0,634 \\
\hline $\begin{array}{l}\text { Participantes com fraturas em } \\
\text { côndilo NT (\%) }\end{array}$ & $17(70,8 \%)$ & $11(37,9 \%)$ & $2(16,7 \%)$ & $0,004^{*}$ \\
\hline $\begin{array}{c}\text { Participantes que passaram por } \\
\text { cirurgia NT (\%) }\end{array}$ & $16(66,6 \%)$ & $15(51,7 \%)$ & $5(41,7 \%)$ & 0,476 \\
\hline $\begin{array}{c}\text { Tempo total (em dias) entre a } \\
\text { correção da fratura e o início do } \\
\text { tratamento fonoaudiológico } \\
M( \pm D P)\end{array}$ & $18,3( \pm 8,0)$ & $59,4( \pm 19,6)$ & $163,3( \pm 76,1)$ & $<0,001^{*}$ \\
\hline $\begin{array}{l}\text { Local da fratura de face } \\
\text { NT (\%) }\end{array}$ & $\begin{array}{c}\text { Terço médio = } \\
2(8,3 \%) \\
\text { Terço inferior }= \\
10(41,7 \%) \\
\text { Ambos }= \\
12(50,0 \%)\end{array}$ & $\begin{array}{c}\text { Terço médio = } \\
5(17,2 \%) \\
\text { Terço inferior }= \\
10(34,5 \%) \\
\text { Ambos }= \\
14(48,3 \%)\end{array}$ & $\begin{array}{c}\text { Terço médio = } \\
4(33,3 \%) \\
\text { Terço inferior = } \\
2(16,7 \%) \\
\text { Ambos }= \\
6(50,0 \%)\end{array}$ & 0,348 \\
\hline
\end{tabular}

Legenda: GP1: Grupo pesquisa 1; GP2: Grupo pesquisa 2; GP3: Grupo pesquisa 3; N: número de participantes; M: gênero masculino; F: gênero feminino; M: média; DP: desvio padrão; NT: número total de participantes; *diferença significativa de acordo com o teste Qui-Quadrado de Pearson. 
Foram realizadas comparações por pares para as variáveis demográficas e dados do prontuário médico que apresentaram diferenças significativas entre os grupos (Tabela 2). Segundo esta análise, foram observadas diferenças significantes apenas entre o GP1 e GP3, com o GP1 apresentando maior número de participantes com fratura de côndilo. Para o tempo total entre a fratura e o início do tratamento fonoaudiológico, foram encontradas diferenças significativas entre todos os grupos, sendo que o GP3 foi o grupo com maior número de dias para iniciar o tratamento fonoaudiológico.

Tabela 2 - Comparações de pares de acordo com as variáveis demográficas e dados do prontuário médico

\begin{tabular}{ccc} 
& & $p$-value \\
\hline Participantes que tiveram fraturas envolvendo & & 0,053 \\
côndilo & GP1 = GP2 & $0,007^{*}$ \\
& GP1 $\neq$ GP3 & 0,653 \\
GP2 $=$ GP3 & $<0,001^{*}$ \\
Tempo total (em dias) entre a fratura e o início & GP1 $\neq$ GP2 & $<0,001^{*}$ \\
do tratamento fonoaudiológico & GP1 $\neq$ GP3 & $0,005^{*}$ \\
\hline Legenda: GP1: Grupo pesquisa 1; GP2: Grupo pesquisa 2; GP3: Grupo pesquisa 3; *diferença significativa de acordo \\
com análise post hoc de pares pelo teste de Dunn com correção de Bonferroni.
\end{tabular}

A Tabela 3 exibe a localização das fraturas para cada um dos grupos, evidenciando que GP1 e GP2 apresentaram maior número de fraturas quando comparados ao GP3, sendo a mandíbula o local mais acometido. 
Tabela 3 - Comparação intergrupos nas variáveis demográficas e dados do prontuário médico

\begin{tabular}{|c|c|c|c|c|c|}
\hline \multicolumn{6}{|c|}{ GP1 ( $N=24)$} \\
\hline & & Total & Bilateral & Esquerda & Direita \\
\hline \multirow{6}{*}{ Mandíbula } & sínfise & 2 & - & - & - \\
\hline & corpo & 17 & 3 & 4 & 10 \\
\hline & ramo & 11 & 2 & 7 & 2 \\
\hline & processo coronóide & 2 & 0 & 2 & 0 \\
\hline & ângulo & 0 & 0 & 0 & 0 \\
\hline & côndilo & 17 & 4 & 7 & 6 \\
\hline Maxila & & 12 & 6 & 3 & 3 \\
\hline Zigoma & & 5 & 2 & 2 & 1 \\
\hline Total & & 66 & 17 & 25 & 22 \\
\hline \multicolumn{6}{|c|}{ GP2 (N=29) } \\
\hline & & Total & Bilateral & Esquerda & Direita \\
\hline \multirow{9}{*}{$\begin{array}{l}\text { Maxila } \\
\text { Zigoma } \\
\text { Total }\end{array}$} & sínfise & 3 & - & - & - \\
\hline & corpo & 12 & 2 & 4 & 6 \\
\hline & ramo & 10 & 3 & 1 & 6 \\
\hline & processo coronóide & 2 & 0 & 1 & 1 \\
\hline & ângulo & 2 & 0 & 2 & 0 \\
\hline & côndilo & 11 & 3 & 6 & 2 \\
\hline & & 16 & 10 & 3 & 3 \\
\hline & & 11 & 4 & 4 & 3 \\
\hline & & 67 & 22 & 21 & 21 \\
\hline \multicolumn{6}{|c|}{ GP3 $(\mathrm{N}=12)$} \\
\hline & & Total & Bilateral & Esquerda & Direita \\
\hline \multirow{9}{*}{$\begin{array}{l}\text { Maxila } \\
\text { Zigoma } \\
\text { Total }\end{array}$} & sínfise & 1 & - & - & - \\
\hline & corpo & 5 & 1 & 3 & 1 \\
\hline & ramo & 3 & 0 & 2 & 1 \\
\hline & processo coronóide & 0 & 0 & 0 & 0 \\
\hline & ângulo & 0 & 0 & 0 & 0 \\
\hline & côndilo & 2 & 1 & 0 & 1 \\
\hline & & 9 & 4 & 3 & 2 \\
\hline & & 8 & 2 & 4 & 2 \\
\hline & & 28 & 8 & 12 & 7 \\
\hline
\end{tabular}

Legenda: GP1: Grupo pesquisa 1; GP2: Grupo pesquisa 2; GP3: Grupo pesquisa 3; N = número de participantes.

Os próximos dados serão apresentados em três etapas, levando em consideração as análises intra e intergrupos para os dados clínicos e de autopercepção e o resultado da avaliação complementar da musculatura mastigatória.

\subsection{Análise intragrupos}

\subsubsection{Avaliação Miofuncional Orofacial}

A Tabela 4 exibe as análises descritivas e a comparação intragrupo de acordo com os resultados do protocolo AMIOFE-E ${ }^{44}$. Foram encontradas diferenças significativas entre as etapas (pré e pós-tratamento) para todas as variáveis e em todos os grupos, indicando que todos os grupos melhoraram em 
todos os aspectos analisados (aparência e condição postural, mobilidade, funções e pontuação total).

Tabela 4 - Comparação intragrupos de acordo com os resultados do protocolo AMIOFE-E

\begin{tabular}{ccccc} 
& $\begin{array}{c}\text { Pontuação AMIOFE } \\
\mathbf{M}( \pm \mathrm{DP})\end{array}$ & $\begin{array}{c}\text { Pré- } \\
\text { tratamento }\end{array}$ & $\begin{array}{c}\text { Pós- } \\
\text { tratamento }\end{array}$ & $\boldsymbol{p}$-value \\
\hline & Aparência e condição postural & $53,1( \pm 4,9)$ & $56,3( \pm 4,1)$ & $0,002^{*}$ \\
GP1 & Mobilidade & $76,2( \pm 15,4)$ & $92,1( \pm 9,8)$ & $<0,001^{*}$ \\
$(\mathrm{~N}=24)$ & Funções & $33,6( \pm 6,7)$ & $43,8( \pm 5,3)$ & $<0,001^{*}$ \\
& PONTUAÇÃO TOTAL & $162,9( \pm 22,1)$ & $192,2( \pm 14,2)$ & $<0,001^{*}$ \\
\hline \multirow{4}{*}{ GP2 } & Aparência e condição postural & $54,7( \pm 4,8)$ & $56,7( \pm 4,2)$ & $0,007^{*}$ \\
$(\mathrm{~N}=29)$ & Mobilidade & $79,6( \pm 19,2)$ & $93,9( \pm 16,8)$ & $<0,001^{*}$ \\
& Funções & $38,9( \pm 6,1)$ & $45,5( \pm 4,4)$ & $<0,001^{*}$ \\
& PONTUAÇÃO TOTAL & $173,2( \pm 24,2)$ & $196,0( \pm 21,3)$ & $<0,001^{*}$ \\
\hline GP3 & Aparência e condição postural & $56,0( \pm 2,5)$ & $56,2( \pm 2,6)$ & $0,003^{*}$ \\
$(\mathrm{~N}=12)$ & Mobilidade & $81,4( \pm 24,0)$ & $93,9( \pm 19,0)$ & $0,009^{*}$ \\
& Funções & $35,8( \pm 7,9)$ & $43,3( \pm 7,2)$ & $0,002^{*}$ \\
& PONTUAÇÃO TOTAL & $173,3( \pm 31,3)$ & $196,4( \pm 27,1)$ & $0,002^{*}$ \\
\hline
\end{tabular}

Legenda: GP1: Grupo pesquisa 1; GP2: Grupo pesquisa 2; GP3: Grupo pesquisa 3; AMIOFE-E: avaliação miofuncional orofacial com escore expandido, M: média; DP: desvio padrão; N: número de participantes, *diferença significativa de acordo com o teste de Wilcoxon para amostras pareadas.

\subsubsection{Avaliação da Mobilidade Mandibular}

A Tabela 5 exibe as análises descritivas e comparação intragrupos de acordo com os resultados da avaliação da mobilidade mandibular. Foram encontradas diferenças significativas entre as etapas (pré e pós-tratamento) para todas as variáveis e em todos os grupos, com a melhora dos três grupos nas medidas de amplitude mandibular realizadas (abertura oral máxima, lateralidade mandibular esquerda e direita, protrusão mandibular).

Tabela 5 - Comparação intragrupos de acordo com os resultados da avaliação da mobilidade mandibular

\begin{tabular}{ccccc}
\hline & $\begin{array}{c}\text { Medidas - mobilidade } \\
\text { mandibular } \\
\mathbf{M}( \pm \mathrm{DP})\end{array}$ & $\begin{array}{c}\text { Pré- } \\
\text { tratamento }\end{array}$ & $\begin{array}{c}\text { Pós- } \\
\text { tratamento }\end{array}$ & $\begin{array}{c}\boldsymbol{p} \text { - } \\
\text { value }\end{array}$ \\
\hline \multirow{3}{*}{ GP1 } & Abertura oral máxima & $24,5( \pm 12,3)$ & $41,9( \pm 9,2)$ & $<0,001^{*}$ \\
$(\mathrm{~N}=24)$ & Lateralidade mandibular direita & $4,1( \pm 3,4)$ & $6,7( \pm 2,8)$ & $<0,001^{*}$ \\
& Lateralidade mandibular esquerda & $4,2( \pm 3,2)$ & $7,1( \pm 3,3)$ & $<0,001^{*}$ \\
& Protrusão mandibular & $3,4( \pm 2,9)$ & $5,2( \pm 2,7)$ & $0,002^{*}$ \\
\hline \multirow{2}{*}{ GP2 } & Abertura oral máxima & $28,8( \pm 12,6)$ & $41,5( \pm 7,0)$ & $<0,001^{*}$ \\
$(\mathrm{~N}=29)$ & Lateralidade mandibular direita & $4,4( \pm 2,9)$ & $7,2( \pm 2,4)$ & $<0,001^{*}$ \\
& Lateralidade mandibular esquerda & $4,8( \pm 3,1)$ & $7,2( \pm 2,3)$ & $<0,001^{*}$ \\
& Protrusão mandibular & $4,0( \pm 2,9)$ & $5,4( \pm 3,2)$ & $0,003^{*}$ \\
\hline \multirow{2}{*}{ GP3 } & Abertura oral máxima & $29,1( \pm 9,2)$ & $42,7( \pm 10,4)$ & $0,002^{*}$ \\
$(\mathrm{~N}=12)$ & Lateralidade mandibular direita & $5,2( \pm 4,3)$ & $7,8( \pm 3,8)$ & $0,008^{*}$ \\
& Lateralidade mandibular esquerda & $3,9( \pm 3,1)$ & $7,5( \pm 3,8)$ & $0,005^{*}$ \\
& Protrusão mandibular & $4,8( \pm 3,4)$ & $6,4( \pm 2,9)$ & $0,041^{*}$ \\
\hline
\end{tabular}

Legenda: GP1: Grupo pesquisa 1; GP2: Grupo pesquisa 2; GP3: Grupo pesquisa 3; N: número de participantes; M: média; DP: desvio padrão; *diferença significativa de acordo com o teste de Wilcoxon para amostras pareadas. 
As análises descritivas e comparação intragrupo de acordo com os resultados da avaliação do desvio mandibular durante a abertura oral estão na Tabela 6. Foram encontradas diferenças significativas para todos os grupos, de acordo com o teste Qui-Quadrado de Pearson. O número de participantes com desvio mandibular durante a abertura oral foi significativamente menor após o tratamento, indicando melhor execução do movimento. Essa diferença ocorreu para todos os grupos.

Tabela 6 - Comparação intragrupos de acordo com os resultados da avaliação da mobilidade mandibular

\begin{tabular}{|c|c|c|c|c|}
\hline & Mobilidade mandibular & Pré-tratamento & Pós-tratamento & $p$-value \\
\hline $\begin{array}{c}\text { GP1 } \\
(\mathrm{N}=24)\end{array}$ & Desvio & $\begin{array}{c}\text { Não }=9(37,5 \%) \\
D=8(33,3 \%) \\
E=7(29,2 \%)\end{array}$ & $\begin{array}{c}\text { Não }=15(62,5 \%) \\
D=4(16,7 \%) \\
E=5(20,8 \%)\end{array}$ & $0,010^{*}$ \\
\hline $\begin{array}{c}\text { GP2 } \\
(N=29)\end{array}$ & Desvio & $\begin{array}{c}\text { Não }=12(41,4 \%) \\
D=12(41,4 \%) \\
E=5(17,2 \%)\end{array}$ & $\begin{array}{c}\text { Não }=18(62,1 \%) \\
D=8(27,6 \%) \\
E=3(10,3 \%)\end{array}$ & $0,002^{*}$ \\
\hline $\begin{array}{c}\text { GP3 } \\
(N=12)\end{array}$ & Desvio & $\begin{array}{c}\text { Não }=4(33,3 \%) \\
D=4(33,3 \%) \\
E=4(33,3 \%)\end{array}$ & $\begin{array}{c}\text { Não }=8(66,7 \%) \\
D=1(8,3 \%) \\
E=3(25,0 \%)\end{array}$ & $0,039^{*}$ \\
\hline
\end{tabular}

Legenda: GP1: Grupo pesquisa 1; GP2: Grupo pesquisa 2; GP3: Grupo pesquisa 3; N: número de participantes; D: sinais e sintomas apresentados do lado direito; E: sinais e sintomas apresentados do lado esquerdo; *diferença significativa de acordo com o teste Qui-Quadrado de Pearson. 


\subsubsection{Autopercepção dos Sinais e Sintomas de DTM}

As Tabelas 7, 8 e 9 exibem as análises descritivas e a comparação intragrupo (GP1) de acordo com os resultados da avaliação de Autopercepção dos Sinais e Sintomas de DTM. Para os sintomas gerais (Tabela 7) foram encontradas diferenças significativas entre as etapas (pré e pós-tratamento) apenas para as variáveis "Dor de cabeça" e "Plenitude"; no pré-tratamento, aproximadamente $20 \%$ dos participantes apresentaram queixas e no póstratamento, nenhum participante apresentou essa queixa.

Tabela 7 - Comparação intragrupo GP1 - resultados da avaliação de autopercepção dos sinais e sintomas de DTM (sintomas gerais)

\begin{tabular}{|c|c|c|c|}
\hline $\begin{array}{l}\text { Sinais e Sintomas de DTM } \\
\text { (Gerais) }\end{array}$ & $\begin{array}{c}\text { Pré-tratamento } \\
\text { NT }(\%)\end{array}$ & $\begin{array}{c}\text { Pós-tratamento } \\
\text { NT (\%) }\end{array}$ & $p$-value \\
\hline Dor muscular & $\begin{aligned} \text { Não } & =15(62,5 \%) \\
D & =0(0,0 \%) \\
E & =6(25,0 \%) \\
B & =3(12,5 \%)\end{aligned}$ & $\begin{aligned} \text { Não } & =19(79,2 \%) \\
D & =0(0,0 \%) \\
E & =5(20,8 \%) \\
B & =0(0,0 \%)\end{aligned}$ & 0,062 \\
\hline Fadiga & $\begin{aligned} \text { Não } & =19(79,2 \%) \\
D & =0(0,0 \%) \\
E & =2(8,3 \%) \\
B & =3(12,5 \%)\end{aligned}$ & $\begin{aligned} \text { Não } & =20(83,3 \%) \\
D & =1(4,2 \%) \\
E & =2(8,3 \%) \\
B & =1(4,2 \%)\end{aligned}$ & 0,276 \\
\hline Dor ATM & $\begin{aligned} \text { Não } & =22(91,7 \%) \\
D & =0(0,0 \%) \\
E & =2(8,3 \%) \\
B & =0(0,0 \%)\end{aligned}$ & $\begin{aligned} \text { Não } & =20(83,3 \%) \\
D & =1(4,2 \%) \\
E & =3(12,5 \%) \\
B & =0(0,0 \%)\end{aligned}$ & 0,450 \\
\hline Ruídos ATM & $\begin{aligned} \text { Não } & =20(83,3 \%) \\
\mathrm{D} & =1(4,2 \%) \\
\mathrm{E} & =3(12,5 \%) \\
\mathrm{B} & =0(0,0 \%)\end{aligned}$ & $\begin{aligned} \text { Não } & =18(75,0 \%) \\
D & =3(12,5 \%) \\
E & =3(12,5 \%) \\
B & =0(0,0 \%)\end{aligned}$ & 0,670 \\
\hline Dor no pescoço & $\begin{aligned} \text { Não } & =22(91,7 \%) \\
D & =0(0,0 \%) \\
E & =0(0,0 \%) \\
B & =2(8,3 \%)\end{aligned}$ & $\begin{aligned} \text { Não } & =23(95,8 \%) \\
D & =0(0,0 \%) \\
E & =0(0,0 \%) \\
B & =1(4,2 \%)\end{aligned}$ & 0,317 \\
\hline Dor de cabeça & $\begin{aligned} \text { Não } & =19(79,2 \%) \\
\mathrm{D} & =0(0,0 \%) \\
\mathrm{E} & =1(4,2 \%) \\
\mathrm{B} & =4(16,7 \%)\end{aligned}$ & $\begin{aligned} \text { Não } & =24(100 \%) \\
D & =0(0,0 \%) \\
E & =0(0,0 \%) \\
B & =0(0,0 \%)\end{aligned}$ & $0,034^{*}$ \\
\hline Otalgia & $\begin{aligned} \text { Não } & =20(83,3 \%) \\
D & =1(4,2 \%) \\
E & =3(12,5 \%) \\
B & =0(0,0 \%)\end{aligned}$ & $\begin{aligned} \text { Não } & =23(95,8 \%) \\
D & =1(4,2 \%) \\
E & =0(0,0 \%) \\
B & =0(0,0 \%)\end{aligned}$ & 0,098 \\
\hline Plenitude & $\begin{aligned} \text { Não } & =18(75,0 \%) \\
D & =0(0,0 \%) \\
E & =6(25,0 \%) \\
B & =0(0,0 \%)\end{aligned}$ & $\begin{aligned} \text { Não } & =24(100 \%) \\
D & =0(0,0 \%) \\
E & =0(0,0 \%) \\
B & =0(0,0 \%)\end{aligned}$ & $0,014^{*}$ \\
\hline Zumbido & $\begin{aligned} \text { Não } & =21(87,5 \%) \\
D & =1(4,2 \%) \\
E & =1(4,2 \%) \\
B & =1(4,2 \%)\end{aligned}$ & $\begin{aligned} \text { Não } & =22(91,7 \%) \\
D & =0(0,0 \%) \\
E & =2(8,3 \%) \\
B & =0(0,0 \%)\end{aligned}$ & 0,593 \\
\hline Dificuldade de mastigação & $\begin{aligned} \text { Não } & =16(69,6 \%) \\
D & =1(4,3 \%) \\
E & =0(0,0 \%) \\
B & =6(26,1 \%)\end{aligned}$ & $\begin{aligned} \text { Não } & =22(91,7 \%) \\
D & =0(0,0 \%) \\
E & =1(4,2 \%) \\
B & =1(4,2 \%)\end{aligned}$ & 0,067 \\
\hline
\end{tabular}


A Tabela 8 exibe as análises descritivas e comparação intragrupo (GP1) de acordo com os resultados referentes aos sintomas observados durante a movimentação mandibular. Foram encontradas diferenças significativas entre as etapas (pré e pós-tratamento) apenas para as variáveis "dificuldade para movimentar a boca", "dificuldade para abrir a boca” e "dificuldade para bocejar", com a redução das queixas após o tratamento fonoaudiológico.

Tabela 8 - Comparação intragrupo GP1 - resultados da avaliação de autopercepção dos sinais e sintomas de DTM (sintomas observados durante a movimentação mandibular)

\begin{tabular}{cccc}
\hline $\begin{array}{c}\text { Sinais e Sintomas de DTM - } \\
\text { Movimentação Mandibular }\end{array}$ & $\begin{array}{c}\text { Pré tratamento } \\
\text { NT }(\%)\end{array}$ & $\begin{array}{c}\text { Pós tratamento } \\
\text { NT }(\%)\end{array}$ & p-value \\
\hline Dificuldade para movimentar a boca & $13(54,2 \%)$ & $6(25,0 \%)$ & $0,020^{*}$ \\
Dificuldade para abrir a boca & $13(54,2 \%)$ & $6(25,0 \%)$ & $0,020^{*}$ \\
Dificuldade para fechar a boca & $4(16,7 \%)$ & $1(4,2 \%)$ & 0,083 \\
Dificuldade para bocejar & $12(50,0 \%)$ & $0(0,0 \%)$ & $0,001^{*}$ \\
Dificuldade para falar & $9(37,5 \%)$ & $4(16,7 \%)$ & 0,166 \\
Dificuldade para deglutir & $4(16,7 \%)$ & $2(8,3 \%)$ & 0,414 \\
Sensibilidade nos dentes & $6(25,0 \%)$ & $2(8,3 \%)$ & 0,102 \\
\hline
\end{tabular}

Legenda: DTM: disfunção temporomandibular; NT: número total de participantes; * diferença significativa de acordo com o teste Qui-Quadrado de Pearson.

A Tabela 9 exibe as análises descritivas e a comparação intragrupo (GP1) de acordo com os resultados de autopercepção referentes aos sintomas observados durante as funções. Foram encontradas diferenças significativas entre as etapas pré e pós-tratamento apenas para a variável "sintomas ao acordar", indicando atenuação dos sintomas nesta situação. 
Tabela 9 - Comparação intragrupo GP1 - resultados da avaliação de autopercepção dos sinais e sintomas de DTM (sintomas observados durante as funções)

\begin{tabular}{|c|c|c|c|c|}
\hline \multicolumn{2}{|c|}{ Sinais e Sintomas de DTM - Funções } & \multirow{2}{*}{$\begin{array}{c}\begin{array}{c}\text { Pré-tratamento } \\
\text { NT }(\%)\end{array} \\
9,0( \pm 12,1)\end{array}$} & \multirow{2}{*}{$\begin{array}{c}\begin{array}{c}\text { Pós-tratamento } \\
\text { NT }(\%)\end{array} \\
2,7( \pm 4,6)\end{array}$} & \multirow{2}{*}{$\frac{p \text {-value }}{0,021^{*}}$} \\
\hline & $\begin{array}{c}\text { Soma } \\
M( \pm D P)\end{array}$ & & & \\
\hline $\begin{array}{l}\text { Sintomas ao } \\
\text { acordar }\end{array}$ & $\begin{array}{c}\text { Classificação } \\
\text { NT (\%) }\end{array}$ & $\begin{array}{c}0=11(45,8 \%) \\
1=5(20,8 \%) \\
2=4(16,7 \%) \\
3=2(8,3 \%) \\
4=2(8,3 \%) \\
5=0(0,0 \%) \\
6=0(0,0 \%)\end{array}$ & $\begin{array}{c}0=15(62,5 \%) \\
1=7(29,2 \%) \\
2=2(8,3 \%) \\
3=0(0,0 \%) \\
4=0(0,0 \%) \\
5=0(0,0 \%) \\
6=0(0,0 \%)\end{array}$ & $0,036^{* *}$ \\
\hline & $\begin{array}{c}\text { Soma } \\
M( \pm D P)\end{array}$ & $7,2( \pm 10,9)$ & $3,1( \pm 6,1)$ & 0,050 \\
\hline $\begin{array}{l}\text { Sintomas ao } \\
\text { mastigar }\end{array}$ & $\begin{array}{c}\text { Classificação } \\
\text { NT (\%) }\end{array}$ & $\begin{array}{c}0=14(58,3 \%) \\
1=3(12,5 \%) \\
2=3(12,5 \%) \\
3=3(12,5 \%) \\
4=1(4,2 \%) \\
5=0(0,0 \%) \\
6=0(0,0 \%)\end{array}$ & $\begin{array}{c}0=17(70,8 \%) \\
1=5(20,8 \%) \\
2=1(4,2 \%) \\
3=1(4,2 \%) \\
4=0(0,0 \%) \\
5=0(0,0 \%) \\
6=0(0,0 \%)\end{array}$ & 0,061 \\
\hline & $\begin{array}{l}\text { Soma } \\
M(+D P)\end{array}$ & $3,4( \pm 7,1)$ & $1,9( \pm 4,7)$ & 0,343 \\
\hline $\begin{array}{l}\text { Sintomas ao } \\
\text { falar }\end{array}$ & $\begin{array}{c}\text { Classificação } \\
\text { NT (\%) }\end{array}$ & $\begin{array}{c}0=16(66,7 \%) \\
1=5(20,8 \%) \\
2=2(8,3 \%) \\
3=1(4,2 \%) \\
4=0(0,0 \%) \\
5=0(0,0 \%) \\
6=0(0,0 \%)\end{array}$ & $\begin{array}{c}0=19(79,2 \%) \\
1=3(12,5 \%) \\
2=2(8,3 \%) \\
3=0(0,0 \%) \\
4=0(0,0 \%) \\
5=0(0,0 \%) \\
6=0(0,0 \%)\end{array}$ & 0,272 \\
\hline & $\begin{array}{l}\text { Soma } \\
M( \pm D P)\end{array}$ & $3,2( \pm 8,7)$ & $1,0( \pm 2,4)$ & 0,406 \\
\hline $\begin{array}{l}\text { Sintomas ao } \\
\text { repousar }\end{array}$ & $\begin{array}{c}\text { Classificação } \\
\text { NT (\%) }\end{array}$ & $\begin{array}{c}0=18(75,0 \%) \\
1=4(16,7 \%) \\
2=1(4,2 \%) \\
3=0(0,0 \%) \\
4=1(4,2 \%) \\
5=0(0,0 \%) \\
6=0(0,0 \%)\end{array}$ & $\begin{array}{c}0=20(83,3 \%) \\
1=4(16,7 \%) \\
2=0(0,0 \%) \\
3=0(0,0 \%) \\
4=0(0,0 \%) \\
5=0(0,0 \%) \\
6=0(0,0 \%)\end{array}$ & 0,272 \\
\hline
\end{tabular}

Legenda: DTM: disfunção temporomandibular; M: média; DP: desvio padrão; NT: número total de participantes; *diferença significativa de acordo com o teste de Wilcoxon para amostras pareadas; ${ }^{* *}$ diferença significativa de acordo com o teste Qui-Quadrado de Pearson.

As Tabelas 10, 11 e 12 exibem as análises descritivas e comparação intragrupo (GP2) de acordo com os resultados da avaliação de Auto Percepção dos Sinais e Sintomas de DTM. Para os sintomas gerais (Tabela 10) foram encontradas diferenças significativas entre as etapas (pré e pós-tratamento) apenas para as variáveis "dor muscular", "dor ATM", "dor no pescoço" e "dificuldade de mastigação". O GP2 apresentou menor ocorrência destes sintomas após o tratamento; o sintoma "dor no pescoço" não foi relatado por nenhum participante após o tratamento. 
Tabela 10 - Comparação intragrupo GP2 - resultados da avaliação de autopercepção dos sinais e sintomas de DTM (sintomas gerais)

\begin{tabular}{|c|c|c|c|}
\hline $\begin{array}{c}\text { Sinais e Sintomas de DTM - } \\
\text { Sintomas Gerais }\end{array}$ & $\begin{array}{c}\text { Pré-tratamento } \\
\text { NT }(\%)\end{array}$ & $\begin{array}{c}\text { Pós-tratamento } \\
\text { NT }(\%)\end{array}$ & $p$-value \\
\hline Dor muscular & $\begin{aligned} \text { Não } & =18(62,1 \%) \\
D & =5(17,2 \%) \\
E & =5(17,2 \%) \\
B & =1(3,4 \%)\end{aligned}$ & $\begin{aligned} \text { Não } & =26(89,7 \%) \\
D & =1(3,4 \%) \\
E & =0(0,0 \%) \\
B & =2(6,9 \%)\end{aligned}$ & $0,018^{*}$ \\
\hline Fadiga & $\begin{aligned} \text { Não } & =21(72,4 \%) \\
D & =4(13,8 \%) \\
E & =1(3,4 \%) \\
B & =3(10,3 \%)\end{aligned}$ & $\begin{aligned} \text { Não } & =27(93,1 \%) \\
D & =0(0,0 \%) \\
E & =1(3,4 \%) \\
B & =1(3,4 \%)\end{aligned}$ & 0,134 \\
\hline Dor ATM & $\begin{aligned} \text { Não } & =19(65,5 \%) \\
D & =3(10,3 \%) \\
E & =6(20,7 \%) \\
B & =1(3,4 \%)\end{aligned}$ & $\begin{aligned} \text { Não } & =26(89,7 \%) \\
D & =1(3,4 \%) \\
E & =2(6,9 \%) \\
B & =0(0,0 \%)\end{aligned}$ & $0,016^{*}$ \\
\hline Ruídos ATM & $\begin{aligned} \text { Não } & =21(72,4 \%) \\
D & =3(10,3 \%) \\
E & =5(17,2 \%) \\
B & =0(0,0 \%)\end{aligned}$ & $\begin{array}{c}\text { Não }=23(79,3 \%) \\
D=1(3,4 \%) \\
E=5(17,2 \%) \\
B=0(0,0 \%)\end{array}$ & 0,839 \\
\hline Dor no pescoço & $\begin{aligned} \text { Não } & =24(82,8 \%) \\
D & =1(3,4 \%) \\
E & =0(0,0 \%) \\
B & =4(13,8 \%)\end{aligned}$ & $\begin{aligned} \text { Não } & =29(100 \%) \\
D & =0(0,0 \%) \\
E & =0(0,0 \%) \\
B & =0(0,0 \%)\end{aligned}$ & $0,034^{*}$ \\
\hline Dor de cabeça & $\begin{aligned} \text { Não } & =23(79,3 \%) \\
D & =2(6,9 \%) \\
E & =2(6,9 \%) \\
B & =2(6,9 \%)\end{aligned}$ & $\begin{aligned} \text { Não } & =27(93,1 \%) \\
D & =1(3,4 \%) \\
E & =0(0,0 \%) \\
B & =1(3,4 \%)\end{aligned}$ & 0,242 \\
\hline Otalgia & $\begin{aligned} \text { Não } & =26(89,7 \%) \\
D & =0(0,0 \%) \\
E & =1(3,4 \%) \\
B & =2(6,9 \%)\end{aligned}$ & $\begin{aligned} \text { Não } & =26(89,7 \%) \\
D & =2(6,9 \%) \\
E & =1(3,4 \%) \\
B & =0(0,0 \%)\end{aligned}$ & 0,458 \\
\hline Plenitude & $\begin{aligned} \text { Não } & =26(89,7 \%) \\
D & =2(6,9 \%) \\
E & =0(0,0 \%) \\
B & =1(3,4 \%)\end{aligned}$ & $\begin{aligned} \text { Não } & =26(89,7 \%) \\
D & =1(3,4 \%) \\
E & =2(6,9 \%) \\
B & =0(0,0 \%)\end{aligned}$ & 0,915 \\
\hline Zumbido & $\begin{aligned} \text { Não } & =27(93,1 \%) \\
D & =1(3,4 \%) \\
E & =0(0,0 \%) \\
B & =1(3,4 \%)\end{aligned}$ & $\begin{array}{c}\text { Não }=26(89,7 \%) \\
D=3(10,3 \%) \\
E=0(0,0 \%) \\
B=0(0,0 \%)\end{array}$ & $>0,999$ \\
\hline Dificuldade de mastigação & $\begin{aligned} \text { Não } & =18(62,1 \%) \\
D & =1(3,4 \%) \\
E & =0(0,0 \%) \\
B & =10(34,5 \%)\end{aligned}$ & $\begin{aligned} \text { Não } & =27(93,1 \%) \\
D & =1(3,4 \%) \\
E & =1(3,4 \%) \\
B & =0(0,0 \%)\end{aligned}$ & $0,002^{*}$ \\
\hline
\end{tabular}


A Tabela 11 exibe as análises descritivas e comparação intragrupo (GP2) de acordo com os resultados de autopercepção referentes aos sintomas observados durante as funções. Foram encontradas diferenças significativas entre as etapas (pré e pós-tratamento) para todas as variáveis, exceto "dificuldade para deglutir".

Tabela 11 - Comparação intragrupo GP2 - resultados da avaliação de autopercepção dos sinais e sintomas de DTM (sintomas observados durante a movimentação mandibular)

\begin{tabular}{cccc} 
Sinais e Sintomas de DTM - & $\begin{array}{c}\text { Pré-tratamento } \\
\text { Movimentação Mandibular }\end{array}$ & $\begin{array}{c}\text { Pós-tratamento } \\
\text { NT }(\%)\end{array}$ & p-value \\
\hline Dificuldade para movimentar a boca & $12(41,4 \%)$ & $4(13,8 \%)$ & $0,011^{*}$ \\
Dificuldade para abrir a boca & $16(55,2 \%)$ & $1(3,4 \%)$ & $<0,001^{*}$ \\
Dificuldade para fechar a boca & $4(13,8 \%)$ & $0(0,0 \%)$ & $0,046^{*}$ \\
Dificuldade para bocejar & $9(32,1 \%)$ & $0(0,0 \%)$ & $0,003^{*}$ \\
Dificuldade para falar & $8(27,6 \%)$ & $2(6,9 \%)$ & $0,014^{*}$ \\
Dificuldade para deglutir & $4(13,8 \%)$ & $1(3,4 \%)$ & 0,180 \\
Sensibilidade nos dentes & $13(44,8 \%)$ & $6(20,7 \%)$ & $0,008^{*}$ \\
\hline
\end{tabular}

Legenda: DTM: disfunção temporomandibular; NT: número total de participantes; * diferença significativa de acordo com o teste Qui-Quadrado de Pearson.

A Tabela 12 exibe as análises descritivas e comparação intragrupo (GP2) de acordo com os resultados da avaliação de autopercepção referentes aos sintomas observados durante as funções. Foram encontradas diferenças significativas entre as etapas (pré e pós-tratamento) para todas as variáveis, com a redução dos sintomas em todas as situações analisadas, mostrando redução dos sintomas após o tratamento fonoaudiológico. 
Tabela 12 - Comparação intragrupo GP2 - resultados da avaliação de autopercepção dos sinais e sintomas de DTM (sintomas observados durante as funções)

\begin{tabular}{|c|c|c|c|}
\hline Sinais e Sintomas de DTM - Funções & $\begin{array}{c}\text { Pré-tratamento } \\
\text { NT }(\%)\end{array}$ & $\begin{array}{c}\text { Pós-tratamento } \\
\text { NT }(\%)\end{array}$ & $p$-value \\
\hline 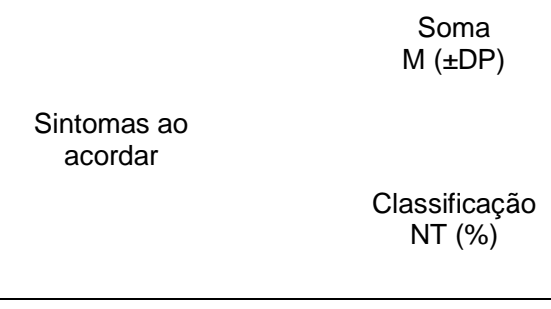 & $\begin{array}{c}10,6( \pm 14,1) \\
0=10(34,5 \%) \\
1=9(31,0 \%) \\
2=5(17,2 \%) \\
3=0(0,0 \%) \\
4=3(10,3 \%) \\
5=2(6,9 \%) \\
6=0(0,0 \%)\end{array}$ & $\begin{array}{c}3,3( \pm 6,1) \\
0=19(65,5 \%) \\
1=6(20,7 \%) \\
2=2(6,9 \%) \\
3=2(6,9 \%) \\
4=0(0,0 \%) \\
5=0(0,0 \%) \\
6=0(0,0 \%)\end{array}$ & $0,002^{* *}$ \\
\hline 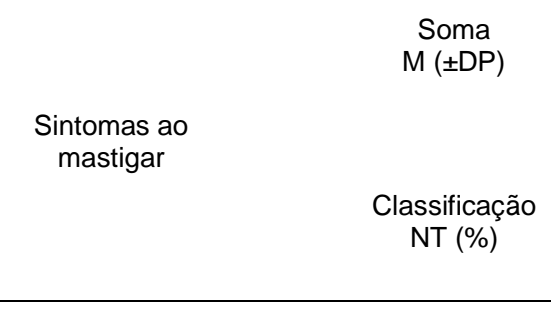 & $\begin{array}{c}9,8( \pm 13,6) \\
0=12(42,9 \%) \\
1=7(25,0 \%) \\
2=3(10,7 \%) \\
3=3(10,7 \%) \\
4=2(7,1 \%) \\
5=1(3,6 \%) \\
6=0(0,0 \%)\end{array}$ & $\begin{array}{c}2,5( \pm 4,9) \\
0=19(65,5 \%) \\
1=7(24,1 \%) \\
2=3(10,3 \%) \\
3=0(0,0 \%) \\
4=0(0,0 \%) \\
5=0(0,0 \%) \\
6=0(0,0 \%)\end{array}$ & $0,001^{*}$ \\
\hline $\begin{array}{l}\text { Soma } \\
M( \pm D P)\end{array}$ & $\begin{array}{c}4,9( \pm 9,4) \\
0=20(69,0 \%) \\
1=5(17,2 \%) \\
2=1(3,4 \%) \\
3=2(6,9 \%) \\
4=1(3,4 \%) \\
5=0(0,0 \%) \\
6=0(0,0 \%)\end{array}$ & $\begin{array}{c}0,8( \pm 3,4) \\
0=27(93,1 \%) \\
1=1(3,4 \%) \\
2=1(3,4 \%) \\
3=0(0,0 \%) \\
4=0(0,0 \%) \\
5=0(0,0 \%) \\
6=0(0,0 \%)\end{array}$ & $0,008^{*}$ \\
\hline $\begin{array}{c}\text { Soma } \\
\text { M ( } \pm \text { DP })\end{array}$ & $\begin{array}{c}3,8( \pm 7,6) \\
0=20(69,0 \%) \\
1=5(17,2 \%) \\
2=2(6,9 \%) \\
3=2(6,9 \%) \\
4=0(0,0 \%) \\
5=0(0,0 \%) \\
6=0(0,0 \%)\end{array}$ & $\begin{array}{c}0,5( \pm 1,4) \\
0=26(89,7 \%) \\
1=3(10,3 \%) \\
2=0(0,0 \%) \\
3=0(0,0 \%) \\
4=0(0,0 \%) \\
5=0(0,0 \%) \\
6=0(0,0 \%)\end{array}$ & $0,011^{*}$ \\
\hline
\end{tabular}

As Tabelas 13, 14 e 15 exibem as análises descritivas e comparação intragrupo (GP3) de acordo com os resultados da avaliação de Autopercepção dos Sinais e Sintomas de DTM. Foram encontradas diferenças significativas entre as etapas (pré e pós-tratamento) apenas para as variáveis "dor muscular", "dor no pescoço", "zumbido" e "dificuldade de mastigação", com redução no número de participantes que relataram estes sinais e sintomas após a terapia fonoaudiológica. 
Tabela 13 - Comparação intragrupo GP3 - resultados da avaliação de autopercepção dos sinais e sintomas de DTM (sintomas gerais)

\begin{tabular}{|c|c|c|c|}
\hline $\begin{array}{c}\text { Sinais e Sintomas de DTM - } \\
\text { Sintomas Gerais }\end{array}$ & $\begin{array}{c}\text { Pré-tratamento } \\
\text { NT (\%) }\end{array}$ & $\begin{array}{c}\text { Pós-tratamento } \\
\text { NT }(\%)\end{array}$ & $p$-value \\
\hline Dor muscular & $\begin{aligned} \text { Não } & =5(41,7 \%) \\
D & =2(16,7 \%) \\
E & =2(16,7 \%) \\
B & =3(25,0 \%)\end{aligned}$ & $\begin{aligned} \text { Não } & =10(83,3 \%) \\
D & =1(8,3 \%) \\
E & =1(8,3 \%) \\
B & =0(0,0 \%)\end{aligned}$ & $0,026^{*}$ \\
\hline Fadiga & $\begin{aligned} \text { Não } & =6(50,0 \%) \\
D & =3(25,0 \%) \\
E & =0(0,0 \%) \\
B & =3(25,0 \%)\end{aligned}$ & $\begin{aligned} \text { Não } & =10(83,3 \%) \\
D & =0(0,0 \%) \\
E & =1(8,3 \%) \\
B & =1(8,3 \%)\end{aligned}$ & 0,165 \\
\hline Dor ATM & $\begin{aligned} \text { Não } & =6(50,0 \%) \\
D & =5(41,7 \%) \\
E & =1(8,3 \%) \\
B & =0(0,0 \%)\end{aligned}$ & $\begin{aligned} \text { Não } & =11(91,7 \%) \\
D & =0(0,0 \%) \\
E & =1(8,3 \%) \\
B & =0(0,0 \%)\end{aligned}$ & 0,096 \\
\hline Ruídos ATM & $\begin{aligned} \text { Não } & =8(66,7 \%) \\
D & =1(8,3 \%) \\
E & =3(25,0 \%) \\
B & =0(0,0 \%)\end{aligned}$ & $\begin{aligned} \text { Não } & =9(75,0 \%) \\
D & =1(8,3 \%) \\
E & =2(16,7 \%) \\
B & =0(0,0 \%)\end{aligned}$ & 0,458 \\
\hline Dor no pescoço & $\begin{aligned} \text { Não } & =7(58,3 \%) \\
D & =2(16,7 \%) \\
E & =0(0,0 \%) \\
B & =3(25,0 \%)\end{aligned}$ & $\begin{aligned} \text { Não } & =11(91,7 \%) \\
D & =0(0,0 \%) \\
E & =1(8,3 \%) \\
B & =0(0,0 \%)\end{aligned}$ & $0,038^{*}$ \\
\hline Dor de cabeça & $\begin{aligned} \text { Não } & =8(66,7 \%) \\
D & =1(8,3 \%) \\
E & =1(8,3 \%) \\
B & =2(16,7 \%)\end{aligned}$ & $\begin{aligned} \text { Não } & =12(100 \%) \\
D & =0(0,0 \%) \\
E & =0(0,0 \%) \\
B & =0(0,0 \%)\end{aligned}$ & 0,066 \\
\hline Otalgia & $\begin{aligned} \text { Não } & =10(83,3 \%) \\
D & =1(8,3 \%) \\
E & =1(8,3 \%) \\
B & =0(0,0 \%)\end{aligned}$ & $\begin{aligned} \text { Não } & =11(91,7 \%) \\
D & =1(8,3 \%) \\
E & =0(0,0 \%) \\
B & =0(0,0 \%)\end{aligned}$ & 0,414 \\
\hline Plenitude & $\begin{aligned} \text { Não } & =8(66,7 \%) \\
D & =1(8,3 \%) \\
E & =3(25,0 \%) \\
B & =0(0,0 \%)\end{aligned}$ & $\begin{aligned} \text { Não } & =11(91,7 \%) \\
D & =0(0,0 \%) \\
E & =1(8,3 \%) \\
B & =0(0,0 \%)\end{aligned}$ & 0,258 \\
\hline Zumbido & $\begin{aligned} \text { Não } & =5(41,7 \%) \\
D & =2(16,7 \%) \\
E & =4(33,3 \%) \\
B & =1(8,3 \%)\end{aligned}$ & $\begin{aligned} \text { Não } & =10(83,3 \%) \\
D & =1(8,3 \%) \\
E & =1(8,3 \%) \\
B & =0(0,0 \%)\end{aligned}$ & $0,039^{*}$ \\
\hline Dificuldade de mastigação & $\begin{aligned} \text { Não } & =5(41,7 \%) \\
D & =0(0,0 \%) \\
E & =0(0,0 \%) \\
B & =7(58,3 \%)\end{aligned}$ & $\begin{aligned} \text { Não } & =8(66,7 \%) \\
D & =1(8,3 \%) \\
E & =3(25,0 \%) \\
B & =0(0,0 \%)\end{aligned}$ & $0,026^{*}$ \\
\hline
\end{tabular}

Legenda: NT: número total de participantes; DTM: disfunção temporomandibular; ATM: articulação temporomandibular; D: sinais e sintomas apresentados do lado direito; E: sinais e sintomas apresentados do lado esquerdo; B: sinais e sintomas apresentados bilateralmente; *diferença significativa de acordo com o teste Qui-Quadrado de Pearson.

A Tabela 14 exibe as análises descritivas e comparação intragrupo (GP3) de acordo com os resultados de autopercepção referentes aos sintomas observados durante as funções. Foram encontradas diferenças significativas entre as etapas (pré e pós-tratamento) para todas as variáveis, exceto "dificuldade para deglutir" e "sensibilidade nos dentes". Houve redução do 
número de participantes com dificuldade em movimentação mandibular após tratamento fonoaudiológico.

Tabela 14 - Comparação intragrupo GP3 - resultados da avaliação de auto percepção dos sinais e sintomas de DTM (sintomas observados durante a movimentação mandibular)

\begin{tabular}{cccc}
\hline $\begin{array}{c}\text { Sinais e Sintomas de DTM - } \\
\text { Movimentação Mandibular }\end{array}$ & $\begin{array}{c}\text { Pré tratamento } \\
\text { NT }(\%)\end{array}$ & $\begin{array}{c}\text { Pós tratamento } \\
\text { NT }(\%)\end{array}$ & p-value \\
\hline Dificuldade para movimentar a boca & $6(50,0 \%))$ & $1(8,3 \%)$ & $0,025^{*}$ \\
Dificuldade para abrir a boca & $10(83,3 \%)$ & $1(8,3 \%)$ & $0,003^{*}$ \\
Dificuldade para fechar a boca & $5(41,7 \%)$ & $1(8,3 \%)$ & $0,046^{*}$ \\
Dificuldade para bocejar & $7(58,3 \%)$ & $0(0,0 \%)$ & $0,008^{*}$ \\
Dificuldade para falar & $6(50,0 \%)$ & $1(8,3 \%)$ & $0,025^{*}$ \\
Dificuldade para deglutir & $3(25,0 \%)$ & $1(8,3 \%)$ & 0,157 \\
Sensibilidade nos dentes & $4(33,3 \%)$ & $2(16,7 \%)$ & 0,317 \\
\hline
\end{tabular}

Legenda: DTM: disfunção temporomandibular; NT: número total de participantes; * diferença significativa de acordo com o teste Qui-Quadrado de Pearson.

A Tabela 15 exibe as análises descritivas e comparação intragrupo GP3 de acordo com os resultados da avaliação de autopercepção referentes aos sintomas observados durante as funções. Foram encontradas diferenças significativas entre as etapas (pré e pós-tratamento) para as variáveis referentes aos "sintomas ao acordar" e "sintomas ao falar"; este grupo apresentou redução das notas dadas para esses sintomas, indicando melhora após o tratamento. 
Tabela 15 - Comparação intragrupo GP3 - resultados da avaliação de auto percepção dos sinais e sintomas de DTM (sintomas observados durante as funções)

\begin{tabular}{|c|c|c|c|c|}
\hline \multicolumn{2}{|c|}{ Sinais e Sintomas de DTM - Funções } & \multirow{2}{*}{$\begin{array}{c}\text { Pré-tratamento } \\
\text { NT }(\%)\end{array}$} & \multirow{2}{*}{$\begin{array}{c}\text { Pós-tratamento } \\
\text { NT }(\%) \\
8,1( \pm 12,2)\end{array}$} & \multirow{2}{*}{$\begin{array}{c}\boldsymbol{p} \text {-value } \\
0,012^{*}\end{array}$} \\
\hline & $\begin{array}{c}\text { Soma } \\
M(+D P)\end{array}$ & & & \\
\hline $\begin{array}{l}\text { Sintomas ao } \\
\text { acordar }\end{array}$ & $\begin{array}{c}\text { Classificação } \\
\text { NT (\%) }\end{array}$ & $\begin{array}{l}0=4(33,3 \%) \\
1=1(8,3 \%) \\
2=2(16,7 \%) \\
3=2(16,7 \%) \\
4=1(8,3 \%) \\
5=2(16,7 \%) \\
6=0(0,0 \%)\end{array}$ & $\begin{array}{l}0=6(50,0 \%) \\
1=2(16,7 \%) \\
2=2(16,7 \%) \\
3=1(8,3 \%) \\
4=1(8,3 \%) \\
5=0(0,0 \%) \\
6=0(0,0 \%)\end{array}$ & $0,016^{* *}$ \\
\hline & $\begin{array}{c}\text { Soma } \\
\text { M ( } \pm D P)\end{array}$ & $15,5( \pm 19,2)$ & $9,6( \pm 16,8)$ & 0,161 \\
\hline $\begin{array}{l}\text { Sintomas ao } \\
\text { mastigar }\end{array}$ & $\begin{array}{c}\text { Classificação } \\
\text { NT (\%) }\end{array}$ & $\begin{array}{l}0=5(41,7 \%) \\
1=2(16,7 \%) \\
2=1(8,3 \%) \\
3=1(8,3 \%) \\
4=2(16,7 \%) \\
5=0(0,0 \%) \\
6=1(8,3 \%)\end{array}$ & $\begin{array}{l}0=7(58,3 \%) \\
1=2(16,7 \%) \\
2=1(8,3 \%) \\
3=0(0,0 \%) \\
4=1(8,3 \%) \\
5=0(0,0 \%) \\
6=1(8,3 \%)\end{array}$ & 0,343 \\
\hline & $\begin{array}{c}\text { Soma } \\
M( \pm D P)\end{array}$ & $11,8( \pm 16,6)$ & $5,3( \pm 11,3)$ & $0,028^{*}$ \\
\hline $\begin{array}{c}\text { Sintomas ao } \\
\text { falar }\end{array}$ & $\begin{array}{c}\text { Classificação } \\
\text { NT (\%) }\end{array}$ & $\begin{array}{l}0=5(41,7 \%) \\
1=2(16,7 \%) \\
2=3(25,0 \%) \\
3=0(0,0 \%) \\
4=1(8,3 \%) \\
5=0(0,0 \%) \\
6=1(8,3 \%)\end{array}$ & $\begin{array}{l}0=8(66,7 \%) \\
1=2(16,7 \%) \\
2=0(0,0 \%) \\
3=1(8,3 \%) \\
4=1(8,3 \%) \\
5=0(0,0 \%) \\
6=0(0,0 \%)\end{array}$ & $0,024^{\star *}$ \\
\hline & $\begin{array}{c}\text { Soma } \\
M( \pm D P)\end{array}$ & & & 0,207 \\
\hline $\begin{array}{l}\text { Sintomas ao } \\
\text { repousar }\end{array}$ & $\begin{array}{c}\text { Classificação } \\
\text { NT (\%) }\end{array}$ & $\begin{array}{l}0=6(50,0 \%) \\
1=5(41,7 \%) \\
2=0(0,0 \%) \\
3=0(0,0 \%) \\
4=0(0,0 \%) \\
5=1(8,3 \%) \\
6=0(0,0 \%)\end{array}$ & $\begin{array}{l}0=9(75,0 \%) \\
1=0(0,0 \%) \\
2=3(25,0 \%) \\
3=0(0,0 \%) \\
4=0(0,0 \%) \\
5=0(0,0 \%) \\
6=0(0,0 \%)\end{array}$ & 0,317 \\
\hline
\end{tabular}

Todos os dados referentes aos três grupos foram apresentados e a seguir as análises realizadas serão intergrupos. Como os resultados das avaliações já foram apresentados, nas próximas tabelas apenas os p-valores serão apresentados. 


\subsection{Analise Intergrupos}

A Tabela 16 exibe as análises descritivas e comparação intergrupos de acordo com os resultados do protocolo AMIOFE-E ${ }^{44}$. No pré-tratamento, os grupos se diferenciaram quanto às funções, GP1 apresentou desempenho inferior quando comparado a GP2. Após o tratamento, não foram encontradas diferenças significativas entre os grupos, de acordo com o teste de KruskalWallis.

Tabela 16 - Comparação intergrupos - resultados do protocolo AMIOFE-E

\begin{tabular}{|c|c|c|c|c|}
\hline \multirow{2}{*}{ Pontuação AMIOFE-E } & \multicolumn{2}{|c|}{ Pré-tratamento } & \multicolumn{2}{|r|}{ Pós-tratamento } \\
\hline & $p$-value & Comparação por Pares & $p$-value & Comparação por Pares \\
\hline $\begin{array}{l}\text { Aparência e condição postural } \\
\qquad( \pm D P)\end{array}$ & 0,189 & - & 0,103 & - \\
\hline \multirow[t]{2}{*}{$\begin{array}{l}\text { Mobilidade } \\
\text { M ( } \pm \text { DP })\end{array}$} & 0,501 & - & 0,297 & - \\
\hline & & $\mathrm{GP} 1 \neq \mathrm{GP} 2-\mathrm{p}=0,012^{\star *}$ & 0,643 & \\
\hline \multirow{2}{*}{$\begin{array}{l}\text { Funções } \\
M( \pm D P)\end{array}$} & $0,015^{\star}$ & $\mathrm{GP} 1=\mathrm{GP} 3-\mathrm{p}>0.999$ & 0,194 & - \\
\hline & & $\mathrm{GP} 2=\mathrm{GP} 3-\mathrm{p}=0,515$ & & \\
\hline $\begin{array}{c}\text { PONTUAÇÃO TOTAL } \\
\text { M (土DP) }\end{array}$ & 0,178 & - & & - \\
\hline
\end{tabular}

A Tabela 17 exibe as análises descritivas e comparação intergrupos de acordo com o índice de melhora do protocolo AMIOFE-E ${ }^{44}$. Foi considerado índice de melhora a porcentagem de melhora calculada com base na diferença entre os valores obtidos na avaliação pré e pós-tratamento fonoaudiológico. Apesar de não ter sido encontrada diferenças na análise anterior, o índice foi realizado com o objetivo de verificar se algum grupo melhorou mais que outro. As análises indicaram que não foram encontradas diferenças significativas entre os grupos, de acordo com o teste de Kruskal-Wallis. 


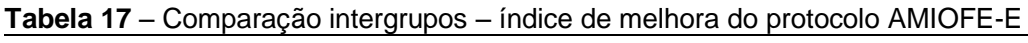

\begin{tabular}{|c|c|c|c|c|}
\hline $\begin{array}{c}\text { Pontuação AMIOFE-E } \\
\text { M ( } \pm \text { DP) }\end{array}$ & $\begin{array}{c}\text { GP1 } \\
(\mathrm{N}=\mathbf{2 4})\end{array}$ & $\begin{array}{c}\text { GP2 } \\
(N=29)\end{array}$ & $\begin{array}{c}\text { GP3 } \\
(N=12)\end{array}$ & $p$-value \\
\hline Aparência e condição postural & $7,4 \%( \pm 7,6)$ & $4,5 \%( \pm 8,0)$ & $5,7 \%( \pm 3,4)$ & 0,090 \\
\hline Mobilidade & $25,6 \%( \pm 25,7)$ & $22,8 \%( \pm 31,4)$ & $22,1 \%( \pm 28,7)$ & 0,681 \\
\hline Funções & $34,5 \%( \pm 27,5)$ & $19,3 \%( \pm 18,0)$ & $22,7 \%( \pm 11,7)$ & 0,070 \\
\hline PONTUACẼO TOTAL & $19,6 \%( \pm 14,8)$ & $14,5 \%( \pm 13,8)$ & $14,7 \%( \pm 10,2)$ & 0,321 \\
\hline
\end{tabular}

A Tabela 18 exibe as análises descritivas e comparação intergrupos de acordo com os resultados da avaliação da mobilidade mandibular. Não foram encontradas diferenças significativas entre os grupos em nenhum dos momentos avaliados, de acordo com o teste de Kruskal-Wallis e com o teste Qui-Quadrado de Pearson. O GP1 apresentou valores menores nas variáveis, porém não foram estatisticamente significantes. Todos os grupos apresentaram desvios mandibulares no pré-tratamento e apresentaram melhor desempenho após o programa terapêutico.

Tabela 18 - Comparação intergrupos - resultados da avaliação da mobilidade mandibular

\begin{tabular}{ccccc} 
Medidas - mobilidade & \multicolumn{2}{c}{ Pré-tratamento } & \multicolumn{2}{c}{ Pós-tratamento } \\
\cline { 2 - 5 } $\begin{array}{c}\text { mandibular } \\
\text { M }( \pm D P)\end{array}$ & $\boldsymbol{p}$-value & Comparação por Pares & $\boldsymbol{p}$-value & Comparação por Pares \\
\hline Abertura oral máxima & 0,562 & - & 0,828 & - \\
Desvio na abertura oral máxima & 0,418 & - & 0,519 & - \\
Lateralidade mandibular D & 0,628 & - & 0,662 & - \\
Lateralidade mandibular E & 0,505 & - & 0,932 & - \\
Protrusão mandibular & 0,393 & 0,341 & - \\
\hline
\end{tabular}
Legenda: M: média; DP: desvio padrão; D: direita; E: esquerda.

A Tabela 19 exibe as análises descritivas e comparação intergrupos de acordo com o índice de melhora do protocolo de medidas de mobilidade mandibular. Foi considerado índice de melhora a porcentagem de melhora foi calculada com base na diferença entre os valores obtidos antes e após o tratamento fonoaudiológico. Apesar de não ter diferença entre os grupos na análise anterior, o índice foi realizado para verificar se algum grupo apresentou desempenho diferente. O GP1 apresentou maior porcentagem de melhora em 
abertura oral e os GP2 e GP3 apresentaram melhora em lateralidade mandibular. Não foram encontradas diferenças significativas entre os grupos, de acordo com o teste de Kruskal-Wallis.

Tabela 19 - Comparação intergrupos - resultados da avaliação da mobilidade mandibular após o tratamento fonoaudiológico

\begin{tabular}{|c|c|c|c|c|}
\hline $\begin{array}{l}\text { Medidas de mobilidade mandibular } \\
\qquad( \pm D P)\end{array}$ & $\begin{array}{c}\text { GP1 } \\
(N=24)\end{array}$ & $\begin{array}{c}\text { GP2 } \\
(N=29)\end{array}$ & $\begin{array}{c}\text { GP3 } \\
(N=12)\end{array}$ & $p$-value \\
\hline Abertura oral máxima & $139,9 \%( \pm 217,3)$ & $83,6 \%( \pm 124,7)$ & $51,2 \%( \pm 26,2)$ & 0,097 \\
\hline Lateralidade mandibular direita & $93,2 \%( \pm 90,7)$ & $159,8 \%( \pm 383,4)$ & $73,7 \%( \pm 71,3)$ & 0,897 \\
\hline Lateralidade mandibular esquerda & $59,6 \%( \pm 81,8)$ & $131,1 \%( \pm 313,5)$ & $151,3 \%( \pm 241,2)$ & 0,819 \\
\hline Protrusão mandibular & $61,3 \%( \pm 69,7)$ & $109,5 \%( \pm 189,2)$ & $33,3 \%( \pm 36,3)$ & 0,580 \\
\hline
\end{tabular}

Legenda: GP1: Grupo pesquisa 1; GP2: Grupo pesquisa 2; GP3: Grupo pesquisa 3; M: média; DP: desvio padrão; N: número de participantes.

A Tabela 20 exibe as análises descritivas e comparação intergrupos de acordo com os resultados da avaliação de Autopercepção dos Sinais e Sintomas de DTM. Antes do tratamento foram observadas diferenças para dor em ATM entre GP1 e GP3 e para zumbido entre os grupos: GP1 e GP3; GP2 e GP3. Não foram encontradas diferenças significativas entre os grupos, de acordo com o teste Qui-Quadrado de Pearson.

Tabela 20 - Comparação intergrupos - resultados da avaliação de autopercepção dos sinais e sintomas de DTM (sintomas gerais)

\begin{tabular}{|c|c|c|c|c|}
\hline \multirow{2}{*}{$\begin{array}{c}\text { Sinais e Sintomas } \\
\text { de DTM - } \\
\text { Sintomas Gerais }\end{array}$} & \multicolumn{2}{|r|}{ Pré-tratamento } & \multicolumn{2}{|c|}{ Pós-tratamento } \\
\hline & $p$-value & Comparação por Pares & $p$-value & Comparação por Pares \\
\hline Dor muscular & 0,171 & & 0,607 & - \\
\hline \multirow[t]{2}{*}{ Fadiga } & 0,186 & & 0,518 & - \\
\hline & & $\mathrm{GP} 1=\mathrm{GP} 2-\mathrm{p}=0,101$ & & \\
\hline \multirow[t]{2}{*}{ Dor ATM } & $0,010^{*}$ & GP1 $1 \neq$ GP3 $-p=0,048^{*}$ & 0,712 & - \\
\hline & & $\mathrm{GP2}=\mathrm{GP} 3-\mathrm{p}>0,999$ & & \\
\hline Ruídos ATM & 0,780 & & 0,962 & - \\
\hline Dor no pescoço & 0,104 & & 0,358 & - \\
\hline Dor de cabeça & 0,742 & & 0,283 & - \\
\hline Otalgia & 0,420 & & 0,691 & - \\
\hline \multirow[t]{2}{*}{ Plenitude } & 0,089 & & 0,286 & - \\
\hline & & $\mathrm{GP} 1=\mathrm{GP} 2-\mathrm{p}>0,999$ & & \\
\hline \multirow[t]{2}{*}{ Zumbido } & $0,004^{*}$ & $\mathrm{GP} 1 \neq \mathrm{GP} 3-\mathrm{p}=0,003^{* *}$ & 0,756 & - \\
\hline & & GP2 $\neq$ GP3 $-p=<0,001^{* *}$ & & \\
\hline
\end{tabular}

Dificuldade de

mastigação

0,430

0,056

Legenda: GP1: Grupo pesquisa 1; GP2: Grupo pesquisa 2; GP3: Grupo pesquisa 3; DTM: disfunção temporomandibular; ATM: articulação temporomandibular; *diferença significativa de acordo com o teste Qui-Quadrado de Pearson. **diferença significativa de acordo com análise post hoc de pares pelo teste de Dunn com correção de Bonferroni. 
A Tabela 21 exibe as análises descritivas e comparação intergrupos de acordo com os resultados da avaliação de Autopercepção dos Sinais e Sintomas de DTM referentes aos sintomas observados durante a movimentação mandibular. Não foram encontradas diferenças significativas entre os grupos, todos eles apresentaram redução dos sinais e sintomas após o programa terapêutico.

Tabela 21 - Comparação intergrupos - resultados da avaliação de autopercepção dos sinais e sintomas de DTM (sintomas observados durante a movimentação mandibular)

\begin{tabular}{ccccc}
\hline Sinais e Sintomas de DTM - & \multicolumn{2}{c}{ Pré-tratamento } & \multicolumn{2}{c}{ Pós-tratamento } \\
\cline { 2 - 5 } Movimentação Mandibular & $\boldsymbol{p}$-value & $\begin{array}{c}\text { Comparação } \\
\text { por Pares }\end{array}$ & $\boldsymbol{p}$-value & $\begin{array}{c}\text { Comparação } \\
\text { por Pares }\end{array}$ \\
Dificuldade para movimentar a boca & 0,640 & - & 0,384 & - \\
Dificuldade para abrir a boca & 0,188 & - & 0,056 & - \\
Dificuldade para fechar a boca & 0,112 & - & 0,351 & - \\
Dificuldade para bocejar & 0,229 & - & $>0,999$ & - \\
Dificuldade para falar & 0,379 & - & 0,503 & - \\
Dificuldade para deglutir & 0,684 & - & 0,721 & - \\
Sensibilidade nos dentes & 0,319 & - & 0,464 & - \\
\hline
\end{tabular}
Legenda: DTM: disfunção temporomandibular.

A Tabela 22 exibe as análises descritivas e comparação intergrupos de acordo com os resultados da avaliação de Autopercepção dos Sinais e Sintomas de DTM, observados durante as funções. Não foram encontradas diferenças significativas entre os grupos. Não foram encontradas diferenças significativas entre os grupos, de acordo com os testes de Kruskall-Wallis (para as variáveis quantitativas) e Qui-Quadrado de Pearson (para as variáveis categóricas). Todos os grupos apresentaram redução dos sinais e sintomas após o programa terapêutico. 
Tabela 22 - Comparação intergrupos - resultados da avaliação de autopercepção dos sinais e sintomas de DTM (sintomas observados durante as funções)

\begin{tabular}{|c|c|c|c|c|c|}
\hline \multicolumn{2}{|c|}{ Sinais e Sintomas de DTM - funções } & \multirow{2}{*}{$\begin{array}{c}\boldsymbol{p} \text {-value } \\
0,292 \\
0,408\end{array}$} & \multirow{2}{*}{$\begin{array}{c}\begin{array}{c}\text { Comparação } \\
\text { por Pares }\end{array} \\
- \\
-\end{array}$} & \multirow{2}{*}{$\begin{array}{c}\boldsymbol{p} \text {-value } \\
0,444 \\
0,416\end{array}$} & \multirow{2}{*}{$\begin{array}{c}\begin{array}{c}\text { Comparação } \\
\text { por Pares }\end{array} \\
- \\
-\end{array}$} \\
\hline Sintomas ao acordar & $\begin{array}{c}\text { Soma M ( } \pm \text { DP) } \\
\text { Classificação NT (\%) }\end{array}$ & & & & \\
\hline Sintomas ao mastigar & $\begin{array}{c}\text { Soma M ( } \pm \text { DP) } \\
\text { Classificação NT (\%) }\end{array}$ & $\begin{array}{l}0,398 \\
0,669\end{array}$ & $\begin{array}{l}- \\
-\end{array}$ & $\begin{array}{l}0,614 \\
0,585\end{array}$ & $\begin{array}{l}- \\
-\end{array}$ \\
\hline Sintomas ao falar & $\begin{array}{c}\text { Soma M ( } \pm \text { DP) } \\
\text { Classificação NT (\%) }\end{array}$ & $\begin{array}{l}0,148 \\
0,245\end{array}$ & $\begin{array}{l}- \\
-\end{array}$ & $\begin{array}{l}0,099 \\
0,092\end{array}$ & $\begin{array}{l}- \\
-\end{array}$ \\
\hline Sintomas ao repousar & $\begin{array}{c}\text { Soma M ( } \pm \text { DP) } \\
\text { Classificação NT }(\%)\end{array}$ & $\begin{array}{l}0,292 \\
0,223\end{array}$ & $\begin{array}{l}- \\
- \\
\end{array}$ & $\begin{array}{l}0,352 \\
0,361 \\
\end{array}$ & $\begin{array}{l}- \\
- \\
\end{array}$ \\
\hline
\end{tabular}

\subsection{Avaliação complementar - Musculatura Mastigatória}

A Tabela 23 exibe as análises descritivas e comparação intergrupos de acordo com os resultados da análise eletromiográfica obtidos antes do tratamento. Foram encontradas diferenças significativas entre os grupos para todas as variáveis, exceto "assimetria intercuspidação temporal", "assimetria algodão temporal" e "ciclos". Pode-se observar que os participantes se diferenciaram no pré-tratamento em todas as provas.

Tabela 23 - Comparação intergrupos - resultados da análise eletromiográfica pré-tratamento

\begin{tabular}{ccccc}
\hline & $\begin{array}{c}\text { Registro EMGs } \\
\text { M ( } \pm \text { DP })\end{array}$ & $\begin{array}{c}\text { GP } \\
(\mathbf{N}=\mathbf{2 5})\end{array}$ & $\begin{array}{c}\text { GC } \\
(\mathbf{N}=\mathbf{2 5})\end{array}$ & $\boldsymbol{p}$-value \\
\hline & TE & $17,2( \pm 27,5)$ & $36,6( \pm 25,4)$ & $<0,001^{*}$ \\
& TD & $19,6( \pm 41,6)$ & $33,7( \pm 21,0)$ & $<0,001^{*}$ \\
& ME & $15,8( \pm 35,1)$ & $30,6( \pm 21,3)$ & $<0,001^{*}$ \\
& MD & $14,7( \pm 27,9)$ & $32,8( \pm 24,3)$ & $<0,001^{*}$ \\
& Assimetria T & $0,6( \pm 0,2)$ & $0,6( \pm 0,2)$ & 0,920 \\
& Assimetria M & $0,6( \pm 0,3)$ & $0,7( \pm 0,2)$ & $0,019^{*}$ \\
\hline & TE & $18,5( \pm 23,9)$ & $39,3( \pm 20,1)$ & $<0,001^{*}$ \\
& TD & $16,1( \pm 19,0)$ & $35,8( \pm 18,2)$ & $<0,001^{*}$ \\
& ME & $15,2( \pm 23,9)$ & $35,3( \pm 21,1)$ & $<0,001^{*}$ \\
& MD & $14,0( \pm 19,5)$ & $37,5( \pm 23,0)$ & $<0,001^{*}$ \\
& Assimetria T & $0,7( \pm 0,2)$ & $0,8( \pm 0,2)$ & 0,128 \\
& Assimetria M & $0,6( \pm 0,3)$ & $0,7( \pm 0,2)$ & $0,015^{*}$ \\
\hline & TE & $11,6( \pm 15,6)$ & $17,4( \pm 8,0)$ & $0,002^{*}$ \\
& TD & $9,1( \pm 13,9)$ & $14,9( \pm 7,2)$ & $<0,001^{*}$ \\
& ME & $10,6( \pm 14,8)$ & $17,1( \pm 8,4)$ & $<0,001^{*}$ \\
& MD & $10,3( \pm 12,4)$ & $17,3( \pm 6,8)$ & $<0,001^{*}$ \\
& Ciclos & $19,8( \pm 5,5)$ & $21,2( \pm 5,3)$ & 0,411 \\
MAST & Assimetria T & $0,7( \pm 0,3)$ & $0,7( \pm 0,2)$ & 0,868 \\
& Assimetria M & $0,6( \pm 0,3)$ & $0,8( \pm 0,2)$ & $0,045^{*}$ \\
\hline
\end{tabular}

Legenda: EMGs: eletromiografia de superfície; GP: grupo pesquisa; GC: grupo controle; M: média; DP: desvio padrão; $\mathrm{N}$ : número de participantes; MIC: apertamento dentário máximo com máxima intercuspidação; ALG: apertamento dentário máximo com rolete de algodão entre os dentes; TE: músculo temporal esquedo; TD: músculo temporal direito; ME: músculo masseter esquerdo, MD: músculo masseter direito; Assimetria T: índice de assimetria dos músculos temporais; Assimetria M: índice de assimetria dos músculos masseteres; *diferença significativa de acordo com o teste de Mann-Whitney. 
A Tabela 24 exibe as análises descritivas e comparação intergrupos de acordo com os resultados da análise eletromiográfica obtidos após o tratamento. Foram encontradas diferenças significativas entre os grupos para as variáveis "máxima intercuspidação masseter esquerdo", "máxima intercuspidação masseter direito", “algodão masseter esquerdo”, “algodão masseter direito”, "mastigação temporal esquerdo", "mastigação temporal direito", "mastigação masseter esquerdo", "mastigação masseter direto" e "assimetria intercuspidação masseter". Após o tratamento, apenas os masseteres para as provas de MIC e ALG diferenciaram os grupos. A prova de mastigação não mostrou mudanças, com diferença estatisticamente significante entre os grupos.

Tabela 24 - Comparação intergrupos - resultados da análise eletromiográfica pós-tratamento

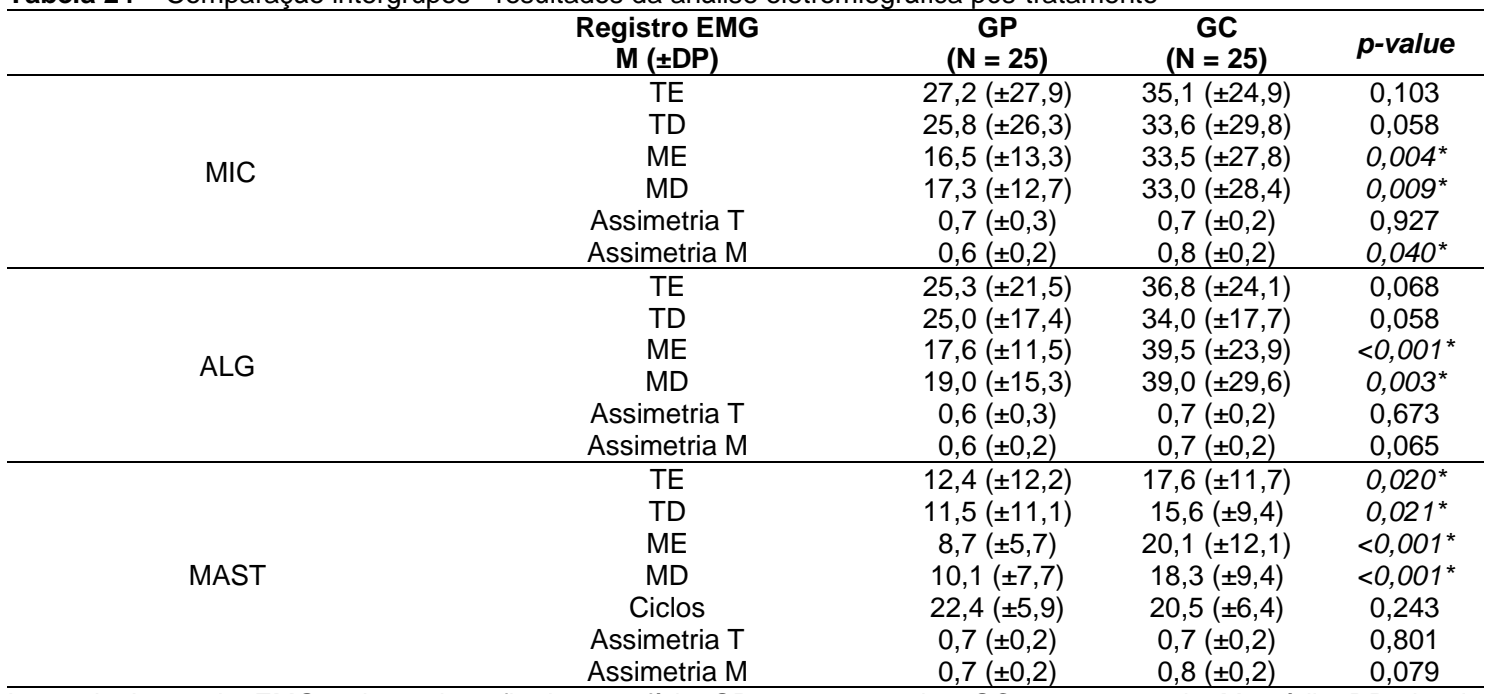

Legenda: Legenda: EMGs: eletromiografia de superfície; GP: grupo pesquisa; GC: grupo controle; M: média; DP: desvio padrão; N: número de participantes; MIC: apertamento dentário máximo com máxima intercuspidação; ALG: apertamento dentário máximo com rolete de algodão entre os dentes; TE: músculo temporal esquerdo; TD: músculo temporal direito; ME: músculo masseter esquerdo, MD: músculo masseter direito; Assimetria T: índice de assimetria dos músculos temporais; Assimetria M: índice de assimetria dos músculos masseteres; *diferença significativa de acordo com o teste de Mann-Whitney.

A Tabela 25 exibe as análises descritivas dos resultados da análise eletromiográfica e comparação intragrupo (GP e GC) dos dados obtidos antes e depois do tratamento. Foram encontradas diferenças estatisticamente significantes apenas para o grupo pesquisa, que foi submetido a terapia 
fonoaudiológica, nas provas de MIC e ALG para os músculos temporais e na prova de ALG para o masseter esquerdo.

Tabela 25 - Comparação intragrupo - resultados da análise eletromiográfica

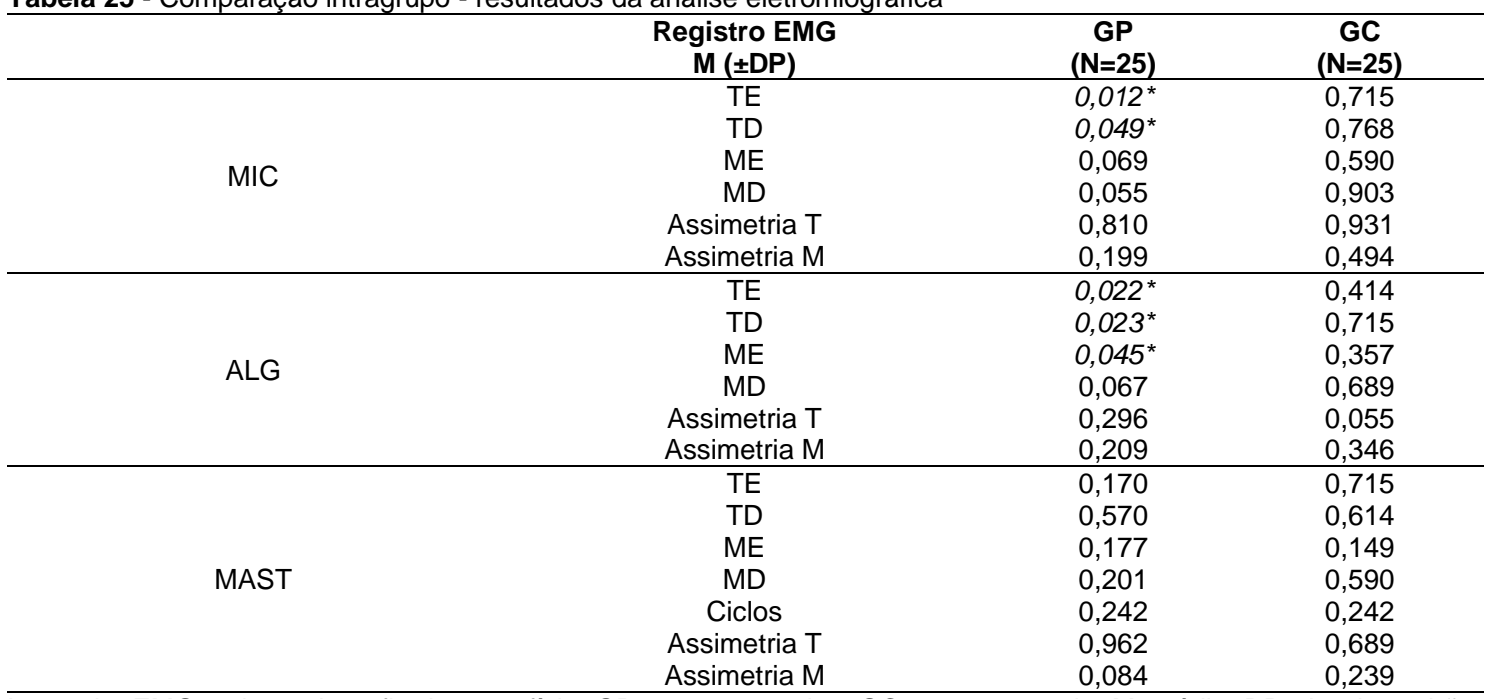

Legenda: EMGs: eletromiografia de superfície; GP: grupo pesquisa; GC: grupo controle; M: média; DP: desvio padrão; $\mathrm{N}$ : número de participantes; MIC: apertamento dentário máximo com máxima intercuspidação; ALG: apertamento dentário máximo com rolete de algodão entre os dentes; TE: músculo temporal esquerdo; TD: músculo temporal direito; ME: músculo masseter esquerdo, MD: músculo masseter direito; Assimetria T: índice de assimetria dos músculos temporais; Assimetria M: índice de assimetria dos músculos masseteres; *diferença significativa de acordo com o teste de Wilcoxon para amostras pareadas. 


\section{DISCUSSÃO}

De acordo com os resultados do presente estudo, a hipótese inicial de que pacientes com menor tempo entre a correção da fratura e a intervenção fonoaudiológica apresentam melhores resultados após a terapia fonoaudiológica, não foi confirmada. Os resultados sugerem que, independentemente do tempo transcorrido entre a correção das fraturas e a intervenção fonoaudiológica, todos os grupos de pacientes apresentaram melhora significativa em: postura, mobilidade e funções miofuncionais orofaciais, mobilidade mandibular e nos sinais e sintomas de DTM.

A maioria dos estudos relaciona tempo entre a correção da fratura e a realização do tratamento médico ${ }^{3,6,18,20-25}$. Em uma revisão sistemática realizada sobre o assunto que analisou os artigos de tratamento com dividindo-os em relação ao tempo 49 (tempo entre o trauma e o cuidado inicial de saúde, tempo entre o cuidado de saúde e o diagnóstico e o tempo entre o diagnóstico e 0 tratamento), concluiu-se que faltam na literatura estudos da relação entre tempo de fraturas com complicações como qualidade de vida a longo prazo, custo do paciente para o governo, entre outros. Além disso, esta revisão apontou que fraturas de côndilo resultam em mais sequelas quando comparadas às outras fraturas de face.

Analisando o local de fratura, quase $71 \%$ dos participantes do GP1 apresentaram fraturas condilares (GP2 - 38\%; GP3 - 17\%). O sucesso da reabilitação da fratura condilar depende de características biológicas individuais e de adaptações realizadas pelo sistema mastigatório ${ }^{3,49}$. Fraturas condilares 
podem levar a mal oclusão, e como consequência, acarretar em alterações funcionais como restrição em mobilidade mandibular, dor e alterações mastigatórias ${ }^{50,51}$. Além destas alterações decorrentes, as fraturas condilares podem apresentar outras sequelas como desvio mandibular, trismo e posição alterada de côndilo mandibular ${ }^{52,53}$. As alterações e possibilidades de sequelas de fraturas condilares são amplamente documentadas em literatura, além disso, os pacientes apresentam maior número de sintomas e alterações funcionais, justificando a maior quantidade destes encaminhados para reabilitação precoce.

O desempenho dos participantes na avaliação miofuncional orofacial com escores e nas medidas de mobilidade mandibular foi semelhante entre os grupos. Os grupos apresentaram valores abaixo do esperado quando comparados aos indivíduos sem alterações ou com os valores da normalidade (pontuação máxima: aspecto/postura - 64 pontos; mobilidade - 114 pontos; funções orofaciais - 52 pontos $)^{43}$. Estes resultados abaixo dos valores de normalidade também foram observados em um estudo que pesquisou as funções orofaciais de pacientes com fratura submetidos ao tratamento cirúrgico e não cirúrgico e em pacientes com fratura condilar ${ }^{1,3}$.

Os estudos que investigam a musculatura orofacial na população com fratura de face são escassos. Entretanto, considerando que os pacientes submetidos à cirurgia ortognática se aproximam dos pacientes acometidos por traumas de face devido a existência de osteotomias e ao reposicionamento ósseo, alguns os resultados podem ser comparados entre estas duas populações ${ }^{1,40}$. Todavia, um ponto que precisar ser ressaltado é que as mudanças que ocorrem em pacientes com traumas de face não são previsíveis como nos casos de pacientes submetidos à cirurgia ortognática ${ }^{3}$. Os pacientes 
submetidos à cirurgia ortognática apresentam no período pós-cirúrgico, redução da extensibilidade e força muscular, aumento da fatigabilidade muscular, hipomobilidade articular e alterações biomecânicas na eficiência e comprimento da musculatura mastigatória ${ }^{35,54}$. Segundo a literatura, esses sinais e sintomas podem ocorrer em até 6 meses após a cirurgia $35,55-58$.

Pesquisadores sugerem que alguns tipos de fraturas podem causar estiramento muscular, o que pode acarretar em redução da força, mobilidade e massa musculares ${ }^{58,59}$. Todos esses aspectos impactam na mobilidade do sistema miofuncional orofacial. Além disso, sabe-se que em pacientes com DTM por exemplo, quanto maior for o número de interferências oclusais e a gravidade da disfunção, maior é o tempo mastigatório e menor a pontuação na avaliação desta função60.

Ao analisar a interferência do tempo no desempenho miofuncional dos participantes com trauma de face, foi possível observar que os participantes com menor tempo entre o trauma e a avaliação fonoaudiológica apresentaram pontuações piores nas funções orofaciais de mastigação e deglutição observadas com a análise do AMIOFE-E ${ }^{43}$. Durante a mastigação e a deglutição, várias estruturas orofaciais são recrutadas e consequentemente, informações motoras são enviadas para língua, hioide, palato mole, lábios, entre outras estruturas $^{61-64}$. A ATM é um componente fundamental para a realização da função mastigatória e no caso dos pacientes com fraturas de côndilo, a atividade muscular e as forças oclusais acabam sendo modificadas ${ }^{65,66}$. Fraturas unilaterais de côndilo podem evoluir com redução em mobilidade mandibular, principalmente na lateralização contralateral à fratura ${ }^{60,65}$. A força de mordida é reduzida no lado fraturado, agindo como uma proteção do organismo para evitar 
sobrecarga na região da fratura. Além da força, movimentos e tipo mastigatório são fortemente influenciados por variáveis como morfologia e integridade das estruturas orofaciais e do tipo de alimento ingerido. (ex: alimentos sólidos em relação aos alimentos semissólidos) $)^{54,64,67,68}$.

Os participantes do presente estudo apresentaram desempenho de mobilidade mandibular inferior ao esperado para a normalidade. Se por um lado pacientes com fraturas recentes poderiam apresentar restrições mandibulares por edema, trismo, contração muscular protetora, e dor ${ }^{35,55,56}$, os pacientes com fraturas mais tardias são mais propensos à ocorrência de anquiloses, DTM e também de dor $35,57,58$. No presente estudo, nenhuma destas condições diferenciou de maneira significativa os grupos de participantes.

Estudos anteriores reportaram os valores esperados para a normalidade quanto a abertura oral máxima (40 a 60mm); lateralidade mandibular (7 a 11mm); protrusão mandibular (7 a $11 \mathrm{~mm})^{58,59}$. A abertura oral máxima é apontada na literatura como parâmetro para avaliação do funcionamento da ATM $55-57,61,65$. A função mandibular se adapta à uma grande variedade de mudanças estruturais e funcionais ${ }^{61,69}$, contudo, nem sempre estas adaptações serão saudáveis e benéficas para as funções orofaciais. Estudos reportaram a presença de déficits funcionais, desvios mandibulares e disfunções após tratamento de fraturas faciais $^{55,56,61,65,69-71}$. No presente estudo, os desvios mandibulares apresentaram melhora significante após o tratamento, demonstrando um funcionamento mais simétrico das articulações.

Após o tratamento cirúrgico aberto das fraturas, a redução na mobilidade mandibular relacionada à redução do movimento de rotação condilar foi o principal resultado. Em relação ao tratamento funcional fechado, foi observada 
principalmente a redução no movimento de translação do côndilo ${ }^{72}$. A incidência de DTM em fraturas faciais aumenta com o tempo de acometimento, mesmo para as fraturas que não envolveram o côndilo mandibular, que também apresentam alterações de mordida e alterações mastigatórias ${ }^{69}$.

A análise realizada com o protocolo de sinais de sintomas de DTMs utilizado no presente estudo demonstrou que o tempo de ocorrência da fratura interferiu nos sinais e sintomas dos participantes em relação à ATM. Os participantes do grupo de fraturas mais tardias apresentaram maiores alterações do que os participantes dos grupos com fraturas mais recentes, o que pode ser constatado pela diferença significante da presença de dor e de zumbido entre os grupos. De acordo com a literatura, a dor é considerada a questão mais relevante quando se fala em qualidade de vida ${ }^{72,73}$. Pacientes que acometidos pela dor diariamente tem maior probabilidade de apresentar prejuízos nas atividades de vida diária ${ }^{73}$. Mais especificamente, as dores faciais e dentárias são as de maior impacto na qualidade de vida dos pacientes ${ }^{74,75}$. Segundo a literatura, a dor facial pode afetar a vida de uma pessoa de maneira mais significativa do que condições sistêmicas como diabetes, hipertensão ou úlceras ${ }^{74,76}$.

A incidência de DTMs em pacientes com traumas de face sem fraturas condilares é alta, sendo que esta incidência aumenta quando não existe intervenção adequada ${ }^{24}$. As fraturas contralaterais em côndilo, ângulo ou corpo da mandíbula contemplam mais critérios de desencadeamento das DTMs do que as fraturas unilaterais de côndilo, ângulo e corpo da mandíbula. Em um estudo abordando essa temática ${ }^{25}$, a frequência de DTM em pacientes acometidos por trauma de face foi maior no lado não fraturado, desta forma, é possível considerar o trauma como fator etiológico. Os sinais e sintomas frequentes de 
DTMs incluem dor em ATM, otalgia, dificuldade ou dor ao mastigar, dor facial, travamento mandibular, e restrição na mobilidade mandibular ${ }^{77-80}$.

Sintomas otológicos também são frequentes em pacientes com DTM, porém, a correlação desses sintomas com as alterações em ATM ainda não foram completamente esclarecidos ${ }^{81-90}$. O zumbido tem sido considerado como um sintoma de impacto negativo na qualidade de vida para alguns indivíduos ${ }^{90}$. Três teorias ${ }^{91-94}$ têm sido descritas para explicar a associação entre zumbido e DTM. A primeira preconiza que os músculos da mastigação estão próximos dos músculos que tem inserção na orelha media (tensor do tímpano). A segunda explica que pode haver uma conexão direta entre os ligamentos da mandíbula e os ossos da orelha media. A terceira teoria sugere que a inervação da ATM apresenta conexões com partes do cérebro que estão envolvidas com a audição e interpretação dos sons ${ }^{39,41,91-94}$. Os sintomas auditivos apresentados pelos participantes do presente estudo melhoraram de forma significativa após a realização do tratamento.

No presente estudo, em relação aos sinais e sintomas de DTMs, foi possível observar que os participantes do GP1 apresentaram dor de cabeça, plenitude auricular, dificuldade na mobilidade e abertura oral e dificuldade para bocejar, principalmente ao acordar. Os participantes do GP2 apresentaram dor muscular em ATM e em cervical, dificuldade na mobilidade, fechamento e abertura oral, dificuldade para bocejar e falar e maior sensibilidade nos dentes. Para o GP2, estes sintomas pioram ao acordar ou ao mastigar, falar e repousar. O GP3 apresentou dor muscular orofacial e cervical, zumbido, dificuldade na mobilidade, fechamento e abertura oral, dificuldade para bocejar, mastigar e falar, apresentando agravamento dos sintomas ao acordar e ao falar. 
Apesar deste estudo não ter investigado os hábitos alimentares dos participantes, sabe-se que nas primeiras semanas após a fratura os mesmos foram orientados a ingerir alimentos mais macios, justificando o fato dos participantes com fraturas mais tardias apresentarem mais queixas relacionadas à mastigação, uma vez que eles já estavam em dieta composta por alimentos sólidos, sem restrições $22,26,29$.

O tratamento de fraturas faciais continua sendo um desafio para os profissionais envolvidos na reabilitação. Estudos abordando os sinais e sintomas tardios das fraturas faciais são escassos, o que dificulta o conhecimento de questões como a existência ou não de treinamento especializado dos profissionais responsáveis pelos cuidados com esta população, desconhecimento relativo aos gastos destes cuidados, tanto para os pacientes quanto para o governo e a interferência das fraturas na qualidade de vida dos mesmos $^{49,52}$. De acordo com a literatura, tratamentos funcionais envolvendo terapia miofuncional orofacial tem demonstrado resultados positivos para redução de dor, sintomas auditivos, assimetrias faciais, e na melhora da mobilidade mandibular e nas funções realizadas por essas estruturas ${ }^{4}$. A terapia miofuncional orofacial também está associada à uma recuperação muscular mais rápida ${ }^{39,95}$.

Para este estudo, todos os grupos tratados apresentaram melhora significativa no desempenho miofuncional orofacial, na mobilidade mandibular e nos sinais de sintomas relacionados com a DTM, indicando que independentemente do tempo de correção da fratura, é possível alcançar a recuperação das estruturas e funções orofaciais. Os resultados ainda sugerem 
que o tratamento precoce otimiza a recuperação e evita maiores sequelas, principalmente relacionadas aos sinais e sintomas de DTM.

Além dos instrumentos utilizados para avaliar os participantes, optou-se por incluir a avaliação objetiva da musculatura mastigatória por meio da EMGs, com o objetivo de avaliar possíveis mudanças na fisiologia muscular. A EMGs permite a avaliação da função muscular analisando os sinais elétricos captados durante a contração muscular, auxiliando na compreensão, interpretação e reconhecimento do dano muscular, assim como a análise do período necessário para a recuperação ${ }^{96}$. Outra possibilidade é a análise da atividade muscular, que pode ser relacionada positivamente com a força de mordida para a análise dos elevadores de mandíbula, sendo um indicador importante da situação funcional do sistema mastigatório ${ }^{97}$. Para esse estudo foi realizada análise dos valores durante repouso, contração de masseteres e temporais e função mastigatória. Os resultados evidenciaram que inicialmente, os grupos se diferenciaram quanto a atividade dos músculos temporais e masseteres nas provas de MIC, ALG e MAST, apresentando ainda, diferença na simetria de masseteres. Após a reabilitação, o grupo pesquisa assemelhou-se ao grupo controle, sugerindo a melhora da fisiologia e do desempenho muscular de indivíduos com traumas de face após a reabilitação fonoaudiológica. A mastigação diferenciou os grupos após o programa terapêutico, entretanto, observou-se que a mobilidade, amplitude e funcionamento muscular voluntário se modificam primeiro. A fisiologia muscular para a função mastigatória necessita de maior tempo para que as mudanças sejam observadas. Vale ressaltar que o acompanhamento longitudinal desses participantes será de extrema importância para esclarecer este aspecto. Um estudo anterior ${ }^{98}$ observou diferença nos valores de 
apertamento dentário (com e sem rolete de algodão), com o músculo temporal apresentando maiores valores de ativação quando comparado ao musculo masseter ${ }^{98}$. Na literatura consultada, não foram encontrados trabalhos que realizaram avaliação eletromiográfica em pacientes acometidos por trauma de face, justificando novamente a utilização de trabalhos envolvendo cirurgias ortognáticas para discussão dos achados. Para os pacientes submetidos à cirurgia ortognática, a recuperação da função de mastigação precede a alteração fisiológica muscular ${ }^{40}$.

A redução da atividade mioelétrica após o tratamento de fraturas mandibulares pode ser explicado pela lesão muscular causada no próprio trauma ou no processo cirúrgico, ou ainda pelos mecanismos neuromusculares protetores que são iniciados após a fratura, no qual componentes que levam a imobilização muscular são ativados ou desativados para proteger o osso fraturado ${ }^{99}$. La literatura, não há consenso quanto ao tempo para verificar a ocorrência de mudanças na fisiologia muscular observada pela análise da atividade eletromiográfica. Após a realização de cirurgias ortognáticas, alguns estudos sugerem ausência de mudanças em um período de um ano ${ }^{100,101}$, enquanto outros estudos mostram um aumento na atividade elétrica muscular durante a mastigação após 6 meses $^{102}$ ou após três anos da cirurgia ortognática $^{103}$. Para pacientes com traumas de face, foi observado aumento significativo nos valores eletromiográficos no acompanhamento longitudinal após a fratura, porém, a função muscular se manteve menor do que em indivíduos saudáveis ${ }^{76}$. Este achado se assemelha ao encontrado no presente estudo, principalmente para os masseteres (em todas as atividades solicitadas) e para a função de mastigação nos músculos temporais e masseteres. Já para 
pacientes com traumas em ângulo mandibular, a atividade eletromiográfica foi inicialmente baixa, com aumento dos valores após 6 meses de tratamento, não atingindo os valores presentados pelos indivíduos sem fraturas faciais ${ }^{61}$. Considerando os períodos após a fratura, foi possível observar mudanças significativas em 7 dias de pós-operatório, com melhora progressiva dos valores eletromiográficos principalmente após a regeneração óssea, com 60 dias após a fratura.

O masseter tem sua origem e inserção no osso zigomático e na mandíbula, ossos proeminentes da face ${ }^{25}$. A fratura destes ossos pode causar uma mudança na atividade do masseter, o que ocorre devido não só ao trauma, mas também pela redução da função mastigatória (que não foi recuperada em até 60 dias), como demonstrado por este estudo. $O$ lado fraturado apresentou menores valores de atividade eletromiográfica. Nos casos de múltiplas fraturas, a redução da atividade muscular ocorreu com maior intensidade no lado da fratura mandibular; as fraturas do complexo zigomático foram as menos afetadas $^{58}$. Considerando que neste trabalho a maioria dos participantes apresentou fraturas no terço médio da face, observou-se que o músculo temporal se recuperou mais rapidamente quando comparado ao masseter, provavelmente pela anatomia muscular e pela relação com as estruturas ósseas afetadas.

Para a cirurgia ortognática, as evidências sugerem que a terapia precoce pode acelerar a recuperação da atividade mioelétrica e reduzir o tempo necessário para a recuperação do sistema miofuncional orofacial. Esta recuperação, quando atingida precocemente, manteve-se por pelo menos 6 meses após realização da cirurgia. Para os participantes que não receberam terapia precoce, a recuperação da atividade mioelétrica foi evidenciada apenas 
após 6 meses da cirurgia ${ }^{39}$. A terapia funcional deve incluir a manutenção da oclusão e a adequação da mobilidade mandibular, com a finalidade de criar e manter uma posição condilar estável durante a recuperação óssea ${ }^{38}$.

Pela dinâmica do hospital e complexidade das fraturas dos participantes incluídos neste estudo, não foi possível parear os grupos por tipo de fratura ou tratamento médico realizado, o que pode ter interferido nos resultados, uma vez que a população era heterogênea. Além disso, outra limitação do estudo é a ausência da análise de outros aspectos relacionados à qualidade de vida, como o bem-estar físico, mental, psicológico e emocional, relacionamentos sociais, entre outros. Estes outros aspectos não foram abordados no presente estudo, não sendo possível verificar o impacto da dor orofacial nas atividades de vida diária dos participantes. Estudos futuros devem englobar protocolos de análise de qualidade de vida, grupos mais homogêneos de pacientes, além de realizar acompanhamento longitudinal para observar se os outros aspetos, como a atividade eletromiográfica de masseter a longo prazo, a manutenção dos resultados obtidos com o programa terapêutico e se a normalização da função muscular é atingida e mantida.

Quando o sistema motor oral sofre mudanças no contato oclusal, são desencadeadas compensações que envolvem inicialmente a movimentação mandibular para garantir melhor intercuspidação, seguida pela ativação de mecanoceptores que reflexamente reduzem os movimentos mandibulares como uma tentativa de adaptação inicial do sistema, que acarretará no aumento do tônus e da incoordenação da musculatura. Esta sobrecarga irá gerar adaptações em outras estruturas, como nas ATMs, periodonto, dentes e músculos, resultando em incoordenação muscular, movimentos mandibulares associados 
para realização das funções orofaciais, redução em velocidade de fala, cansaço e dificuldade mastigatória ${ }^{104}$. Seguindo esse raciocínio e fazendo uma relação com os achados do presente estudo, é possível considerar que os pacientes acometidos por traumas de face apresentam alterações no sistema motor oral, implicando em menor eficiência para realização das funções de mastigação e deglutição, alteração da mobilidade mandibular, desorganização muscular com menor potencial de ação, sinais e sintomas de DTMs (principalmente dor facial, em ATM e cervical) e sintomas auditivos (plenitude auricular e zumbido).

O programa terapêutico aplicado neste estudo foi previamente publicado², com delineamento específico para pacientes com traumas de face e restrição em mobilidade mandibular. Sua eficácia foi comprovada com este estudo, demonstrando que todos os pacientes foram beneficiados, apresentando melhora significativa em todas as variáveis pesquisadas. Estudos anteriores realizados com pacientes acometidos por traumas de face apresentam número restrito de participantes e não foram divulgadas informações sobre o programa terapêutico utilizado ${ }^{1,3,26}$. Para os pacientes submetidos à cirurgia ortognática, é possível comprovar a melhora no sistema miofuncional orofacial ${ }^{40}$, além disso, quanto mais precoce for o tratamento, menor será o tempo para a reabilitação 39 . Um estudo de revisão de literatura demonstrou que os pacientes com DTM apresentam resultados significativos para redução de dor a palpação, melhora de sintomas otológicos, melhora na simetria muscular, na mobilidade mandibular e nas funções orofaciais após a realização da terapia miofuncional orofacial ${ }^{4}$.

A reabilitação baseada em evidências foca no estabelecimento de relações entre as intervenções e seus resultados. Esta prática analisa os 
resultados baseados em estudos e comprovações e requer que os profissionais identifiquem, implementem e organizem os objetivos e metas do processo de reabilitação para que haja eficácia no tratamento ${ }^{105}$. A terapia fonoaudiológica para os participantes do presente estudo, acometidos por traumas de face, foi eficaz para a melhora da postura, mobilidade e funções orofaciais, mobilidade mandibular, sinais e sintomas de DTM, recuperação da atividade eletromiográfica, principalmente para os músculos temporais.

O programa terapêutico aplicado nesse estudo foi eficaz para todos os grupos. O sistema miofuncional orofacial (postura, mobilidade e funções), mobilidade mandibular, sinais e sintomas de DTM apresentaram melhora após a aplicação do programa. Quanto à fisiologia muscular, os participantes apresentaram resultados semelhantes aos do grupo controle após realização do programa terapêutico. 


\section{CONCLUSÃO}

O programa de reabilitação utilizado neste estudo mostrou-se eficaz, uma vez que todos os participantes apresentaram melhora significativa em todas as variáveis pesquisadas.

As diferenças observadas entre os grupos nas avaliações pré-tratamento foram minimizadas após aplicação do programa terapêutico fonoaudiológico, indicando que, independentemente do tempo de correção da fratura, a intervenção fonoaudiológica foi eficiente para os participantes do estudo. 


\title{
7. ANEXOS
}

\subsection{Anexo A. Parecer consubstanciado e no CAPPESQ}

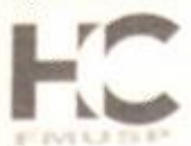

\author{
HOSPITAL DAS CLINICAS DA \\ FACULDADE DE MEDICINA DA \\ USP - HCFMUSP
}

\section{PARECER CONSUBSTANCIADO DO CEP}

\section{DADOS DO PROJETO DE PESQUISA}

Titulo da Pesquisa: Efetividade de um programa de reabilitaçăo fonoaudiológića para pacientes adultos com trauma de face e restriçà em movimento mandibular

Pesquisador: Claudia Regina Furquim de Andrade

Área Temática:

Versăo: 2

CAAE: 60565016.8 .0000 .0068

Instituiçăo Proponente: HOSPITAL DAS CLINICAS DA FACULDADE DE MEDICINA DA US P

Patrocinador Principal: Financiamento Próprio

\section{DADOS DO PARECER}

Número do Parecer: 1.856 .950

\section{Apresentaçăo do Projeto:}

O orojeto intitulado Efetividade de um programa de reabilitaçăo fonoaudiologica para pacientes adultos com trauma de face e restriça em movimento mandibular esta delineado como uma pesquisa prospectiva com individuos que sofreram fraturas faciais com impactos fonoaudiologicos pós tratamento.

Objetivo da Pesquisa:

A pesquisa tem como objetivo verificar a efetividade de um programa fonoaudiologico para pacientes adultos com trauma de face e restriçào do movimento mandibular.

\section{Avaliação dos Riscos e Benefícios:}

Segundo os autores, esse estudo nåo apresenta riscos para os sujeitos.

\section{Comentários e Consideraçŏes sobre a Pesquisa:}

Trata-se de projeto bem delineado e de releváncia cientifica e social, cuja hipotese de que terapia fonoaudiologica auxolia na recuperaçăo muscular e funcional dos pacientes acometidos por traumas de face. principalmente na melhora de

mobilidade mandibular e de funcionalidade em mastigaçåo e deglutiçào, assim como melhora simetria muscular observada pela eletromiografia de superficie, se comprovada, trará beneficios

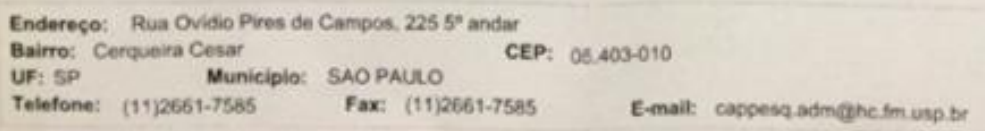




\section{HOSPITAL DAS CLINICAS DA FACULDADE DE MEDICINA DA R Prosil USP - HCFMUSP}

Continuaçầ do Parecer 1856.950

aos individuos que sofreram esse trauma de face.

Consideraçōes sobre os Termos de apresentação obrigatória:

Os autores inseriram TCLE especifico para o grupo controle.

\section{Recomendações:}

A pesquisadora responsável respondeu ou atendeu aos apontamentos realizados no parecer anterior. Como recomendaçăo, sugerimos a uniformizaçăo do título para o TCLE do grupo controle e para o projeto original, segundo consta do título na Plataforma Brasil.

\section{Conclusōes ou Pendências e Lista de Inadequaçōes:}

Os apontamentos realizados no parecer anterior foram atendidos pelos autores: TCLE para o Grupo Controle com o respectivo detalhamento dos procedimentos a serem realizados com este grupo.

Em relaçāo à carta de anuência, a pesquisadora responsável esclarece que os participantes que aceitarem participar fazem parte do fluxo comum à rotina da Divisăo de fonoaudiologia, em ambulatório destinado a esses pacientes, ressaltando não ser necessária a anuência da Disciplina de Cirurgia Plástica.

O outro ponto justificado pela pesquisadora trata-se do detalhamento referente ao procedimento médico. cuja argumentaçăo está pertinente.

Dessa forma, não hă impedimento para a realizaçăo da pesquisa em termos éticos.

\section{Consideraçōes Finais a critério do CEP:}

Em conformidade com a Resoluçăo CNS $n^{\circ} 466 / 12$ - cabe ao pesquisador: a) desenvolver o projeto conforme delineado; b) elaborar e apresentar relatorios parciais e final; c)apresentar dados solicitados pelo CEP, a qualquer momento; d) manter em arquivo sob sua guarda, por 5 anos da pesquisa, contendo fichas individuais e todos os demais documentos recomendados pelo CEP; e) encaminhar os resultados para publicaçăo, com os devidos créditos aos pesquisadores associados e ao pessoal técnico participante do projeto; f) justificar perante ao CEP interrupção do projeto ou a năo publicaçāo dos resultados.

Este parecer foi elaborado baseado nos documentos abaixo relacionados:

\begin{tabular}{|l|l|c|l|c|}
\hline Tipo Documento & Arquivo & Postagem & Autor & Situaçāo \\
\hline $\begin{array}{l}\text { Informaçōes Básicas } \\
\text { do Projeto }\end{array}$ & PB_INFORMAÇOES_BASICAS_DO_P & $\begin{array}{c}21 / 11 / 2016 \\
10: 04: 00\end{array}$ & & Aceito \\
\hline TCLE / Termos de & RojeTO 793647.pdf & $21 / 11 / 2016$ & Claudia Regina & Aceito \\
\hline
\end{tabular}

Endereço: Rua Ovidio Pires de Campos, $2255^{\circ}$ andar Bairro: Cerqueira Cesar
UF: SP Municiplo: SAOPAULO CEP: $05.403-010$
Telefone:
(11)2661-75e5
Fax: (11)2661-7585
E-mait: cappesq.admghic.tm usp.br 


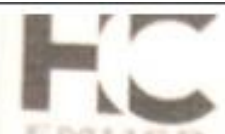

Continuaça do Parecer 1 A56.956
HOSPITAL DAS CLINICAS DA FACULDADE DE MEDICINA DA USP - HCFMUSP

\begin{tabular}{|c|c|c|c|c|}
\hline $\begin{array}{l}\text { Assentimento / } \\
\text { Justificativa de } \\
\text { Ausência } \\
\text { Outrns }\end{array}$ & tclegrupocontrole.pdf & $10: 02: 59$ & Furquim de Andrade & Aceit \\
\hline Outros & respostacappesq.pdf & $\begin{array}{c}04 / 11 / 2016 \\
10: 39: 07\end{array}$ & $\begin{array}{l}\text { Claudia Regina } \\
\text { Furquim de Andrade }\end{array}$ & Aceit \\
\hline $\begin{array}{l}\text { Projeto Detalhado / } \\
\text { Brochura } \\
\text { Investigador } \\
\text { Outros }\end{array}$ & PROJETO.pdf & $\begin{array}{c}04 / 11 / 2016 \\
10: 37: 18\end{array}$ & $\begin{array}{l}\text { Claudia Regina } \\
\text { Furquim de Andrade }\end{array}$ & Aceit \\
\hline Outros & ANEXO2ASSINADO.PDF & $\begin{array}{c}03 / 10 / 2016 \\
09: 11: 42\end{array}$ & $\begin{array}{l}\text { Claudia Regina } \\
\text { Furquim de Andrade }\end{array}$ & $\overline{\text { Aceits }}$ \\
\hline $\begin{array}{l}\text { TCLE / Termos de } \\
\text { Assentimento / } \\
\text { Justificativa de } \\
\text { Ausência } \\
\text { Folha de Rocto }\end{array}$ & TCLE.pdf & $\begin{array}{c}03 / 10 / 2016 \\
09: 10: 56\end{array}$ & $\begin{array}{l}\text { Claudia Regina } \\
\text { Furquim de Andrade }\end{array}$ & Aceitc \\
\hline Folha de Rosto & folhaderostoassinada.PDF & $\begin{array}{c}03 / 10 / 2016 \\
09: 08: 11\end{array}$ & $\begin{array}{l}\text { Claudia Regina } \\
\text { Furquim de Andrade }\end{array}$ & Aceitc \\
\hline
\end{tabular}

Aprovado

Necessita Apreciação da CONEP:

Nắo

SAO PAULO, 08 de Dezembro de 2016

Assinado por:

ALFREDO JOSE MANSUR

(Coordenador)

Endereço: Rua Ovidio Pires de Campos, $2255^{\circ}$ andar

Bairro: Cerqueira Cessar

UF: SP

Municipio: SAO PAULO

Telefone:

(11)2661-7585

Fax: (11)2661-7585

EP: $05403-010$

E-mail: cappesq.admeghc.fm.usp.br 


\subsection{Anexo B. Termo de consentimento livre e esclarecido}

\section{HOSPITAL DAS CLÍNICAS DA FACULDADE DE MEDICINA DA UNIVERSIDADE DE SÃO PAULO-HCFMUSP}

TERMO DE CONSENTIMENTO LIVRE E ESCLARECIDO

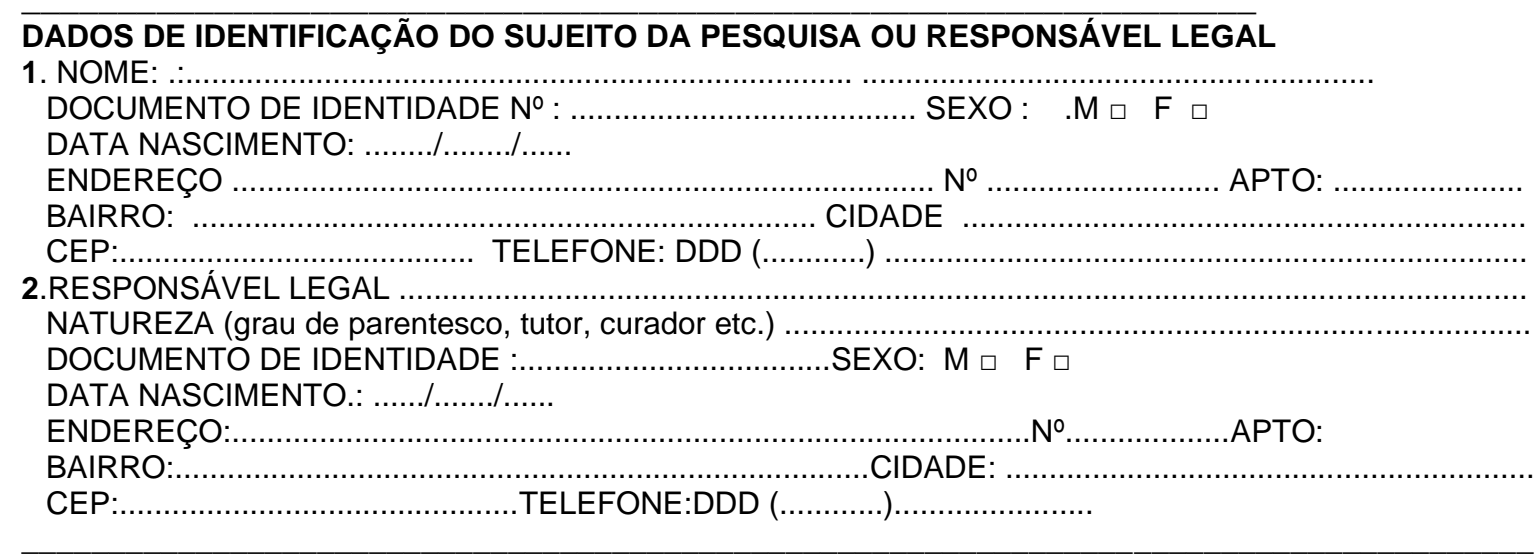

\section{DADOS SOBRE A PESQUISA}

1. TÍTULO DO PROTOCOLO DE PESQUISA: Atuação Fonoaudiológica em pacientes adultos com trauma de face e restrição em mobilidade mandibular.

PESQUISADOR EXECUTANTE: Ms. Amanda Pagliotto da Silva

CARGO/FUNÇÃO: Fonoaudióloga

INSCRIÇÃO CONSELHO REGIONAL № 2-17001

UNIDADE DO HCFMUSP: Departamento de Fisioterapia, Fonoaudiologia, e Terapia Ocupacional da Faculdade de Medicina da Universidade de São Paulo

3. AVALIAÇÃO DO RISCO DA PESQUISA:

$\begin{array}{lll}\text { RISCO MÍNIMO } & X & \text { RISCO MÉDIO } \\ \text { RISCO BAIXO } & \square & \text { RISCO MAIOR }\end{array}$

4.DURAÇÃO DA PESQUISA : 48 meses 


\section{HOSPITAL dAS CLÍNICAS dA FACULDADE DE MEDICINA DA UNIVERSIDADE dE SÃo PAULO-HCFMUSP}

O(a) senhor(a) está sendo convidado(a) a participar de uma pesquisa desenvolvida na área de Fonoaudiologia. A seguir explicarei os objetivos e a importância deste estudo.

Esta pesquisa tem como objetivo apresentar formas de avaliar pessoas que sofreram algum tipo de trauma no rosto, assim como o(a) senhor(a), visando/buscando principalmente a correção da mastigação e melhora na abertura de boca. Sabe-se que existem seqüelas importantes depois de um trauma no rosto. A fonoaudiologia pode trabalhar para adequar/corrigir as funções como respiração, mastigação, engolir e falar, mas existem poucos estudos que mostram como a avaliação e o tratamento podem ser realizados.

Com a realização deste estudo poderemos melhorar o atendimento oferecido aos pacientes que sofreram trauma de face.

Esse estudo será realizado com três grupos de participantes: aqueles com fraturas na face que realizarão tratamento cirúrgico e aqueles que realizarão tratamento não cirúrgico. Além deles, o estudo terá o terceiro grupo com sujeitos controle, que não apresentam alterações na face e farão os mesmos procedimentos que os demais grupos. Os três grupos serão avaliados e tratados da mesma forma. No grupo com fratura em face com tratamento cirúrgico o tratamento será iniciado após a cirurgia.

Essa possibilidade de tratamento fonoaudiológico foi discutida entre médicos, dentistas e fonoaudiólogos, e se acredita que o paciente possa se beneficiar do tratamento apos a cirurgia e mesmo quando a cirurgia não é indicada.

As avaliações serão realizadas em uma única sessão, de aproximadamente 60 minutos, na qual o(a) senhor(a) realizará:

- Avaliação clínica: serão utilizados meios de avaliação (protocolos) de pesquisas anteriores, que verificarão a situação dos músculos de seu rosto e pescoço e como estes estão funcionando (para respirar, engolir e mastigar). O fonoaudiólogo solicitará alguns movimentos e funções de seu rosto, pescoço e cabeça e vai avaliar se esses movimentos e funções estão sendo realizados da forma correta. Esses movimentos serão registrados em máquina fotográfica com fotos e vídeos.

- Exame de Eletromiografia de Superfície (EMGs): esse exame avaliará o funcionamento dos músculos responsáveis pela sua mastigação. Para isso, será colocado em sua pele - na região das têmporas (ao lado da testa) e das bochechas (logo a frente da orelha) um eletrodo. Será pedido que o(a) senhor(a) permaneça sem realizar nenhum movimento com o rosto e pescoço durante 30 segundos e será avaliado o funcionamento dos músculos no repouso. Depois será pedido que o(a) senhor(a) aperte um dente contra o outro (morda) durante 5 segundos e será avaliado o funcionamento dos músculos. Logo após, será colocado um pedaço de algodão entre os seus dentes e pedido que o(a) senhor(a) aperte um dente contra o outro (morda) durante 5 segundos e será avaliado o funcionamento dos músculos.

O tratamento será realizado no Hospital das Clínicas. $O(A)$ senhor(a) deverá comparecer ao hospital uma vez por semana, por seis semanas seguidas ( 6 sessões), e cada sessão terá quarenta minutos de duração. Será realizado o Programa Fonoaudiológico de Tratamento para Pacientes com Trauma de Face, que busca a correção dos músculos e das funções realizadas pelo seu rosto e pescoço. Para isso serão realizadas orientações; atividades em que o(a) senhor(a) terá que ter atenção na forma como mastiga, engole, fala e respira; exercícios com os músculos do rosto e pescoço; e treinos de mastigar, engolir, falar e respirar da forma correta. Será solicitado que o(a) senhor(a) faça alguns exercícios e treinos em casa (diariamente, no mínimo três vezes por dia) de algumas atividades aprendidas e realizadas durante as sessões. Ao final da terapia será realizada a reavaliação com os mesmos procedimentos realizados na avaliação inicial.

Para os sujeitos do terceiro grupo não será realizada terapia fonoaudiológica pois os mesmos não apresentam alterações faciais, a avaliação ocorrerá em dois momentos, sendo o segundo momento após 6 semanas da data da primeira avaliação.

As atividades programadas tanto na avaliação como no tratamento não trazem nenhum desconforto ao indivíduo e nenhum risco.

Trata-se de estudo experimental testando a hipótese de que a intervenção fonoaudiológica poderá auxiliar a retomada da abertura de boca e da mastigação de forma mais rápida e mais adequada possível.

Não existem procedimentos alternativos que possam ser vantajosos aos pacientes.

Em qualquer etapa do estudo o senhor(a) terá acesso aos profissionais responsáveis pela pesquisa para esclarecimento de eventuais dúvidas. Os investigadores são a Profa. Dra. Claudia Regina Furquim de Andrade e a fonoaudióloga Amanda Pagliotto da Silva que podem ser encontradas na Rua Cipotania, 51 - Campus Cidade Universitária - CEP 05360-160 - São Paulo, SP, Brazil - Tel: 11 3091-8406. Se você tiver alguma consideração ou dúvida sobre a ética da pesquisa, entre em contato com o Comitê de Ética em Pesquisa (CEP) - Rua Ovídio Pires de Campos, 225 - 5o andar - tel: 3069-6442 ramais 16, 17, 18 ou 20, FAX: 3069-6442 ramal 26 - E-mail: cappesq@hcnet.usp.br

É garantida a liberdade da retirada de consentimento a qualquer momento e deixar de participar do estudo, sem qualquer prejuízo à continuidade de seu tratamento na Instituição;

As informações obtidas serão analisadas em conjunto com outros pacientes, não sendo divulgado a identificação de nenhum paciente. 
Não há despesas pessoais para o participante em qualquer fase do estudo, incluindo exames e consultas. Também não há compensação financeira relacionada à sua participação. Se existir qualquer despesa adicional, ela será absorvida pelo orçamento da pesquisa.

Os dados coletados serão utilizados apenas para esta pesquisa.

Acredito ter sido suficientemente informado a respeito das informações que li ou que foram lidas para mim, descrevendo o estudo "Atuação Fonoaudiológica em pacientes adultos com trauma de face e restrição em mobilidade mandibular". Eu discuti com a Profa. Dra. Claudia Regina Furquim de Andrade e/ou Fga. Ms. Amanda Pagliotto da Silva sobre a minha decisão em participar nesse estudo. Ficaram claros para mim quais são os propósitos do estudo, os procedimentos a serem realizados, seus desconfortos e riscos, as garantias de confidencialidade e de esclarecimentos permanentes. Ficou claro também que minha participação é isenta de despesas e que tenho garantia do acesso a tratamento hospitalar quando necessário. Concordo voluntariamente em participar deste estudo e poderei retirar o meu consentimento a qualquer momento, antes ou durante o mesmo, sem penalidades ou prejuízo ou perda de qualquer benefício que eu possa ter adquirido, ou no meu atendimento neste Serviço.

Assinatura do paciente/representante legal

Data

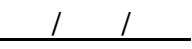

Assinatura da testemunha

Data

para casos de pacientes menores de 18 anos, analfabetos, semi-analfabetos ou portadores de deficiência auditiva ou visual.

(Somente para o responsável do projeto)

Declaro que obtive de forma apropriada e voluntária o Consentimento Livre e Esclarecido deste paciente ou representante legal para a participação neste estudo.

Assinatura do responsável pelo estudo

Data 


\subsection{Anexo C}

\section{HOSPITAL DAS CLÍNICAS DA FACULDADE DE MEDICINA DA UNIVERSIDADE DE SÃO PAULO-HCFMUSP}

\section{TERMO DE CONSENTIMENTO LIVRE E ESCLARECIDO}

\section{DADOS DE IDENTIFICAÇÃO DO SUJEITO DA PESQUISA OU RESPONSÁVEL LEGAL}

1. NOME: :

DOCUMENTO DE IDENTIDADE N ${ }^{\circ}$ : SEXO : $\quad M \square F \square$

DATA NASCIMENTO

ENDEREÇO

№

APTO:

BAIRRO :

CEP:

TELEFONE: DDD

..)

2.RESPONSÁVEL LEGAL

NATUREZA (grau de parentesco, tutor, curador etc.)

DOCUMENTO DE IDENTIDADE SEXO: $M \square F \square$

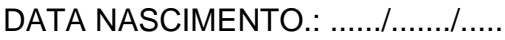

ENDEREÇO:

№

APTO

BAIRRO: CIDADE:

CEP:

TELEFONE: DDD.

DADOS SOBRE A PESQUISA

1. TÍTULO DO PROTOCOLO DE PESQUISA: Atuação Fonoaudiológica em pacientes adultos com trauma de face e restrição em mobilidade mandibular.

PESQUISADOR EXECUTANTE: Ms. Amanda Pagliotto da Silva CARGO/FUNÇÃO: Fonoaudióloga INSCRIÇÃO CONSELHO REGIONAL № 2-17001

UNIDADE DO HCFMUSP: Departamento de Fisioterapia, Fonoaudiologia, e Terapia Ocupacional da Faculdade de Medicina da Universidade de São Paulo

3. AVALIAÇÃO DO RISCO DA PESQUISA:

$\begin{array}{llll}\text { RISCO MÍNIMO } & X & \text { RISCO MÉDIO } \\ \text { RISCO BAIXO } & \square & \text { RISCO MAIOR } & \square\end{array}$

4.DURAÇÃO DA PESQUISA : 48 meses 


\section{hOSPITAL DAS CLÍNICAS DA FACULDADE DE MEDICINA DA UNIVERSIDADE DE SÃO PAULO-HCFMUSP}

O(a) senhor(a) está sendo convidado(a) a participar de uma pesquisa desenvolvida na área de Fonoaudiologia. A seguir explicarei os objetivos e a importância deste estudo.

Esta pesquisa tem como objetivo apresentar formas de avaliar pessoas que sofreram algum tipo de trauma no rosto, visando/buscando principalmente a correção da mastigação e melhora na abertura de boca. Sabe-se que existem seqüelas importantes depois de um trauma no rosto. A fonoaudiologia pode trabalhar para adequar/corrigir as funções como respiração, mastigação, engolir e falar, mas existem poucos estudos que mostram como a avaliação e o tratamento podem ser realizados.

Com a realização deste estudo poderemos melhorar o atendimento oferecido aos pacientes que sofreram trauma de face.

Para que possamos comparar os efeitos do tratamento e muito importante para p trabalho termos pessoas que não sofreram traumas no rosto, para comparar os desempenhos dos músculos e das funções como respiração, mastigação, engolir e falar,

Esse estudo será realizado com três grupos de participantes: aqueles com fraturas na face que realizarão tratamento cirúrgico e aqueles que realizarão tratamento não cirúrgico. Além deles, o estudo terá o terceiro grupo com sujeitos controle, que não apresentam alterações na face e farão os mesmos procedimentos que os demais grupos. O senhor(a) está sendo convidado para participar do grupo controle.

As avaliações serão realizadas em uma única sessão, de aproximadamente 60 minutos, na qual o(a) senhor(a) realizará:

- Avaliação clínica: serão utilizados meios de avaliação (protocolos) de pesquisas anteriores, que verificarão a situação dos músculos de seu rosto e pescoço e como estes estão funcionando (para respirar, engolir e mastigar). O fonoaudiólogo solicitará alguns movimentos e funções de seu rosto, pescoço e cabeça e vai avaliar se esses movimentos e funções estão sendo realizados da forma correta. Esses movimentos serão registrados em máquina fotográfica com fotos e vídeos.

- Exame de Eletromiografia de Superfície (EMGs): esse exame avaliará o funcionamento dos músculos responsáveis pela sua mastigação. Para isso, será colocado em sua pele - na região das têmporas (ao lado da testa) e das bochechas (logo a frente da orelha) um eletrodo. Será pedido que o(a) senhor(a) permaneça sem realizar nenhum movimento com o rosto e pescoço durante 30 segundos e será avaliado o funcionamento dos músculos no repouso. Depois será pedido que o(a) senhor(a) aperte um dente contra o outro (morda) durante 5 segundos e será avaliado o funcionamento dos músculos. Logo após, será colocado um pedaço de algodão entre os seus dentes e pedido que o(a) senhor(a) aperte um dente contra o outro (morda) durante 5 segundos e será avaliado o funcionamento dos músculos.

Caso o senhor(a) apresente alguma alteração durante a avaliação fonoaudiológica será encaminhado para tratamento e acompanhamento na Divisão de Fonoaudiologia do Hospital das Clínicas da Faculdade de Medicina da Universidade de São Paulo (HCFMUSP). Para os sujeitos do terceiro grupo não será realizada terapia fonoaudiológica pois os mesmos não apresentam alterações faciais, a avaliação ocorrerá em dois momentos, sendo o segundo momento após 6 semanas da data da primeira avaliação.

Caso o senhor não apresente alterações na avaliação será incluído do grupo pesquisa do trabalho, e será convocado novamente depois de 6 semanas que realizar a avaliação inicial.

As atividades programadas tanto na avaliação como no tratamento não trazem nenhum desconforto ao indivíduo e nenhum risco.

Trata-se de estudo experimental testando a hipótese de que a intervenção fonoaudiológica poderá auxiliar a retomada da abertura de boca e da mastigação de forma mais rápida e mais adequada possível.

Em qualquer etapa do estudo o senhor(a) terá acesso aos profissionais responsáveis pela pesquisa para esclarecimento de eventuais dúvidas. Os investigadores são a Profa. Dra. Claudia Regina Furquim de Andrade e a fonoaudióloga Amanda Pagliotto da Silva que podem ser encontradas na Rua Cipotania, 51 - Campus Cidade Universitária - CEP 05360-160 - São Paulo, SP, Brazil - Tel: 11 3091-8406. Se você tiver alguma consideração ou dúvida sobre a ética da pesquisa, entre em contato com o Comitê de Ética em Pesquisa (CEP) - Rua Ovídio Pires de Campos, 225 - 5o andar - tel: 3069-6442 ramais 16, 17, 18 ou 20, FAX: 3069-6442 ramal 26 - E-mail: cappesq@hcnet.usp.br

É garantida a liberdade da retirada de consentimento a qualquer momento e deixar de participar do estudo, sem qualquer prejuízo à continuidade de seu tratamento na Instituição;

As informações obtidas serão analisadas em conjunto com outros pacientes, não sendo divulgado a identificação de nenhum paciente.

Não há despesas pessoais para o participante em qualquer fase do estudo, incluindo exames e consultas. Também não há compensação financeira relacionada à sua participação. Se existir qualquer despesa adicional, ela será absorvida pelo orçamento da pesquisa.

Os dados coletados serão utilizados apenas para esta pesquisa.

Acredito ter sido suficientemente informado a respeito das informações que li ou que foram lidas para mim, descrevendo o estudo "Atuação Fonoaudiológica em pacientes adultos com trauma de face e restrição em mobilidade mandibular". Eu discuti com a Profa. Dra. Claudia Regina Furquim de Andrade e/ou Fga. Ms. Amanda Pagliotto da Silva sobre a minha decisão em participar nesse estudo. Ficaram claros para mim quais são os propósitos do estudo, os procedimentos a serem realizados, seus desconfortos e riscos, as garantias de confidencialidade e de esclarecimentos permanentes. Ficou claro também que minha 
participação é isenta de despesas e que tenho garantia do acesso a tratamento hospitalar quando necessário. Concordo voluntariamente em participar deste estudo e poderei retirar o meu consentimento a qualquer momento, antes ou durante o mesmo, sem penalidades ou prejuízo ou perda de qualquer benefício que eu possa ter adquirido, ou no meu atendimento neste Serviço.

Assinatura do paciente/representante legal

Data

Assinatura da testemunha

Data

para casos de pacientes menores de 18 anos, analfabetos, semi-analfabetos ou portadores de deficiência auditiva ou visual.

(Somente para o responsável do projeto)

Declaro que obtive de forma apropriada e voluntária o Consentimento Livre e Esclarecido deste paciente ou representante legal para a participação neste estudo.

Assinatura do responsável pelo estudo

Data 


\subsection{Anexo D}

\section{Plano Terapêutico Fonoaudiológico para Trauma de Face com Restrição Mandibular}

\section{Sessões 1 e 2:}

\begin{tabular}{|c|c|c|}
\hline Atividade & Estratégia & Efeito da Atividade \\
\hline $\begin{array}{l}\text { Percepção / } \\
\text { Propriocepção }\end{array}$ & $\begin{array}{l}\text { Uso de figuras, exames do paciente, } \\
\text { espelho e vídeos do paciente para } \\
\text { explicar a função das estruturas que } \\
\text { apresentam alteração em seu } \\
\text { funcionamento. }\end{array}$ & $\begin{array}{c}\text { Compreensão das } \\
\text { consequências do trauma } \\
\text { com relação ao sistema } \\
\text { miofuncional orofacial e a } \\
\text { importância da reabilitação. }\end{array}$ \\
\hline $\begin{array}{l}\text { Drenagem de } \\
\text { Edemas }\end{array}$ & $\begin{array}{c}\text { Com os dedos indicadores, realizar } \\
\text { leve pressão, contínua e descendente } \\
\text { e bilateral na face. Iniciar na região } \\
\text { mediana da lateral do nariz (base } \\
\text { nasal); deslizar pela bochecha e } \\
\text { quando atingir o arco zigomático } \\
\text { continuar movimento deslizando até a } \\
\text { base da mandíbula (região do corpo } \\
\text { mandibular). }\end{array}$ & $\begin{array}{l}\text { Remoção de fluido intersticial } \\
\text { e melhora da circulação } \\
\text { sanguínea no local drenado. }\end{array}$ \\
\hline $\begin{array}{l}\text { Mobilidade } \\
\text { Mandibular }\end{array}$ & $\begin{array}{l}\text { Realizar abertura e fechamento de } \\
\text { boca com a língua apoiada em papilas } \\
\text { palatinas. }\end{array}$ & $\begin{array}{l}\text { Melhora da lubrificação } \\
\text { articular e oxigenação da } \\
\text { musculatura mastigatória. }\end{array}$ \\
\hline $\begin{array}{l}\text { Manipulação } \\
\text { Muscular }\end{array}$ & $\begin{array}{c}\text { Realizar movimentos com os dedos, } \\
\text { circulares, descendentes e bilaterais. } \\
\text { Realizar durante } 1 \text { a } 2 \text { minutos em } \\
\text { temporal, masseter, } \\
\text { esternocleidomastoídeo, trapézio. }\end{array}$ & $\begin{array}{l}\text { 1. Aumento do fluxo } \\
\text { sanguíneo e da oxigenação } \\
\text { dos tecidos. } \\
\text { 2. Remoção dos resíduos } \\
\text { metabólicos. } \\
\text { 3. Remissão da tensão } \\
\text { muscular e contraturas. }\end{array}$ \\
\hline Abertura oral & $\begin{array}{c}\text { Realizar abertura oral máxima, manter } \\
\text { por } 3 \text { segundos e retornar ao repouso } \\
\text { mandibular. }\end{array}$ & \multirow{2}{*}{$\begin{array}{l}\text { 1. Ganho de massa muscular } \\
\text { 2. Melhora da mobilidade } \\
\text { mandibular. } \\
\text { 3. Aumento da amplitude } \\
\text { mandibular. }\end{array}$} \\
\hline $\begin{array}{l}\text { Lateralidade } \\
\text { Mandibular }\end{array}$ & $\begin{array}{c}\text { Deslizar a mandíbula para o lado, } \\
\text { manter por } 3 \text { segundos e retornar à } \\
\text { posição inicial, fazer o mesmo para o } \\
\text { outro lado. }\end{array}$ & \\
\hline $\begin{array}{c}\text { Treino da } \\
\text { Respiração Nasal }\end{array}$ & $\begin{array}{l}\text { Perceber lábios ocluídos, língua } \\
\text { apoiada em papilas palatinas, dentes } \\
\text { mantendo espaço funcional livre. } \\
\text { Observar respiração, realizar } \\
\text { inspiração e expiração nasal. }\end{array}$ & $\begin{array}{l}\text { 1. Melhorar percepção e } \\
\text { adequação de postura de } \\
\text { repouso de lábios, língua e } \\
\text { mandíbula. } \\
\text { 2. Promover respiração nasal. }\end{array}$ \\
\hline
\end{tabular}

Os pacientes devem ser instruídos para realizar os mesmos exercícios em

casa, diariamente, 3 vezes ao dia. 
Sessões 3 e 4:

\begin{tabular}{|c|c|c|}
\hline Atividade & Estratégia & Efeito da Atividade \\
\hline $\begin{array}{l}\text { Drenagem de } \\
\text { Edemas }\end{array}$ & $\begin{array}{l}\text { Com os dedos indicadores, realizar leve } \\
\text { pressão, contínua e descendente e } \\
\text { bilateral na face. Iniciar na região } \\
\text { mediana da lateral do nariz (base nasal); } \\
\text { deslizar pela bochecha e quando atingir o } \\
\text { arco zigomático continuar movimento } \\
\text { deslizando até a base da mandíbula } \\
\text { (região do corpo mandibular). }\end{array}$ & $\begin{array}{l}\text { Remoção de fluido intersticial } \\
\text { e melhora da circulação } \\
\text { sanguínea no local drenado. }\end{array}$ \\
\hline $\begin{array}{l}\text { Mobilidade } \\
\text { Mandibular }\end{array}$ & $\begin{array}{c}\text { Realizar abertura e fechamento de boca } \\
\text { com a língua apoiada em papilas } \\
\text { palatinas. }\end{array}$ & $\begin{array}{l}\text { Melhora da lubrificação } \\
\text { articular e oxigenação da } \\
\text { musculatura mastigatória. }\end{array}$ \\
\hline $\begin{array}{l}\text { Manipulação } \\
\text { Muscular }\end{array}$ & $\begin{array}{c}\text { Realizar movimentos com os dedos, } \\
\text { circulares, descendentes e bilaterais. } \\
\text { Realizar durante } 1 \text { a } 2 \text { minutos em } \\
\text { temporal, masseter, } \\
\text { esternocleidomastoídeo, trapézio. }\end{array}$ & $\begin{array}{l}\text { 1. Aumento do fluxo } \\
\text { sanguíneo e da oxigenação } \\
\text { dos tecidos. } \\
\text { 2. Remoção dos resíduos } \\
\text { metabólicos. } \\
\text { 3. Remissão da tensão } \\
\text { muscular e contraturas. }\end{array}$ \\
\hline Abertura oral & $\begin{array}{l}\text { - Abertura oral máxima, manter por } 3 \\
\text { segundos e retornar ao repouso } \\
\text { mandibular. } \\
\text { - Abertura oral máxima sem desvio, } \\
\text { manter por } 3 \text { segundos e retornar à } \\
\text { posição de repouso mandibular. }\end{array}$ & \multirow{3}{*}{$\begin{array}{l}\text { 1. Ganho de massa muscular } \\
\text { 2. Aumento da oxigenação dos } \\
\text { tecidos. } \\
\text { 3. Aumento da força muscular. } \\
\text { 4. Melhora da mobilidade } \\
\text { mandibular. } \\
\text { 5. Aumento da amplitude } \\
\text { mandibular. } \\
\text { 6. Melhora da simetria dos } \\
\text { movimentos mandibulares. }\end{array}$} \\
\hline $\begin{array}{l}\text { Lateralidade } \\
\text { Mandibular }\end{array}$ & $\begin{array}{l}\text { Levar o queixo para o lado, a mão irá } \\
\text { auxiliar no movimento, fazendo leve } \\
\text { pressão em região mandibular para o } \\
\text { lado do movimento. }\end{array}$ & \\
\hline $\begin{array}{l}\text { Protrusão } \\
\text { Mandibular }\end{array}$ & $\begin{array}{l}\text { Com os dentes em contato leve, deslizar } \\
\text { a mandíbula para a frente, realizando o } \\
\text { movimento de protrusão, manter por } 3 \\
\text { segundos e retornar à posição inicial. }\end{array}$ & \\
\hline $\begin{array}{l}\text { Treino da } \\
\text { Respiração } \\
\text { Nasal }\end{array}$ & $\begin{array}{l}\text { - Perceber lábios ocluídos, língua apoiada } \\
\text { em papilas palatinas, dentes mantendo } \\
\text { espaço funcional livre. } \\
\text { - Observar respiração, realizar inspiração } \\
\text { e expiração nasal. }\end{array}$ & $\begin{array}{l}\text { 1. Melhorar percepção e } \\
\text { adequação de postura de } \\
\text { repouso de lábios, língua e } \\
\text { mandíbula. } \\
\text { 2. Promover respiração nasal. }\end{array}$ \\
\hline $\begin{array}{l}\text { Treino da } \\
\text { Deglutição }\end{array}$ & $\begin{array}{c}\text { - Perceber lábios ocluídos, língua apoiada } \\
\text { em papilas palatinas. } \\
\text { - Perceber e evitar contração de } \\
\text { musculatura perioral assim como } \\
\text { movimentação cervical e de cabeça } \\
\text { durante a deglutição. }\end{array}$ & $\begin{array}{l}\text { 1. Melhorar percepção e } \\
\text { adequação de postura durante } \\
\text { a deglutição. } \\
\text { 2. Promover função de } \\
\text { deglutição. }\end{array}$ \\
\hline $\begin{array}{l}\text { Treino da } \\
\text { Mastigação }\end{array}$ & $\begin{array}{c}\text { - Perceber lado de preferência } \\
\text { mastigatória. } \\
\text { alternada. } \\
\text { - Iniciar treino de mastigaão bilateral } \\
\text { - Perceber e adequar, se necessário, } \\
\text { movimentos de lábios, língua, bochechas } \\
\text { e mandíbula durante a mastigação. } \\
\text { - perceber e adequar postura cervical e } \\
\text { de cabeça durante a mastigação. } \\
\text { - Considerar condição oclusão e articular } \\
\text { antes e durante treino de mastigação. }\end{array}$ & $\begin{array}{l}\text { 1. Melhorar percepção e } \\
\text { adequação de postura durante } \\
\text { a mastigação. } \\
\text { 2. Otimizar processo de } \\
\text { mastigação. }\end{array}$ \\
\hline
\end{tabular}


Os pacientes devem ser instruídos para realizar os mesmos exercícios em casa, diariamente, 3 vezes ao dia. Os exercícios que envolvem contra resistência, carga e/ou treino mastigatório só serão realizados após estabilização da fratura e discussão da equipe multiprofissional para autorização dos procedimentos. O paciente será orientado a realizar o treino das funções de respiração, mastigação e deglutição durante as atividades diárias e em todos os momentos possíveis. 
Sessões 5 e 6 :

\begin{tabular}{|c|c|c|}
\hline Atividade & Estratégia & Efeito da Atividade \\
\hline $\begin{array}{l}\text { Percepção / } \\
\text { Propriocepção }\end{array}$ & $\begin{array}{l}\text { Uso de figuras, exames do paciente, } \\
\text { espelho e vídeos do paciente para } \\
\text { explicar a função das estruturas que } \\
\text { apresentam alteração em seu } \\
\text { funcionamento. }\end{array}$ & $\begin{array}{l}\text { Compreensão das } \\
\text { consequências do trauma } \\
\text { com relação ao sistema } \\
\text { miofuncional orofacial e a } \\
\text { importância da reabilitação. }\end{array}$ \\
\hline $\begin{array}{l}\text { Mobilidade } \\
\text { Mandibular }\end{array}$ & $\begin{array}{c}\text { Realizar abertura e fechamento de boca } \\
\text { com a língua apoiada em papilas } \\
\text { palatinas. }\end{array}$ & $\begin{array}{l}\text { Melhora da lubrificação } \\
\text { articular e oxigenação da } \\
\text { musculatura mastigatória. }\end{array}$ \\
\hline $\begin{array}{l}\text { Manipulação } \\
\text { Muscular }\end{array}$ & $\begin{array}{l}\text { Realizar movimentos com os dedos, } \\
\text { circulares, descendentes e bilaterais. } \\
\text { Realizar durante } 1 \text { a } 2 \text { minutos em } \\
\text { temporal, masseter, } \\
\text { esternocleidomastoídeo, trapézio. }\end{array}$ & $\begin{array}{l}\text { 1. Aumento do fluxo } \\
\text { sanguíneo e da oxigenação } \\
\text { dos tecidos. } \\
\text { 2. Remoção dos resíduos } \\
\text { metabólicos. } \\
\text { 3. Remissão da tensão } \\
\text { muscular e contraturas. }\end{array}$ \\
\hline Abertura oral & $\begin{array}{l}\text { - Abertura oral máxima sem desvio, } \\
\text { manter por } 3 \text { segundos e retornar à } \\
\text { posição de repouso mandibular. } \\
\text { - Apoiar espátulas em região de molares, } \\
\text { uma em cima da outra, até a abertura oral } \\
\text { máxima, realizar movimento de alavanca } \\
\text { com as espátulas (com os dedos, dividi- } \\
\text { las ao meio e abrir espaço entre elas). }\end{array}$ & \multirow{3}{*}{$\begin{array}{l}\text { 1. Ganho de massa } \\
\text { muscular } \\
\text { 2. Aumento da oxigenação } \\
\text { dos tecidos. } \\
\text { 3.Aumento da força } \\
\text { muscular. } \\
\text { 4. Melhora da mobilidade } \\
\text { mandibular. } \\
\text { 5. Aumento da amplitude } \\
\text { mandibular. } \\
\text { 6. Melhora da simetria dos } \\
\text { movimentos mandibulares. }\end{array}$} \\
\hline $\begin{array}{l}\text { Lateralidade } \\
\text { Mandibular }\end{array}$ & $\begin{array}{l}\text { Levar o queixo para o lado, a mão irá } \\
\text { auxiliar no movimento, fazendo leve } \\
\text { pressão em região mandibular para o } \\
\text { lado do movimento. }\end{array}$ & \\
\hline $\begin{array}{l}\text { Protrusão } \\
\text { Mandibular }\end{array}$ & $\begin{array}{l}\text { Com os dentes em contato leve, deslizar } \\
\text { a mandíbula para a frente, realizando o } \\
\text { movimento de protrusão, manter por } 3 \\
\text { segundos e retornar à posição inicial. }\end{array}$ & \\
\hline $\begin{array}{l}\text { Treino da } \\
\text { Mastigação }\end{array}$ & $\begin{array}{l}\text { - Perceber lado de preferência } \\
\text { mastigatória. } \\
\text { - Iniciar treino de mastigação bilateral } \\
\text { alternada. } \\
\text { - Perceber e adequar, se necessário, } \\
\text { movimentos de lábios, língua, bochechas } \\
\text { e mandíbula durante a mastigação. } \\
\text { - perceber e adequar postura cervical e } \\
\text { de cabeça durante a mastigação. } \\
\text { - Considerar condição oclusão e articular } \\
\text { antes e durante treino de mastigação. }\end{array}$ & $\begin{array}{l}\text { 1. Melhorar percepção e } \\
\text { adequação de postura } \\
\text { durante a mastigação. } \\
\text { 2. Otimizar processo de } \\
\text { mastigação. }\end{array}$ \\
\hline $\begin{array}{l}\text { Manutenção dos } \\
\text { Resultados } \\
\text { Obtidos }\end{array}$ & $\begin{array}{l}\text { Reforçar a importância, ao término do } \\
\text { tratamento e durante o processo } \\
\text { terapêutico, da necessidade de monitorar } \\
\text { posturas no repouso e posicionamento } \\
\text { muscular durante as funções (respiração, } \\
\text { mastigação e deglutição). }\end{array}$ & $\begin{array}{l}\text { 1. Manter percepção e } \\
\text { adequação de postura } \\
\text { durante a deglutição. }\end{array}$ \\
\hline
\end{tabular}


Os pacientes devem ser instruídos para realizar os mesmos exercícios em casa, diariamente, 3 vezes ao dia. Os exercícios que envolvem contra resistência, carga e/ou treino mastigatório só serão realizados após estabilização da fratura e discussão da equipe multiprofissional para autorização dos procedimentos. Para o treino das funções de respiração, mastigação e deglutição o paciente será orientado a realizar nas atividades diárias, e em todos os momentos possíveis. 


\section{REFERÊNCIAS BIBLIOGRÁFICAS}

1. Silva AP, Sassi FC, Andrade CRF. Caracterização miofuncional orofacial e eletromiográfica de pacientes submetidos à correção da fratura condilar por redução aberta e fechada. CoDAS. 2016;28(5):558-66.

2. Silva AP, Sassi FC, Mangilli LD, Andrade CRF. Trauma de Face com Restrição de Amplitude Mandibular. In: Pró-Fono. Planos Terapêuticos Fonoaudiológicos (PTFs). São Paulo: Pró-Fono; 2015. v. 2, p.539-56.

3. Silva AP, Sassi FC, Bastos E, Alonso N, de Andrade CRF. Oral motor and electromyographic characterization of adults with facial fractures: a comparison between different fracture severities. Clinics. 2017;72(5):27683.

4. Sassi FC, Silva AP, Santos RKS, Andrade CRF. Tratamento para disfunções temporomandibulares: uma revisão sistemática. Audiol Commun Res. 2018;23(0):e1871.

5. Krug EG, Sharma GK, Lozano R. The global burden of injuries. Am J Public Health. 2000;90(4):523-26.

6. Alvi A, Doherty T, Lewen G. Facial fractures and concomitant injuries in trauma patients. Laryngoscope. 2013;113(1):102-6.

7. World Health Organization. The road traffic death rate by WHO region and income level 2013. Available from: http:/www.who.int/gho/ road_safety/en. Accessed December 20, 2016.

8. Marchini L, Allareddy V. Epidemiology of facial fractures among older adults: A retrospective analysis of a nationwide emergency department database. Dental Traumatology. 2019;35(2):109-14. 
9. Allareddy V, Allareddy V, Nalliah RP. Epidemiology of facial fracture injuries. J Oral Maxillofac Surg. 2011;69(10):2613-8.

10.Gassner R, Tuli T, Hachl O, Rudisch A, Ulmer H. Cranio-maxillofacial trauma: a 10 year review of 9,543 cases with 21,067 injuries. Craniomaxillofac Surg. 2003;31(1):51-61.

11. Leles JLR, Santos EJ, Jorge FD, Silva, ET, Leles CR. Risk factors for maxillofacial injuries in a Brazilian emergency hospital sample. J App/Oral Sci. 2010;18(1): 23-9.

12. lida S, Hassfeld S, Reuther T, Schweigert HG, Haag C, Klein J, et al: Maxillofacial fractures resulting from falls. J Craniomaxillofac Surg. 2003;31(5):278-83.

13. Motamedi $\mathrm{MH}$. An assessment of maxillofacial fractures: a 5- year study of 237 patients. J Oral Maxillofac Surg. 2003;61:61-4.

14. Gerbino G, Roccia F, Benech A, Caldarelli C. Analysis of 158 frontal sinus fractures: current surgical management and complications. $J$ Craniomaxillofac Surg. 2000;28(3):133-9.

15. lida S, Kogo M, Sugiura T, Mima T, Matsuya T. Retrospective analysis of 1502 patients with facial fractures. Int $J$ Oral Maxillofac Surg. $2001 ; 30(4): 286-90$.

16. Lee KH, Snape L, Steenberg LJ, Worthington J. Comparison between interpersonal violence and motor vehicle accidents in the aetiology of maxillofacial fractures. ANZ J Surg. 2007;77:695-8.

17. Adebayo ET, Ajike OS, Adekeye EO. Analysis of the pattern of maxillofacial fractures in Kaduna, Nigeria. $\mathrm{Br} J$ Oral Maxillofac Surg. 2003;41(6):396-400. 
18. Yang WG, Chen CT, Tsay PK, Chen YR. Functional results of unilateral condylar process fractures after open and closed treatment. J Trauma Acute Care Surg. 2002;52(3):498-503.

19. Filho FVM, Fernandes C. Epidemiologia em traumas de face In: Felicio CM, Trawitzki LVV (Eds). Interfaces da medicina, odontologia e fonoaudiologia no complexo cérvico-craniofacial. Barueri: Pró-Fono; 2009. p.315-32.

20. Choi BH, Yi CK, Yoo JH. MRI examination of the TMJ after surgical treatment of condylar fractures. Int J Oral Maxillofac Surg. 2001;30(4):2969.

21. Kar IB, Mahavoi BR. Retrospective Analysis of 503 Maxillo-facial trauma cases in odisha during the period of dec'04-nov'09. J Maxillofac Oral Surg. $2012 ; 11(2): 177-81$.

22. Choi KY, Yang JD, Chung HY, Cho BC. Current concepts in the mandibular condyle fracture management part I: overview of condylar fracture. Arch Plast Surg.2012;39(4):291-300.

23. Jensen T, Jensen J, Norholt SE, Dahl M, Lenk-Hansen L, Svensson P. Open reduction and rigid internal fixation of mandibular condylar fractures by an intraoral approach: a long-term follow-up study of 15 patients. J Oral Maxillofac Surg. 2006;64(12):1771-9.

24. Junjie $Y$, Weidong $L$, Ren $L$, Min $Y$. Incidence and risk factors of the temporomandibular joint disorders in the patients without condylar fractures. Med Sci. 2018;34:39-42. 
25. Tabrizi R, Bahramnejad E, Mohaghegh M, Alipour S. Is the Frequency of Temporomandibular Dysfunction Different in Various Mandibular Fractures? J Oral Maxillofac Surg. 2014;72:755-61.

26. Bianchini EMG. Articulação Temporomandibular - Implicações, limites e possibilidade fonoaudiológicas. Barueri: Pró fono; 2000.

27. Benaglia MB, Gaetti-Jardim EC, Oliveira JG, Mendonça JC. Bilateral temporomandibular joint ankylosis as sequel of bilateral fracture of the mandibular condyle and symphysis. Oral Maxillofac Surg. 2014;18(1):3942.

28. King BJ, Park EP, Christensen BJ, Danrad R. On-site 3-dimensional printing and preoperative adaptation decrease operative time for Mmandibular fracture repair. J Oral Maxillofac Surg. 2018;76:1950.e1-e8.

29. Conforte JJ, Alves CP, Sanchez MPR, Ponzoni D. Impact of trauma and surgical treatment on the quality of life of patients with facial fractures. Int J Oral Maxillofac Surg. 2016;45:575-81.

30. Agbaje J, Luyten J, Politis C. Pain complaints in patients undergoing orthognathic surgery. Pain Res Manag. 2018;ID 4235025.

31. Crandall JA. An Introduction to Orofacial Pain. Dent Clin $N A m$. 2018;62:511-23.

32. Elegbede A, Mermulla S, Diaconu SD, McNichols C, Liang Y, Liang F, et al. Patient-reported outcomes in facial reconstruction: assessment of FACE-Q scales and predictors of satisfaction. Plast Reconstr Surg Glob Open. 2018;6:e2004. 
33. Palmieri C, Edward E, Gaylord T. Mandibular motion after closed and open treatment of unilateral mandibular condylar process fractures. Int $\mathrm{J}$ Oral Maxillofac Surg. 1999;57(7):764-75.

34. Ko EWC, Huang CS, Lo LJ, Chen YR. Alteration of masticatory electromyographic activity and stability of orthognathic surgery in patients with skeletal class III malocclusion. J Oral Maxillofac Surg. 2013;71(7):1249- 60.

35. Le Bell Y, Lehtinen R, Peltomäki T, Peltola J. Function of masticatory system after surgical-orthodontic correction of maxilomandibular discrepancies. Proc Finn Dent Soc. 1993;89(3-4):101-7.

36. Conselho Federal e Regionais de Fonoaudiologia. Classificação Brasileira de Procedimentos em Fonoaudiologia. 2a Ed. Revisada em agosto de 2007.

37. Bianchini EMG, Moraes RB, Nazario D, Luz JGC. Terapêutica interdisciplinar para fratura cominutiva de côndilo por projétil de arma de fogo - enfoque miofuncional. Rev. CEFAC. 2010;12(5):881-88.

38. Ellis E, Robert VW. Treatment of Malocclusion and TMJ Dysfunction Secondary to Condylar Fractures. CMTR Open. 20092(1):1-18.

39. Ko EW, Terry TT, Chiung SH. The effect of early physiotherapy on the recovery of mandibular function after orthognathic surgery for class III correction. Part II: Electromyographic activity of masticatory muscles. $J$ Oral Maxillofac Surg. 2015;43:138-43.

40. Mangilli LD. Programa de avaliação e tratamento fonoaudiológico para a reabilitação da função mastigatória de indivíduos submetidos à cirurgia 
ortognática por deformidade dentofacial [tese]. São Paulo. Faculdade de Medicina, Universidade de São Paulo; 2012.

41. Felício CM, et al. Otologic symptoms of temporomandibular disorder and effect of orofacial myofunctional therapy. J Oral Maxillofac Pract. 2008;26(2):118-25.

42. Ariji Y, et al. Potential clinical application of masseter and temporal muscle massage treatment using an oral rehabilitation robot in temporomandibular disorder patients with myofascial pain. Cranio. 2015;33(4):256-62.

43. Felício CM, Folha GA, Ferreira CLP, Medeiros APM. Expanded protocol of orofacial myofunctional evaluation with scores: validity and reliability. Int J Pediatr Otorhinolaryngol. 2010;74(11):1230-9.

44. Folha GA, Valera FCP, de Felıcio CM. Validity and reliability of a protocol of orofacial myofunctional evaluation for patients with obstructive sleep apnea. Eur J Oral Sci. 2015;123(3):165-72.

45. Proffit WR, Naini FB, Gill DS. Prevalence of malocclusion and orthodontic treatment need in the United States: estimates from the NHANES III survey. Int Adult Orthodon Orthognath Surg. 1997;13(2):97-106.

46. Nakata Y, Ueda HM, Kato M, Tabe H, Shikata-Wakisaka N, Matsumoto E, et al. Change in stomatognatic function induced by orthogatic surgery in patients with mandibular prognathism. $J$ Oral Maxillofac Surg. 2007;65:444-51.

47. Sforza C, Ugolini A, Rocchette D, Galante D, Mapelli A, Gianni AB. Mandibular kinematics after orthognathic surgical treatment - A pilot study. Br J Oral Maxillofac Surg. 2010;48:110-4. 
48. Soderberg GL, Cook MT. Electromyography in biomechanics. Phys Ther. 1984;64(12):1813-20.

49. Hurrell MJL, Batstone MD. The effect of treatment timing on the management of facial fractures: a systematic review. Int. J. Oral Maxillofac Surg. 2014;43:944-50.

50. Kang-Young C, Jung-Dug Y, Ho-Yun C, Byung-Chae C. Current concepts in the mandibular condyle fracture management part I: overview of condylar fracture. Arch Plast Surg. 2012;39(4):291-300.

51. Kang-Young C, Jung-Dug Y, Ho-Yun C, Byung-Chae C. Current concepts in the mandibular condyle fracture management part II: open reduction versus closed reduction. Arch Plast Surg. 2012;39(4):301-8.

52. Becking AG, Zijderveld SA, Tuinzing DB. Management of posttraumatic malocclusion caused by condylar process fractures. J Oral Maxillofac Surg. 1998;56:1370-7.

53. Silvennoinen U, lizuka T, Oikarinen K, Lindqvist C. Analysis of possible factors leading to problems after nonsurgical treatment of condylar fractures. J Oral Maxillofac Surg. 1994;52:753-66.

54. Chen I. Traumatic dislocation of the mandibular condyle into the middle cranial fossa treated by an intraoral approach. J Formos Med Assoc. $2019 ; 118(7): 1161-5$

55. Kang DH. Surgical management of a mandible subcondylar fracture. Arch Plast Surg.2012;39:284-90.

56. Lauriti L, Luz JGC, Mesquita-Ferrari RA, Fernandes KPS, Deana AM, Horliana ACRT, et al. Evaluation of the effect of phototherapy in patients 
with mandibular fracture on mandibular dynamics, pain, edema, and bite force: a pilot study. Photomed Laser Surg. 2017;36(1):24-30.

57. Svenddon P. Pain Mechanisms in myogenous temporomandibular disorders. Pain Forum. 1997;6(3):158-65.

58. Campolongo GD, Barros TEP, Sevilha FM, Oliveira RJ, Luz JGC. Electromyographic study in patients with surgically treated facial fractures. J Craniofac Surg. 2012;23:1329-32.

59. Celic R, Jerolimov V, Knezovic-Zlataric D, Klaic B. Measurement of mandibular movements in patients with temporomandibular disorders and in asymptomatic subjects. Coll Antropol. 2003;2:43-9.

60. Silvestri AR, Cohen SN, Connolly RJ. Muscle physiology during functional activities and parafunctional habits. J Prosthet Dent. 1980;44: 64-7.

61. Felício CM, Melchior MO, Silva MAMR, Celeghini RMS. Desempenho mastigatório em adultos relacionado com a desordem temporomandibular e com a oclusão. Pró-Fono. 2007;19(2):151-58.

62. Cattoni DM. Alterações da mastigação e deglutição. In: Ferreira LP, BefiLopes DM, Limongi SCO (orgs). Tratado de fonoaudiologia. São Paulo: Roca; 2004: 277-91.

63. Ahlgren J. Mechanism of mastication. Acta Odontol Scand. 1966;24(44):1109.

64. Talwar RM, Ellis E3rd, Tbrockmorton GS. Adaptations of the masticatory system after bilateral fractures of the mandibular condylar process. J Oral Maxillofac Surg. 1998;56(4):430-9. 
65. Yamada R, Ogawa T, Koyano K. The effect of head posture on direction and stability of mandibular closing movement. J Oral Rehabil. $1999 ; 26(6): 511-20$.

66. Lindahl L. Condylar fractures of the mandible. IV. Function of the masticatory system. Int J Oral Surg. 1977;6(4):195-203.

67. Pasinato F, Oliveira AG, Santos-Couto-Paz CC, Zeredo JLL, Bolzan GP, Macedo SB et al. Study of the kinematic variables of unilateral and habitual mastication of healthy individuals. CoDAS. 2017;29(2):1-8.

68. Cavalcante FT, Moura CP, Perazzo PAT, Cavalcante FT, Cavalcante MT. Prevalência de dificuldade na mastigação e fatores associados em adultos. Cien Saude Colet. 2019; 24(3):1001-10.

69. Schneider M, Erasmus F, Gerlach KL, Kuhlisch E, Loukota RA, Rasse M, et al. Open reduction and internal fixation versus closed treatment and mandibulomaxillary fixation of fractures of the mandibular condylar process: a randomized, prospective, multicenter study with special evaluation of fracture level. J Oral Maxillofac Surg. 2008;66(12):2537-44.

70. Salentijn EG, Boverhoff J, Heymans MW, van den Bergh B, Forouzanfar T. The clinical and radiographical characteristics of zygomatic complex fractures: a comparison between the surgically and non-surgically treated patients. J Craniomaxillofac Surg. 2014;42(5):492-7.

71. Nogami S, Yamauchi K, Kataoka Y, Takano H, Yamashita Y, Takahashi T. Clinical comparison between arthrocentesis and conventional conservative treatment with maxillomandibular fixation for unilateral high condylar fractures. J Oral Rehabil. 2014;41(2):141-7. 
72. Katz N. The impact of pain management on quality of life. J Pain Symptom Manag. 2002;24(1):38-47.

73. Silva SRC, Leite CMC, Ferraz MAAL, Silva MFB, Souza YTCS. Orofacial pain and quality of life for adults. Rev Odontol Bras Central. 2012;21(56):421-5.

74. Kuroiwa, DN et al. Desordens temporomandibulares e dor orofacial: estudo da qualidade de vida medida pelo Medical Outcomes Study 36 Item Short Form Health Survey. Rev Dor. 2011;12(2):93-8.

75. Biazevic MGH, Araújo ME, Michel-Crosato E. Indicadores de qualidade de vida relacionados com a saúde bucal: revisão sistemática. Rev Odontol. 2002;4(1):13-25.

76. Bither S, Mahindra U, Halli R, Bakshi M, Kini Y, Shende M, et al. Electromyographic analysis of anterior temporalis and superficial masseter muscles in mandibular angle fractures-a pilot study. Oral Maxillofac Surg. 2012;16(3):299-304.

77. Bontempo K, Zavanelli R. Desordem temporomandibular: prevalência e necessidade de tratamento em pacientes portadores de próteses totais duplas. Rev Gaúcha Odontol. 2011;59(1):87-94.

78. Cavalcanti MOA, Lima J, Batista A, Oliveira LMC, Lucena LBS. Grau de severidade da disfunção temporomandibular e hábitos parafuncionais em policiais militares. Rev Gaúcha Odontol. 2011;59(3):351-6.

79. Vieira MM, Ávila CRB, Caovilla HH, Ganança MM. Repercussão otoneurológica da disfunção da articulação temporomandibular. Acta AWHO. 1992;11(2):68-72. 
80. Jennifer J, Buescher MSPH. Temporomandibular joint disorders. Am Fam Physician. 2007;76(10):1477-82.

81. Henderson DH, Cooper JC, Bryan GW, van Sickels JE. Otologic Complaints in temporomandibular joint syndrome. Arch. Otolaryngol Head and Neck Surg. 1992;118(11):1208-13.

82. Ren $Y$, Isberg A. Tinnitus in patients with temporomandibular joint internal derangement. J Craniomandib Pract 13(2): 75-80, 1995.

83. Barbosa CMR, Martinelli DA, Albergaria-Barbosa JB. Pacientes portadores de zumbido e os sinais e sintomas de DCM. RGO (Porto Alegre). 1998;46(1):42-9, 1998.

84. Felício CM, Oliveira, JAA, Nunes LJ, Jeronymo LFG, Ferreira-Jeronymo, RR. Alterações auditivas relacionadas ao zumbido nos distúrbios otológicos e da articulação temporomandibular. Rev Bras Otolaringol. 1999;65(2):141-6.

85. Kuttila S, Kuttila M, Le Bell Y, Alanen P, Jouko S. Aural symptoms and signs temporomandibular disorder in association with treatment need and visits to a phisician. Laryngoscope. 1999;109:1669-73.

86. D'Antonio WEPA, Ikino CMY, Castro SM, Balbani APS, Jurado JRP, Bento RF. Distúrbio temporomandibular como causa de otalgia: um estudo clínico. Rev Bras Otorrinolaringol. 2000;66(1):46-50.

87. Pascoal MIN, Rapoport A, Chagas JFS, Pascoal MBN, Costa CC, Magna LA. Prevalência dos sintomas otológicos na desordem temporomandibular: estudo de 126 casos. Rev Bras Otolaringol. 2001;67(5):627-33. 
88. Felício CM, Mazzetto MO, Dos Santos, CPA. Masticatory behavior in individuals with temporomandibular disorders. Minerva Stomatol. $2002 ; 51(4)$ 111-20.

89. Williamson $\mathrm{EH}$. The interrelationship of internal derangements of the temporomandibular joint, headache, vertigo and tinnitus: A survey of 25 patients. J Craniomandib Pract. 1990;8(4):301-6.

90. Calderon PS, Hilgenberg PB, Rossetti LMN, Laurenti JVEH, Conti PCR. Influence of tinnitus on pain severity and quality of life in patients with temporomandibular disorders. J Appl Oral Sci. 2012;20(2):170-3.

91. Koskinen J, Paavolainen M, Raivio M, Roschier J. Otological manifestations in temporomandibular joint dysfunction. J Oral Rehabil. 1980;7(1): 249-54.

92. Keersmaekers K, Boever, JA, van den Bergue L. Otalgia in patients with temporomandibular joint disorders. J Prosthet Dent. 1996;75(1):72-6.

93. Malkin DP. The role of tTMJ dysfunction in the etiology of middle ear disease. Int J. Orthod. 1987;25(1):20-1.

94.Dos Reis AC, Hotta TH, Ferreira-Jeronymo, RR, Felício CM, Ribeiro RF. Ear symptomatology and occlusal factors: a clinical report. J Prosthet Dent. $2000 ; 83(1): 21-4$.

95. Ahmad N, Seidman M. Tinnitus in the older adult: epidemiology, pathophysiology and treatment options. Drugs Aging. 2004;21:297-305.

96. Hjorth T, Melsen B, Møller E. Masticatory muscle function after unilateral condylar fractures: a prospective and qualitative electromyographic study. Eur J Oral Sci. 1997;105:298Y304. 
97. Adisen MZ, Okkesim A, Misirlioglu M. A possible association between medial depression of mandibular ramus and maximum bite force. Folia Morphol. 2018;77(4):711-6.

98. Mangilli LD, Sassi FC, Sernik RA, Tanaka C, Andrade CRF. Avaliação eletromiográfica e ultrassonográfica do músculo masseter em indivíduos normais: estudo piloto. Pró-Fono. 2009;21(3):261-4.

99. Gerlach KL, Schwarz A. Bite forces in patients after treatment of mandibular angle fractures with miniplate osteosynthesis according to champy. Int $J$ Oral Maxillofac Surg. 2002;31:345-8.

100. Iwase M, Sugimori M, Kurachi Y, Nagumo N. Changes in bite force and occlusal contacts in patients treated for mandibular prognathism by orthognathic surgery. J Oral Maxillofac Surg. 1998;56(7):850-5.

101. Kasai RC, Portella MQ. The phono-audiology treatment for patients submitted to orthognatic surgery. Rev Dent Press Ortodon Ortop Maxilar. $2001 ; 6(2): 79-84$.

102. Trawitzki LV, Dantas RO, Mello-Filho FV, Marques W Jr. Effect of treatment of dentofacial deformities on the electromyographic activity of masticatory muscles. Int J Oral Maxillofac Surg. 2006;35(2):170-3.

103. Trawitzki LV, Dantas RO, Mello-Filho FV, Marques W Jr. Masticatory muscle function three years after surgical correction of class III dentofacial deformity. Int J Oral Maxillofac Surg. 2010;39(9):853-6.

104. Douglas CR, Avoglio JLV, Oliveira H. Stomatognathic adaptive motor syndrome is the correct diagnosis for temporomandibular disorder. Med Hypotheses. 2010;74(4):710-8. 
105. Frain MP, Tschopp MK, Bishop M. Predictors of Outcomes in Rehabilitation. J Rehabil. 2009;75(1):27-35. 